Supporting Information for

\title{
Phenothiazine versus Phenoxazine: Structural Effects on the Photophysical Properties of NIR-II AIE Fluorophores
}

Shun Li,${ }^{\dagger}$ Tianyuan Cheng, ${ }^{\dagger}$ Changfeng Yin,${ }^{\dagger}$ Sensen Zhou, ${ }^{\dagger}$ Quli Fan,,${ }^{\ddagger}$ Wei Wu $, *, \dagger$ and Xiqun Jiang ${ }^{\dagger}$

$\dagger$ Department of Polymer Science \& Engineering, College of Chemistry \& Chemical Engineering, Nanjing University, Nanjing 210023, P. R. China.

Key Lab Organ Elect \& Informat Displays, Nanjing University Posts \& Telecommun, Nanjing 210023, P. R. China.

* To whom correspondence should be addressed.

E-mail: wuwei@,nju.edu.cn 


\section{Materials and Methods}

\section{Materials}

All reagents and solvents were purchased from commercial reagent companies (TCI, J\&K, and SigmaAldrich, etc.). Dry toluene and tetrahydrofuran were obtained by distilling over sodium under argon and dry $N, N$-Dimethylformamide was purchased from J\&K. All air and moisture sensitive reactions were carried out in flame-dried glassware under an argon atmosphere. Compound 2, 3 and 4 were synthesized following our previously published procedures. ${ }^{1}$

\section{Characterization}

${ }^{1} \mathrm{H}(400 \mathrm{MHz}, 500 \mathrm{MHz})$ and ${ }^{13} \mathrm{C}(100 \mathrm{MHz}, 125 \mathrm{MHz})$ nuclear magnetic resonance (NMR) spectra were recorded on Bruker AVANCE III 400 and Bruker AVANCE III HD 500 spectrometer by using $\mathrm{CDCl}_{3}, \mathrm{DMSO}-d_{6}$ and dichloromethane- $d_{2}$ as the solvents, tetramethylsilane was used as an internal reference. MALDI-TOF-MS was carried out on Bruker ultrafleXtreme TOF/TOF mass spectrometer. ESI-MS was carried out on Shimadzu LCMS-2020 spectrometer. UV-vis absorption spectra were measured using Shanghai Metash Instruments UV-8000S UV-Vis-NIR spectrophotometer. Photoluminescence (PL) measurements were carried out on HORIBA Fluolog3 spectrophotometer, and fluorescence lifetime was determined by using HORIBA FL-3 3D fluorescence spectrometer. The solid-state PL spectra were recorded on EDINGURGH FLS980 spectrometer. Dynamic light Scattering (DLS) data was obtained by using Brookhaven NanoBrook Omni. Transmission electron microscope (TEM) observations were carried out on JEOL JEM-1101 microscope at an accelerating voltage of $80 \mathrm{kV}$.

\section{Quantum chemistry calculations}

All the quantum chemical calculations were conducted using Gaussian16 A03 GNU/Linux program. ${ }^{2}$ The ground state $\left(\mathrm{S}_{0}\right)$ geometry of the fluorophores were optimized using density functional theory (DFT) method at B3LYP/6-31G* level of theory, and then reoptimized at $\omega$ B97XD*/6-31G* level of theory. The vertical excitation energies were calculated using time-dependent density functional theory (TD-DFT) method at TD- $\omega$ B97XD*/6-31G* level of theory. The geometries of the first excited state 
$\left(\mathrm{S}_{1}\right)$ of the fluorophores were also optimized at TD- $\omega \mathrm{B} 97 \mathrm{XD} * / 6-31 \mathrm{G}^{*}$ level of theory. Solute electron density (SMD) solvation model was used in the calculations in the presence of solvents. The rangeseparation parameters $\omega\left(\right.$ bohr $\left.^{-1}\right)$ were optimized by using optDFTw program. ${ }^{3}$ The results of the quantum chemical calculations were analyzed by using Multiwfn program and the calculation-related pictures were drawn by using VMD program. ${ }^{4}$ 


\section{Experimental section}

\section{Synthesis}

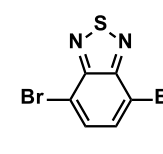

1<smiles></smiles><smiles>O=[N+]([O-])C1C(Br)=C(Br)C2N=NC1C2Br</smiles>

2

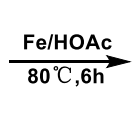

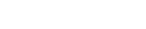

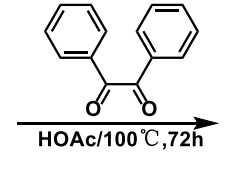
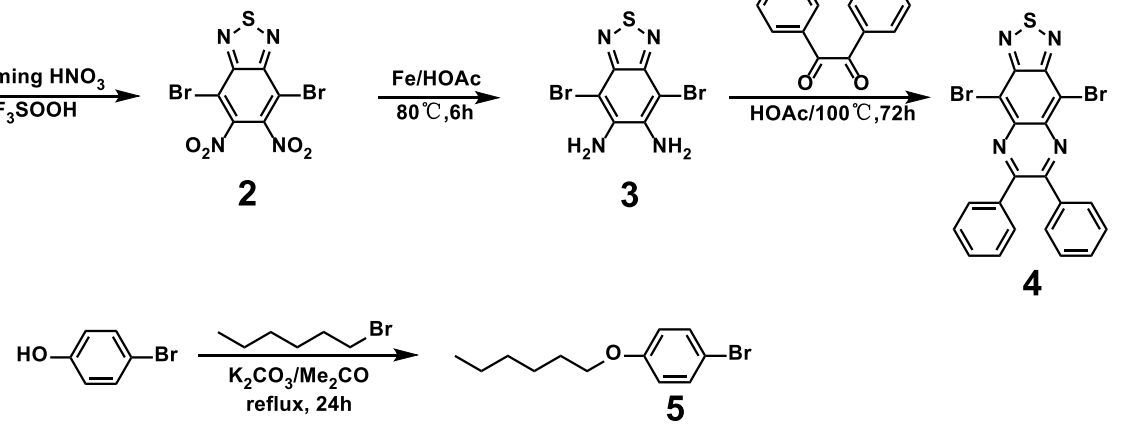

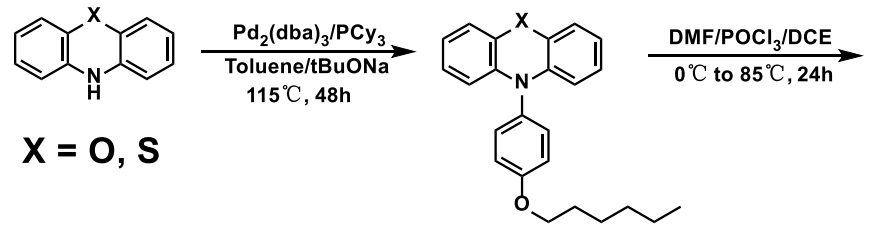

6a $X=S$

$6 b X=0$

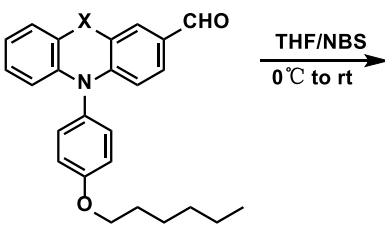

$7 \mathrm{a} X=\mathrm{S}$

$7 b X=0$<smiles>CCCCCCOc1ccc(-n2c3ccc(C=O)c[Y]3c3cc(Br)ccc32)cc1</smiles>

$8 \mathrm{a} X=\mathrm{S}$

$8 b X=0$

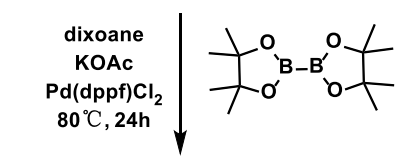

$4+9 a \underset{\mathrm{K}_{3} \mathrm{PO}_{4} / \mathrm{H}_{2} \mathrm{O} / \mathrm{THF} / 85^{\circ} \mathrm{C}}{\stackrel{\mathrm{Pd}(\mathrm{OAc})_{2} / \mathrm{SPhos}}{\longrightarrow}}$
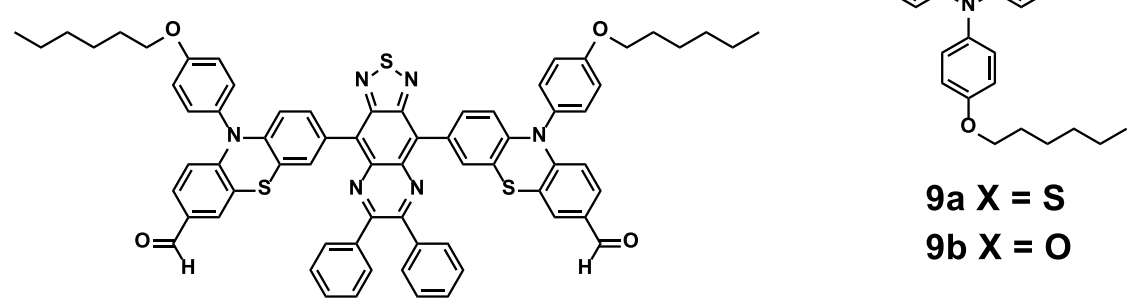

9a $X=S$

$9 b X=0$

DPTQ-PhPTZ

$4+9 b \frac{\mathrm{Pd}(\mathrm{OAc})_{2} / \mathrm{SPhos}}{\mathrm{K}_{3} \mathrm{PO}_{4} / \mathrm{H}_{2} \mathrm{O} / \text { Toluene } / 105^{\circ} \mathrm{C}}$

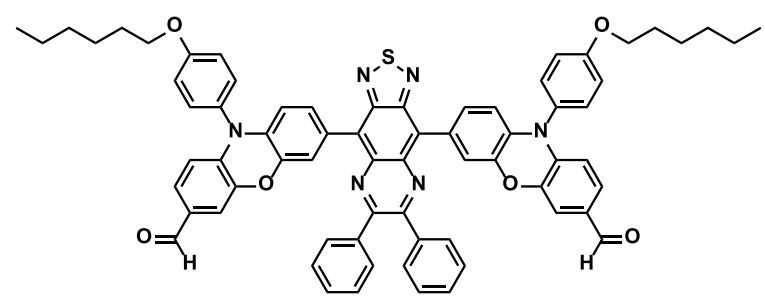

DPTQ-PhPXZ

Scheme S1. Synthetic route of DPTQ-PhPTZ and DPTQ-PhPXZ. 


\section{Synthesis of 1-bromo-4-(hexyloxy)benzene (5)}

4-Bromophenol (5.2 g, $30 \mathrm{mmol})$, anhydrous $\mathrm{K}_{2} \mathrm{CO}_{3}$ (8.3 g, $\left.60 \mathrm{mmol}\right)$, 1-bromohexane (6.4 g, $\left.39 \mathrm{mmol}\right)$ and $50 \mathrm{~mL}$ of acetone were added into a $100 \mathrm{~mL}$ round-bottom flask, and the mixture was refluxed for $24 \mathrm{~h}$. After cooling down to room temperature, $50 \mathrm{~mL}$ of water was added, and the resulting mixture was extracted with hexane. The organic phase was combined, and dried with anhydrous $\mathrm{Na}_{2} \mathrm{SO}_{4}$. After removal of the solvent under reduced pressure, the residue was purified by column chromatography on silica gel using hexane as eluent yielding 5 as a colorless oil $(7.4 \mathrm{~g}, 95.7 \%)$.

${ }^{1} \mathrm{H}$ NMR (400 MHz, Chloroform- $d$ ) $\delta$ 7.40-7.33 (m, 2H), 6.82-6.73 (m, 2H), $3.91(\mathrm{t}, J=6.6 \mathrm{~Hz}, 2 \mathrm{H})$, $1.83-1.72(\mathrm{~m}, 2 \mathrm{H}), 1.51-1.41(\mathrm{~m}, 2 \mathrm{H}), 1.41-1.29(\mathrm{~m}, 4 \mathrm{H}), 0.97-0.88(\mathrm{~m}, 3 \mathrm{H})$.

${ }^{13} \mathrm{C} \mathrm{NMR}\left(100 \mathrm{MHz}, \mathrm{CDCl}_{3}\right) \delta 158.38,132.30,116.42,112.66,68.38,31.70,29.27,25.81,22.73$, 14.16.

\section{Synthesis of 10-(4-(hexyloxy)phenyl)-10H-phenothiazine (6a)}

A $50 \mathrm{~mL}$ Schlenk flask were charged with 10H-phenothiazine (2.5 g, $12.5 \mathrm{mmol})$, (5)1-bromo-4(hexyloxy)benzene $(3.9 \mathrm{~g}, 15.2 \mathrm{mmol})$, tricyclohexylphosphine $(250 \mathrm{mg}, 0.89 \mathrm{mmol}), t$-BuONa $(1.7$ $\mathrm{g}, 17.7 \mathrm{mmol}$ ), and $20 \mathrm{~mL}$ of dry toluene. The flask was vacuumed and purged with argon three times. Then Tris(dibenzylideneacetone)dipalladium(0) $(550 \mathrm{mg}, 0.6 \mathrm{mmol})$ was added. The mixture was heated at $115{ }^{\circ} \mathrm{C}$ for $48 \mathrm{~h}$. After cooling down and diluted with $20 \mathrm{~mL}$ of water, the mixture was extracted with dichloromethane. The organic phase was collected, and dried with anhydrous $\mathrm{Na}_{2} \mathrm{SO}_{4}$. After removal of the solvent under reduced pressure, the residue was purified by column chromatography on silica gel using dichloromethane and hexane $(\mathrm{v} / \mathrm{v}=1 / 8)$ as eluent and the product was recrystallized in ethanol yielding $6 \mathbf{a}$ as a white solid (3.4 g, 72.5\%).

${ }^{1} \mathrm{H}$ NMR (400 MHz, DMSO-d $)$ d 7.34-7.28 (m, 2H), 7.21-7.14 (m, 2H), 7.03 (dd, $\left.J=7.5,1.6 \mathrm{~Hz}, 2 \mathrm{H}\right)$, 6.94-6.86 (m, 2H), 6.85-6.78 (m, 2H), $6.13(\mathrm{dd}, J=8.2,1.2 \mathrm{~Hz}, 2 \mathrm{H}), 4.04(\mathrm{t}, J=6.4 \mathrm{~Hz}, 2 \mathrm{H}), 1.81$ $1.70(\mathrm{~m}, 2 \mathrm{H}), 1.51-1.39(\mathrm{~m}, 2 \mathrm{H}), 1.38-1.27(\mathrm{~m}, 4 \mathrm{H}), 0.93-0.85(\mathrm{~m}, 3 \mathrm{H})$.

${ }^{13} \mathrm{C}$ NMR (100 MHz, DMSO) $\delta$ 158.40, 144.01, 132.27, 131.88, 127.19, 126.49, 122.42, 118.69, $116.55,115.53,67.77,31.00,28.65,25.22,22.09,13.91$.

ESI-MS: calcd. 375.53, found: $376.05(100 \%)$ for $[\mathrm{M}+\mathrm{H}]^{+}$. 


\section{Synthesis of 10-(4-(hexyloxy)phenyl)-10H-phenoxazine (6b)}

A $50 \mathrm{~mL}$ Schlenk flask were charged with 10H-phenoxazine (2.3 g, $12.5 \mathrm{mmol})$, (5)1-bromo-4(hexyloxy)benzene (3.9 g, $15.2 \mathrm{mmol})$, tricyclohexylphosphine (250 mg, $0.89 \mathrm{mmol}), t$-BuONa (1.7 $\mathrm{g}, 17.7 \mathrm{mmol}$ ) and $20 \mathrm{~mL}$ of dry toluene. The flask was vacuumed and purged with argon three times. Then tris(dibenzylideneacetone)dipalladium(0) $(550 \mathrm{mg}, 0.6 \mathrm{mmol})$ was added, and the mixture was heated at $115{ }^{\circ} \mathrm{C}$ for $48 \mathrm{~h}$. After cooling down and diluted with $20 \mathrm{~mL}$ of water, the mixture was extracted with dichloromethane. The organic phase was collected, and dried with anhydrous $\mathrm{Na}_{2} \mathrm{SO}_{4}$. After removal of the solvent by rotary evaporator, the residue was purified by column chromatography on silica gel using dichloromethane and hexane $(\mathrm{v} / \mathrm{v}=1 / 8)$ as eluent and the product was recrystallized in ethanol yielding $\mathbf{6 b}$ as a white solid (3.2 $\mathrm{g}, 71.2 \%)$

${ }^{1} \mathrm{H}$ NMR (400 MHz, DMSO-d6) $\delta$ 7.31-7.26 (m, 2H), 7.20-7.14 (m, 2H), 6.74-6.68 (m, 2H), 6.67-6.61 (m, 4H), $5.86(\mathrm{dd}, J=6.0,3.5 \mathrm{~Hz}, 2 \mathrm{H}), 4.04(\mathrm{t}, J=6.5 \mathrm{~Hz}, 2 \mathrm{H}), 1.84-1.66(\mathrm{~m}, 2 \mathrm{H}), 1.51-1.40(\mathrm{~m}, 2 \mathrm{H})$, 1.38-1.27 (m, 4H), 0.94-0.84 (m, 3H).

${ }^{13} \mathrm{C}$ NMR (100 MHz, DMSO) $\delta$ 158.50, 143.14, 134.28, 131.46, 130.37, 123.64, 121.22, 116.87, $115.15,113.08,67.76,30.98,28.62,25.20,22.07,13.90$.

ESI-MS: calcd. 359.47, found: $360.10(100 \%)$ for $[\mathrm{M}+\mathrm{H}]^{+}$.

\section{Synthesis of 10-(4-(hexyloxy)phenyl)-10H-phenothiazine-3-carbaldehyde (7a)}

Dry N,N-Dimethylformamide (DMF) (3.85 g, $52.7 \mathrm{mmol})$, 1,2-dichloroethane (15 mL) were added into a $100 \mathrm{~mL}$ round-bottom flask in an ice-water bath. Then $\mathrm{POCl}_{3}(8.09 \mathrm{~g}, 52.7 \mathrm{mmol})$ in $10 \mathrm{~mL}$ of 1,2-dichloroethane (DCE) was slowly dropped into the flask over $30 \mathrm{~min}$, and the resulting mixture was stirred for another $1 \mathrm{~h}$. Further on, 6a (3.3 g, $8.79 \mathrm{mmol})$ in $20 \mathrm{~mL}$ of 1,2-dichloroethane was dropped into the flask and then the flask was heated at $85{ }^{\circ} \mathrm{C}$ for $24 \mathrm{~h}$. After cooling, saturated $\mathrm{NaHCO}_{3}$ solution was slowly added, the mixture was extracted with dichloromethane. The organic phase was combined, and dried with anhydrous $\mathrm{Na}_{2} \mathrm{SO}_{4}$. After removed the solvent under reduced pressure, the residue was purified by column chromatography on silica gel using dichloromethane and hexane (v/v $=1 / 1)$ mixture as eluent yielding $7 \mathbf{a}$ as a yellow solid $(3.1 \mathrm{~g}, 87.4 \%)$.

${ }^{1} \mathrm{H}$ NMR (400 MHz, DMSO-d 6 ) $\delta 9.69(\mathrm{~s}, 1 \mathrm{H}), 7.49$ (d, $\left.J=1.8 \mathrm{~Hz}, 1 \mathrm{H}\right), 7.41(\mathrm{dd}, J=8.6,2.0 \mathrm{~Hz}, 1 \mathrm{H})$, 
7.37 - $7.30(\mathrm{~m}, 2 \mathrm{H}), 7.24-7.18(\mathrm{~m}, 2 \mathrm{H}), 7.05(\mathrm{dd}, J=7.2,1.9 \mathrm{~Hz}, 1 \mathrm{H}), 6.96-6.85(\mathrm{~m}, 2 \mathrm{H}), 6.19(\mathrm{~d}, J$ $=8.6 \mathrm{~Hz}, 1 \mathrm{H}), 6.11(\mathrm{dd}, J=7.6,1.9 \mathrm{~Hz}, 1 \mathrm{H}), 4.05(\mathrm{t}, J=6.4 \mathrm{~Hz}, 2 \mathrm{H}), 1.86-1.66(\mathrm{~m}, 2 \mathrm{H}), 1.54-1.40$ $(\mathrm{m}, 2 \mathrm{H}), 1.40-1.27(\mathrm{~m}, 4 \mathrm{H}), 0.94-0.85(\mathrm{~m}, 3 \mathrm{H})$.

${ }^{13} \mathrm{C}$ NMR (100 MHz, DMSO) $\delta$ 190.18, 158.73, 148.71, 142.35, 131.52, 131.48, 130.77, 129.80, $127.51,127.24,126.56,123.65,118.89,117.98,116.81,116.29,115.07,67.83,31.01,28.64,25.22$, $22.09,13.92$.

ESI-MS: calcd. 403.54, found: $404.10(100 \%)$ for $[\mathrm{M}+\mathrm{H}]^{+}$.

\section{Synthesis of 10-(4-(hexyloxy)phenyl)-10H-phenoxazine-3-carbaldehyde (7b)}

Dry DMF (2.63 g, $36 \mathrm{mmol})$, 1,2-dichloroethane $(20 \mathrm{~mL})$ were added into a $100 \mathrm{~mL}$ round-bottom flask with an ice-water bath. Then $\mathrm{POCl}_{3}(5.53 \mathrm{~g}, 36 \mathrm{mmol})$ in $10 \mathrm{~mL}$ of 1,2-dichloroethane was slowly dropped into the flask over $30 \mathrm{~min}$, and the resulting mixture was stirred for another 1 hour. Further on, $6 \mathbf{b}(2.16 \mathrm{~g}, 6 \mathrm{mmol})$ in $50 \mathrm{~mL}$ of 1,2-dichloroethane was dropped into the flask and then the flask was heated at $85{ }^{\circ} \mathrm{C}$ for $24 \mathrm{~h}$. After cooling down, saturated $\mathrm{NaHCO}_{3}$ solution was slowly added, and the mixture was extracted with dichloromethane. The organic phase was combined, and dried with anhydrous $\mathrm{Na}_{2} \mathrm{SO}_{4}$. After removal of the solvent under reduced pressure, the residue was purified by column chromatography on silica gel using dichloromethane and hexane mixture as eluent yielding $\mathbf{7 b}$ as a yellow solid $(1.9 \mathrm{~g}, 81.7 \%)$.

${ }^{1} \mathrm{H}$ NMR (400 MHz, DMSO-d 6 ) $\delta 9.63(\mathrm{~s}, 1 \mathrm{H}), 7.38-7.32(\mathrm{~m}, 2 \mathrm{H}), 7.24(\mathrm{dd}, J=8.3,1.8 \mathrm{~Hz}, 1 \mathrm{H}), 7.22-$ $7.17(\mathrm{~m}, 2 \mathrm{H}), 7.09(\mathrm{~d}, J=1.8 \mathrm{~Hz}, 1 \mathrm{H}), 6.81-6.65(\mathrm{~m}, 3 \mathrm{H}), 5.96(\mathrm{~d}, J=8.2 \mathrm{~Hz}, 1 \mathrm{H}), 5.89(\mathrm{dd}, J=7.8$, $1.5 \mathrm{~Hz}, 1 \mathrm{H}), 4.04(\mathrm{t}, J=6.5 \mathrm{~Hz}, 2 \mathrm{H}), 1.82-1.69(\mathrm{~m}, 2 \mathrm{H}), 1.52-1.39(\mathrm{~m}, 2 \mathrm{H}), 1.38-1.27(\mathrm{~m}, 4 \mathrm{H}), 0.94-$ $0.85(\mathrm{~m}, 3 \mathrm{H})$.

${ }^{13} \mathrm{C}$ NMR (100 MHz, DMSO) $\delta 189.98,158.88,143.41,142.94,139.85,132.70,131.07,129.92$, $129.17,128.14,123.93,122.68,117.01,115.35,113.84,112.66,67.82,30.97,28.60,25.18,22.06$, 13.89 .

ESI-MS: calcd. 387.48, found: $388.05(100 \%)$ for $[\mathrm{M}+\mathrm{H}]^{+}$. 


\section{Synthesis of 7-bromo-10-(4-(hexyloxy)phenyl)-10H-phenothiazine-3-carbaldehyde (8a)}

7a $(3.03 \mathrm{~g}, 7.51 \mathrm{mmol})$ and dry THF $(60 \mathrm{~mL})$ were added into a $150 \mathrm{~mL}$ round-bottom flask in an icewater bath, and NBS (1.45 g, $8.14 \mathrm{mmol})$ was added into the flask in three portions over 30 minutes under dark. Then the solution was stirred overnight at room temperature. Thereafter, $50 \mathrm{~mL}$ of water was added, and the mixture was extracted with dichloromethane. The organic phase was combined, and dried with anhydrous $\mathrm{Na}_{2} \mathrm{SO}_{4}$. After removal of the solvent under reduced pressure, the residue was purified by column chromatography on silica gel using dichloromethane and hexane $(\mathrm{v} / \mathrm{v}=1 / 1)$ mixture as eluent yielding $8 \mathbf{a}$ as a yellow solid (3.37 g, 93.0\%).

${ }^{1} \mathrm{H}$ NMR (400 MHz, DMSO-d $) \delta 9.69$ (s, $\left.1 \mathrm{H}\right), 7.50$ (d, $\left.J=1.9 \mathrm{~Hz}, 1 \mathrm{H}\right), 7.43(\mathrm{dd}, J=8.6,1.9 \mathrm{~Hz}, 1 \mathrm{H})$, 7.38-7.31 (m, 2H), 7.28 (d, $J=2.3 \mathrm{~Hz}, 1 \mathrm{H}), 7.24-7.17(\mathrm{~m}, 2 \mathrm{H}), 7.09(\mathrm{dd}, J=8.8,2.4 \mathrm{~Hz}, 1 \mathrm{H}), 4.05(\mathrm{t}$, $J=6.4 \mathrm{~Hz}, 2 \mathrm{H}), 1.81-1.70$ (m, 2H), 1.50-1.40 (m, 2H), 1.37-1.30 (m, 4H), 0.94-0.85 (m, 3H).

${ }^{13} \mathrm{C}$ NMR (101 MHz, DMSO) $\delta$ 190.23, 158.86, 148.23, 141.86, 131.40, 131.18, 130.97, 130.05, $129.95,128.32$, 127.38, 120.60, 118.23, 117.82, 116.94, 115.31, 114.92, 67.85, 31.00, 28.64, 25.22, $22.09,13.93$.

MALDI-TOF $m / z$ : calcd. 481.0711 , found: $483.2556(100 \%)$ for $[\mathrm{M}]^{+}$

\section{Synthesis of 7-bromo-10-(4-(hexyloxy)phenyl)-10H-phenoxazine-3-carbaldehyde (8b)}

(7b)10-(4-(hexyloxy)phenyl)-10H-phenoxazine-3-carbaldehyde (1.35 g, 3.5mmol) and dry THF (30 $\mathrm{mL})$ were added into a $100 \mathrm{~mL}$ round-bottom flask in an ice-water bath. NBS (685 mg, $3.85 \mathrm{mmol})$ was added into the flask in three portions over 30 minutes under dark. Then the solution was stirred overnight at room temperature. Thereafter, $50 \mathrm{~mL}$ of water was added. The mixture was extracted with dichloromethane. The organic phase was combined, and dried with anhydrous $\mathrm{Na}_{2} \mathrm{SO}_{4}$. After removal of the solvent under reduced pressure, the residue was purified by column chromatography on silica gel using dichloromethane and hexane $(\mathrm{v} / \mathrm{v}=1 / 1)$ mixture as eluent yielding $\mathbf{8 b}$ as a yellow solid (1.4 g, 85.8\%).

${ }^{1} \mathrm{H}$ NMR (400 MHz, DMSO-d6) $\delta 9.64(\mathrm{~s}, 1 \mathrm{H}), 7.39-7.32(\mathrm{~m}, 2 \mathrm{H}), 7.26$ (dd, $\left.J=8.3,1.8 \mathrm{~Hz}, 1 \mathrm{H}\right), 7.23-$ $7.17(\mathrm{~m}, 2 \mathrm{H}), 7.10(\mathrm{~d}, J=1.8 \mathrm{~Hz}, 1 \mathrm{H}), 6.98(\mathrm{~d}, J=2.2 \mathrm{~Hz}, 1 \mathrm{H}), 6.87$ (dd, $J=8.6,2.2 \mathrm{~Hz}, 1 \mathrm{H}), 5.98$ $(\mathrm{d}, J=8.3 \mathrm{~Hz}, 1 \mathrm{H}), 5.80(\mathrm{~d}, J=8.6 \mathrm{~Hz}, 1 \mathrm{H}), 4.04(\mathrm{t}, J=6.5 \mathrm{~Hz}, 2 \mathrm{H}), 1.84-1.61(\mathrm{~m}, 2 \mathrm{H}), 1.50-1.39(\mathrm{~m}$, 
2H), $1.38-1.27(\mathrm{~m}, 4 \mathrm{H}), 0.95-0.83(\mathrm{~m}, 3 \mathrm{H})$.

${ }^{13} \mathrm{C}$ NMR (100 MHz, DMSO-d6) $\delta$ 190.03, 159.01, 143.78, 143.07, 139.31, 132.46, 130.95, 130.09, $128.81,128.30,126.50,117.96,117.09,115.26,114.05,113.10,112.90,67.83,30.97,28.60,25.18$, $22.06,13.90$.

MALDI-TOF $m / z$ : calcd. 465.094, found: 467.2390 (100\%) for [M] $]^{+}$

Synthesis of 10-(4-(hexyloxy)phenyl)-7-(4,4,5,5-tetramethyl-1,3,2-dioxaborolan-2-yl)-10Hphenothiazine-3-carbaldehyde (9a)

(8a) 7-bromo-10-(4-(hexyloxy)phenyl)-10H-phenothiazine-3-carbaldehyde (3.3 g, $6.84 \mathrm{mmol}$ ), bis(pinacolato)diboron (2.08 g, $8.2 \mathrm{mmol})$, anhydrous KOAc (2.01 g, $20.52 \mathrm{mmol})$, and 1,4-dioxane $(30 \mathrm{~mL})$ were added into a $50 \mathrm{~mL}$ Schlenk flask. The flask was vacuumed and purged with argon three times. Then [1,1'-bis(diphenylphosphino)ferrocene]dichloropalladium(II), complex with dichloromethane $(170 \mathrm{mg}, 0.21 \mathrm{mmol})$ was added. The mixture was heated at $80{ }^{\circ} \mathrm{C}$ for $24 \mathrm{~h}$. After cooling down and the addition of water, the mixture was extracted with dichloromethane. The organic phase was combined, and dried with anhydrous $\mathrm{Na}_{2} \mathrm{SO}_{4}$. After removal of the solvent under reduced pressure, the residue was purified by column chromatography on silica gel using ethyl acetate and hexane $(\mathrm{v} / \mathrm{v}=1: 10)$ as eluent yielding 9a as a yellow solid $(2.8 \mathrm{~g}, 77 \%)$.

${ }^{1} \mathrm{H}$ NMR $\left(400 \mathrm{MHz}, \mathrm{DMSO}-d_{6}\right) \delta 9.69(\mathrm{~s}, 1 \mathrm{H}), 7.48(\mathrm{~d}, J=1.9 \mathrm{~Hz}, 1 \mathrm{H}), 7.40(\mathrm{dd}, J=8.6,2.0 \mathrm{~Hz}, 1 \mathrm{H})$, 7.35-7.30 (m, 2H), 7.24-7.16 (m, 4H), $6.16(\mathrm{~d}, J=8.6 \mathrm{~Hz}, 1 \mathrm{H}), 6.10(\mathrm{~d}, J=8.2 \mathrm{~Hz}, 1 \mathrm{H}), 4.09-4.01(\mathrm{t}$, 2H), 1.80-1.71 (m, 2H), 1.50-1.39 (m, 2H), 1.36-1.29(m, 4H), 1.26(s, 12H), 0.93-0.86(m, 3H).

${ }^{13} \mathrm{C}$ NMR (100 MHz, DMSO) $\delta$ 190.26, 158.80, 148.10, 144.87, 134.05, 132.31, 131.37, 131.25, $131.09,129.63,127.28,119.05,117.35,116.89,115.71,115.44,83.65,67.82,31.01,28.65,25.23$, $24.57,22.09,13.92$.

MALDI-TOF $m / z:$ [M]+ calcd. 529.2458; found, 529.2004 (100\%).

Synthesis of 10-(4-(hexyloxy)phenyl)-7-(4,4,5,5-tetramethyl-1,3,2-dioxaborolan-2-yl)-10Hphenoxazine-3-carbaldehyde (9b)

(8b)7-bromo-10-(4-(hexyloxy)phenyl)-10H-phenoxazine-3-carbaldehyde $(1.1 \quad \mathrm{~g}, \quad 2.36 \mathrm{mmol})$, 
bis(pinacolato)diboron (720 mg, $2.83 \mathrm{mmol})$, anhydrous KOAc (705mg, 7.19mmol), and 1,4-dioxane $(15 \mathrm{~mL})$ were added into a $50 \mathrm{~mL}$ Schlenk flask, and the flask was vacuumed and purged with argon three times. Then [1,1'-bis(diphenylphosphino)ferrocene]dichloropalladium(II) (80 mg, $0.109 \mathrm{mmol})$ was added. The mixture was heated at $80{ }^{\circ} \mathrm{C}$ for $24 \mathrm{~h}$. After cooling down and the addition of water, the mixture was extracted with dichloromethane. The organic phase was combined, and dried with anhydrous $\mathrm{Na}_{2} \mathrm{SO}_{4}$. After removal of the solvent by rotary evaporator, the residue was purified by column chromatography on silica gel using ethyl acetate and hexane $(\mathrm{v} / \mathrm{v}=1: 10)$ as eluent yielding $\mathbf{9 b}$ as a yellow solid $(0.95 \mathrm{~g}, 78.5 \%)$

${ }^{1} \mathrm{H}$ NMR (400 MHz, DMSO-d ${ }_{6}$ ) $\delta 9.65$ (s, 1H), 7.34 (d, $\left.J=8.4 \mathrm{~Hz}, 2 \mathrm{H}\right), 7.28-7.17$ (m, 3H), 7.10 (d, $J$ $=1.8 \mathrm{~Hz}, 1 \mathrm{H}), 7.01(\mathrm{~d}, J=8.0 \mathrm{~Hz}, 1 \mathrm{H}), 6.90(\mathrm{~s}, 1 \mathrm{H}), 5.98(\mathrm{~d}, J=8.2 \mathrm{~Hz}, 1 \mathrm{H}), 5.91(\mathrm{~d}, J=8.0 \mathrm{~Hz}, 1 \mathrm{H})$, $4.05(\mathrm{t}, J=6.3 \mathrm{~Hz}, 2 \mathrm{H}), 1.82-1.71(\mathrm{~m}, 2 \mathrm{H}), 1.50-1.40(\mathrm{~m}, 2 \mathrm{H}), 1.38-1.31(\mathrm{~m}, 4 \mathrm{H}), 1.25(\mathrm{~s}, 12 \mathrm{H}), 0.93-$ $0.87(\mathrm{~m}, 3 \mathrm{H})$.

${ }^{13} \mathrm{C}$ NMR (100 MHz, DMSO) $\delta 190.20,159.00,143.66,142.51,139.40,135.56,130.98,130.37$, $128.91,127.97,120.32,117.08,114.02,114.01,113.06,83.58,67.84,31.01,28.65,25.23,24.61,22.07$, 13.94.

MALDI-TOF $m / z$ : calcd. 513.2687, found: 513.1995 (100\%) for [M] ${ }^{+}$

\section{Synthesis of DPTQ-PhPTZ}

9a (1.0 g, $1.89 \mathrm{mmol}), 4$ (340 $\mathrm{mg}, 0.68 \mathrm{mmol}$, synthesized following our published procedures $\left.{ }^{1}\right)$, anhydrous $\mathrm{K}_{3} \mathrm{PO}_{4}(534 \mathrm{mg}, 2.52 \mathrm{mmol}$ ), 2-dicyclohexylphosphino-2',6'-dimethoxybiphenyl (140 mg, $0.34 \mathrm{mmol})$, dry THF $(16 \mathrm{~mL})$, and $\mathrm{H}_{2} \mathrm{O}(1.6 \mathrm{~mL})$ were added into a $50 \mathrm{~mL}$ Schlenk flask, and the flask was vacuumed and purged with argon three times. Then palladium (II) acetate ( $38 \mathrm{mg}, 0.17 \mathrm{mmol})$ was added, and the mixture was heated at $85^{\circ} \mathrm{C}$ for $24 \mathrm{~h}$. After cooling down and the addition of water, the mixture was extracted with dichloromethane. The organic phase was combined, and dried with anhydrous $\mathrm{Na}_{2} \mathrm{SO}_{4}$. After removal of the solvent by rotary evaporator, the residue was purified by column chromatography on silica gel using dichloromethane and hexane $(\mathrm{v} / \mathrm{v}=3: 1)$ as eluent yield DPTQ-PhPTZ as a green solid (300 mg, 38.4\%).

${ }^{1} \mathrm{H}$ NMR (500 MHz, Methylene Chloride- $\left.d_{2}\right) \delta 9.70$ (s, 2H), 7.67 (d, $\left.J=2.0 \mathrm{~Hz}, 2 \mathrm{H}\right)$, 7.64-7.59 (m, 
4H), 7.56-7.48 (m, 4H), 7.43-7.33 (m, 10H), 7.31 (dd, $J=8.6,2.0 \mathrm{~Hz}, 2 \mathrm{H}), 7.22-7.15(\mathrm{~m}, 4 \mathrm{H}), 6.39$ $(\mathrm{d}, J=8.6 \mathrm{~Hz}, 2 \mathrm{H}), 6.27(\mathrm{~d}, J=8.5 \mathrm{~Hz}, 2 \mathrm{H}), 4.07(\mathrm{t}, J=6.5 \mathrm{~Hz}, 4 \mathrm{H}), 1.89-1.81(\mathrm{~m}, 4 \mathrm{H}), 1.57-1.48$ (m, 4H), 1.44-1.35 (m, 8H), $0.94(\mathrm{t}, J=6.7 \mathrm{~Hz}, 6 \mathrm{H})$.

${ }^{13} \mathrm{C}$ NMR $\left(125 \mathrm{MHz}, \mathrm{CD}_{2} \mathrm{Cl}_{2}\right) \delta$ 190.07, 160.04, 153.90, 153.31, 149.60, 143.47, 139.02, 136.37, $132.49,132.40,132.17,131.73,131.57,130.67,130.51,130.43,130.13,128.81,128.03,127.51$, $120.53,118.45,117.33,116.23,115.84,69.06,32.16,29.76,26.28,23.20,14.39$.

MALDI-TOF $m / z$ : [M]+ calcd. 1143.4484; found, 1143.4687(100\%).

\section{Synthesis of DPTQ-PhPXZ}

9b (770 mg, $1.50 \mathrm{mmol}), 4$ (300 mg, $0.60 \mathrm{mmol}$, synthesized following our published procedures ${ }^{1}$ ), anhydrous $\mathrm{K}_{3} \mathrm{PO}_{4}(380 \mathrm{mg}, 1.80 \mathrm{mmol})$, 2-dicyclohexylphosphino-2',6'-dimethoxybiphenyl (246 mg, $0.60 \mathrm{mmol})$, dry tolunene $(15 \mathrm{~mL})$, and $\mathrm{H}_{2} \mathrm{O}(1.5 \mathrm{~mL})$ were added into a $50 \mathrm{~mL}$ Schlenk flask, and the flask was vacuumed and purged with argon three times. Then palladium (II) acetate ( $68 \mathrm{mg}, 0.30 \mathrm{mmol})$ was added, and the mixture was heated at $105{ }^{\circ} \mathrm{C}$ for $48 \mathrm{~h}$. After cooling down and the addition of water, the mixture was extracted with dichloromethane. The organic phase was combined, and dried with anhydrous $\mathrm{Na}_{2} \mathrm{SO}_{4}$. After removal of the solvent by rotary evaporator, the residue was purified by column chromatography on silica gel using dichloromethane and hexane $(\mathrm{v} / \mathrm{v}=5: 1)$ as eluent yield DPTQ-PhPXZ as a green solid (85 mg, 12.7\%).

${ }^{1} \mathrm{H}$ NMR $\left(500 \mathrm{MHz}, \mathrm{DMSO}-d_{6}\right) \delta 9.66(\mathrm{~s}, 2 \mathrm{H}), 7.56$ - $7.51(\mathrm{~m}, 4 \mathrm{H}), 7.46-7.33(\mathrm{~m}, 14 \mathrm{H}), 7.29(\mathrm{dd}, J$ $=8.3,1.8 \mathrm{~Hz}, 2 \mathrm{H}), 7.24(\mathrm{~d}, J=8.8 \mathrm{~Hz}, 4 \mathrm{H}), 7.18(\mathrm{~d}, J=1.8 \mathrm{~Hz}, 2 \mathrm{H}), 6.09(\mathrm{~d}, J=8.4 \mathrm{~Hz}, 2 \mathrm{H}), 6.04(\mathrm{~d}$, $J=8.3 \mathrm{~Hz}, 2 \mathrm{H}), 4.07(\mathrm{t}, J=6.4 \mathrm{~Hz}, 4 \mathrm{H}), 1.84-1.75(\mathrm{~m}, 4 \mathrm{H}), 1.51-1.45(\mathrm{~m}, 4 \mathrm{H}), 1.39-1.32(\mathrm{~m}, 8 \mathrm{H})$, 0.93-0.89 (m, 6H).

${ }^{13} \mathrm{C}$ NMR (125 MHz, DMSO) $\delta 190.11,159.02,153.01,152.13,143.64,142.21,139.54,138.29$, $135.22,132.75,131.10,130.26,129.64,129.45,129.23,129.04,128.87,128.16,126.97,119.75$, $117.09,114.06,112.99,112.82,67.87,31.03,28.66,25.25,22.11,13.95$.

MALDI-TOF $m / z:$ [M]+ calcd. 1111.4484; found, 1111.8491(100\%). 


\section{Lippert-Mataga plot}

Lippert-Mataga plot is usually used to describe the solvent effects of fluorophores. Commonly, it's given by eq1

$$
\bar{v}=\overline{v_{a}}-\overline{v_{f}}=\frac{2\left(\mu_{e}-\mu_{g}\right)^{2}}{h c a^{3}} \Delta f+\text { Constant }
$$

Where $\bar{v}_{a}, \bar{v}_{f}$ are the maximum absorption wavelength and maximum emission wavelength of the fluorophore in solvents, which are expressed in wavenumber $\left(\mathrm{cm}^{-1}\right) ; \mu_{e}$ and $\mu_{g}$ are the dipole moments of the excited state and ground state; $h$ is the Planck constant; $c$ is the velocity of light in vacuum; $a$ is the Onsager diameter of the fluorophore; $\Delta f$ is the polar parameter, which is calculated by eq 2

$$
\Delta f=f(\varepsilon)-f\left(n^{2}\right)=\frac{\varepsilon-1}{2 \varepsilon+1}-\frac{n^{2}-1}{2 n^{2}+1}
$$

Where $\varepsilon$ is the dielectric constant of the solvent and $n$ is the refractive index of the solvent. And the slope of linear-fitting of the $\bar{v}$ versus $\Delta f$ could give the $\mu_{e}-\mu_{g}$.

\section{Quantum yield measurements}

A series of the dilute solutions of the fluorophores and the reference dye were prepared at different concentrations, respectively. Their absorption and emission spectra were measured and their QYs $\left(\phi_{s}\right)$ were calculated by the following formula,

$$
\phi_{s}=\phi_{\text {ref }} \times \frac{\text { Slope }_{s}}{\text { Slope }_{\text {ref }}} \times\left(\frac{n_{s}}{n_{\text {ref }}}\right)^{2}
$$

Where $\phi_{\text {ref }}$ is the QY of the reference dye, Slope $e_{s}$ and Slope $e_{r e f}$ are the linear-fitted slopes of the integrated fluorescence intensities versus the corresponding absorption values at $655 \mathrm{~nm}$ of the fluorophore and reference dye solutions, respectively, and the $n_{s}$ and $n_{\text {ref }}$ are the refractive index of the solvents. 


\section{Photophysical rate constant calculations}

Photophysical rate constant could be calculated by QY and radiative lifetime. Generally, QY $\phi_{r}$ is given by eq 4

$$
\phi_{r}=\frac{k_{r}}{k_{r}+k_{n r}}
$$

Where $k_{r}$ is the radiative rate constant, and $k_{n r}$ is the nonradiative rate constant. And the radiative lifetime $\tau_{r}$ is given by eq 5

$$
\tau_{r}=\frac{1}{k_{r}+k_{n r}}
$$

\section{Preparation of fluorophore-loaded nanoparticles}

A stock chloroform solution $(1 \mathrm{mg} / \mathrm{mL})$ of DPTQ-PhPTZ or DPTQ-PhPXZ $(1 \mathrm{~mL})$ and a stock chloroform solution $(30 \mathrm{mg} / \mathrm{mL})$ of Pluronic F-127 $(1 \mathrm{~mL})$ were added into a $10 \mathrm{~mL}$ round-bottom flask. Then the solvent was removed by rotary evaporator at $60{ }^{\circ} \mathrm{C} .1 \mathrm{~mL}$ of saline was added into the flask, and the mixture was sonicated for 5 minutes at $37^{\circ} \mathrm{C}$. The resulting solution was filtered by using a syringe-driven filter $(0.22 \mu \mathrm{m}$ hole diameters $)$. A clear solution was obtained and used directly for the further experiments. The loading contents and encapsulation efficiencies of the fluorophores in the NPs were measured by absorbance analyses using pre-established calibration curves and calculated by eq 6 and 7 , respectively:

$$
\begin{gathered}
\text { Loading content } \%=\frac{\text { Weight of the fluorophore in NPs }}{\text { Weight of the NPs }} \times 100 \% \\
\text { Encapsulation efficiency } \%=\frac{\text { Weight of the fluorophore in NPs }}{\text { Weight of the feeding fluorophore }} \times 100 \%
\end{gathered}
$$




\section{Cytotoxicity}

MCF-7 cells were seeded in a 96-well plate at a density of $5 \times 10^{3}$ cells $/ \mathrm{mL}$ and incubated for $24 \mathrm{~h}$ in DMEM medium supplemented with $10 \%$ of fetal bovine serum (FBS), 100 units $/ \mathrm{mL}$ of penicillin and $100 \mathrm{mg} / \mathrm{mL}$ of streptomycin at $37^{\circ} \mathrm{C}$ in a humidified atmosphere of $5 \% \mathrm{CO}_{2}$. Then the cells were treated with the fluorophore-loaded NPs at different concentrations and co-incubated for another $24 \mathrm{~h}$. $5.0 \mathrm{mg} / \mathrm{mL}$ stock solution of MTT was prepared in PBS and this stock solution (10 $\mu \mathrm{L})$ was added to each well. After additional $4.0 \mathrm{~h}$ incubation, the medium and MTT were removed, and the MTTformazan crystals in each well were dissolved in $100 \mu \mathrm{L}$ of DMSO. The absorbance of the suspension was recorded by a microplate reader (CMax Plus, Molecular Devices, Shanghai) at a wavelength of $562 \mathrm{~nm}$.

\section{Animal experiments}

All animal experiments were implemented according to the National Institute of Health Guide for the Care and Use of Laboratory Animals and approved by the Animal Ethics Committee of Drum Tower Hospital (Nanjing, China). To establish a H22 tumor model, H22 cells $\left(5 \times 10^{6}\right.$ cells dispersed in 200 $\mathrm{ml}$ of PBS) were injected subcutaneously into the lateral thigh of male nude mice (18-22 $\mathrm{g})$. When the tumors reached a mean volume of $\sim 150 \mathrm{~mm}^{3}$, the mice were injected with the fluorophore-loaded NPs in saline via tail vein and imaged immediately on the NIR-II fluorescence imaging system.

\section{Histology study}

Male ICR mice $(n=9,18-22 \mathrm{~g})$ were randomly divided into 3 groups ( $\mathrm{n}=3$ per group). Mice in group one and group two were injected with $200 \mu \mathrm{L}$ of DPTQ-PhPXZ NPs in saline (containing $200 \mu \mathrm{g}$ DPTQ-PhPXZ NPs) via tail vein, respectively. Mice in group three were injected with $200 \mu \mathrm{L}$ of saline via tail vein as control. All the mice were sacrificed at $24 \mathrm{~h}$ or on the 8 th day after the injection of the DPTQ-PhPXZ NPs. The main organs of the mice including heart, lung, liver, spleen and kidney were 
collected and fixed in $4 \%$ paraformaldehyde overnight at $4{ }^{\circ} \mathrm{C}$. Thereafter, the samples were embedded in paraffin, sectioned, and stained with hematoxylin and eosin $(\mathrm{H} \& \mathrm{E})$. The histological sections were imaged under an optical microscope with objective lens of 20X and 40X.

\section{Optical system for NIR-II fluorescence imaging}

An $808 \mathrm{~nm}$ laser system was used as the excitation light source. An 808nm long-pass filter and a 1000$1100 \mathrm{~nm}$ band-pass filter were used to extract the NIR-II signal. All the images were taken with an electric-cooling two-dimensional (640 pixels $\times 512$ pixels) InGaAs camera. The power density of the laser is $120 \mathrm{~mW} / \mathrm{cm}^{2}$ and the exposure time is $500 \mathrm{~ms}$. 


\section{NMR \& MS Data}

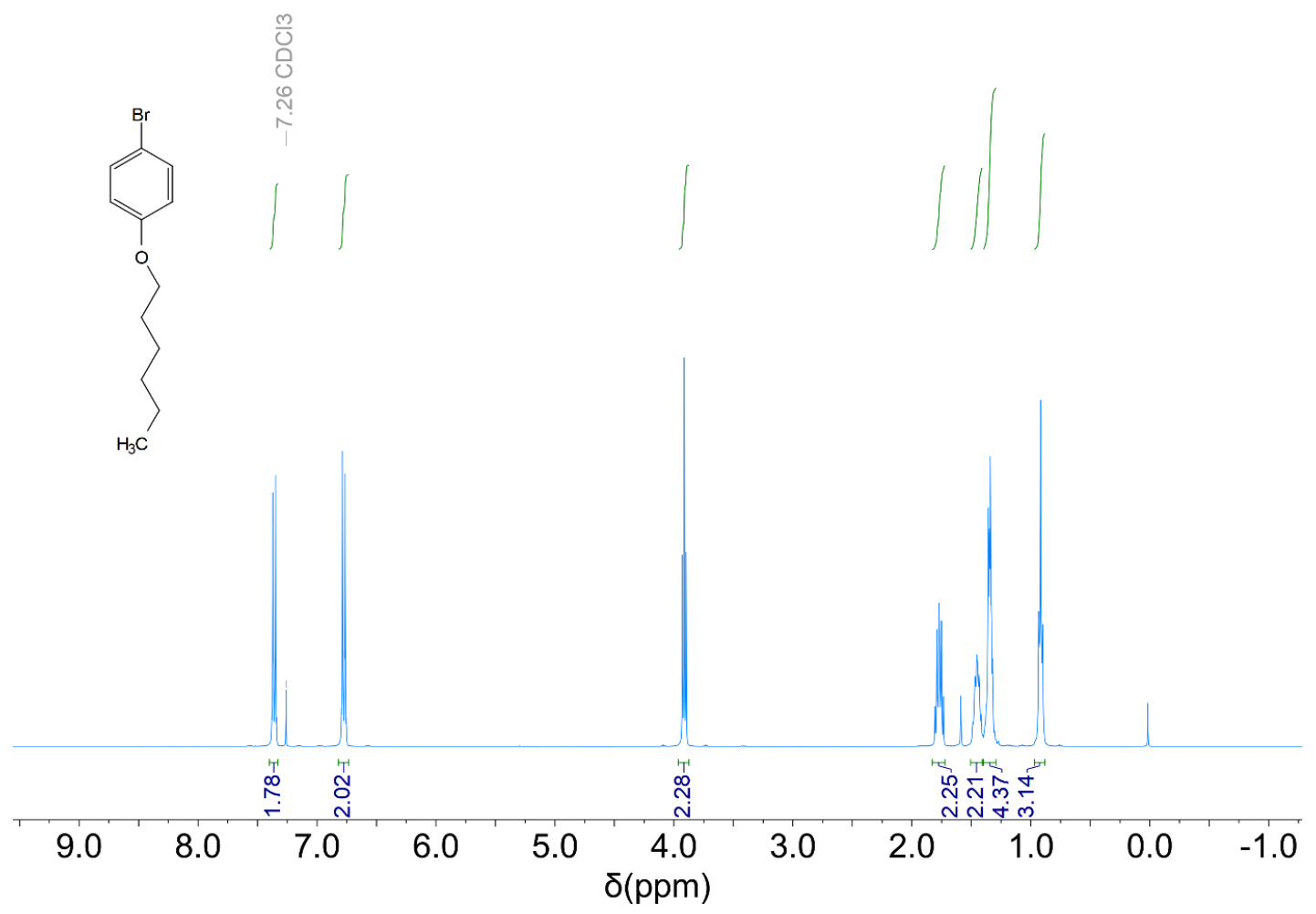

Figure $\mathbf{S 1}{ }^{1} \mathrm{H}-\mathrm{NMR}$ spectrum of 1-bromo-4-(hexyloxy)benzene in $\mathrm{CDCl}_{3}$.

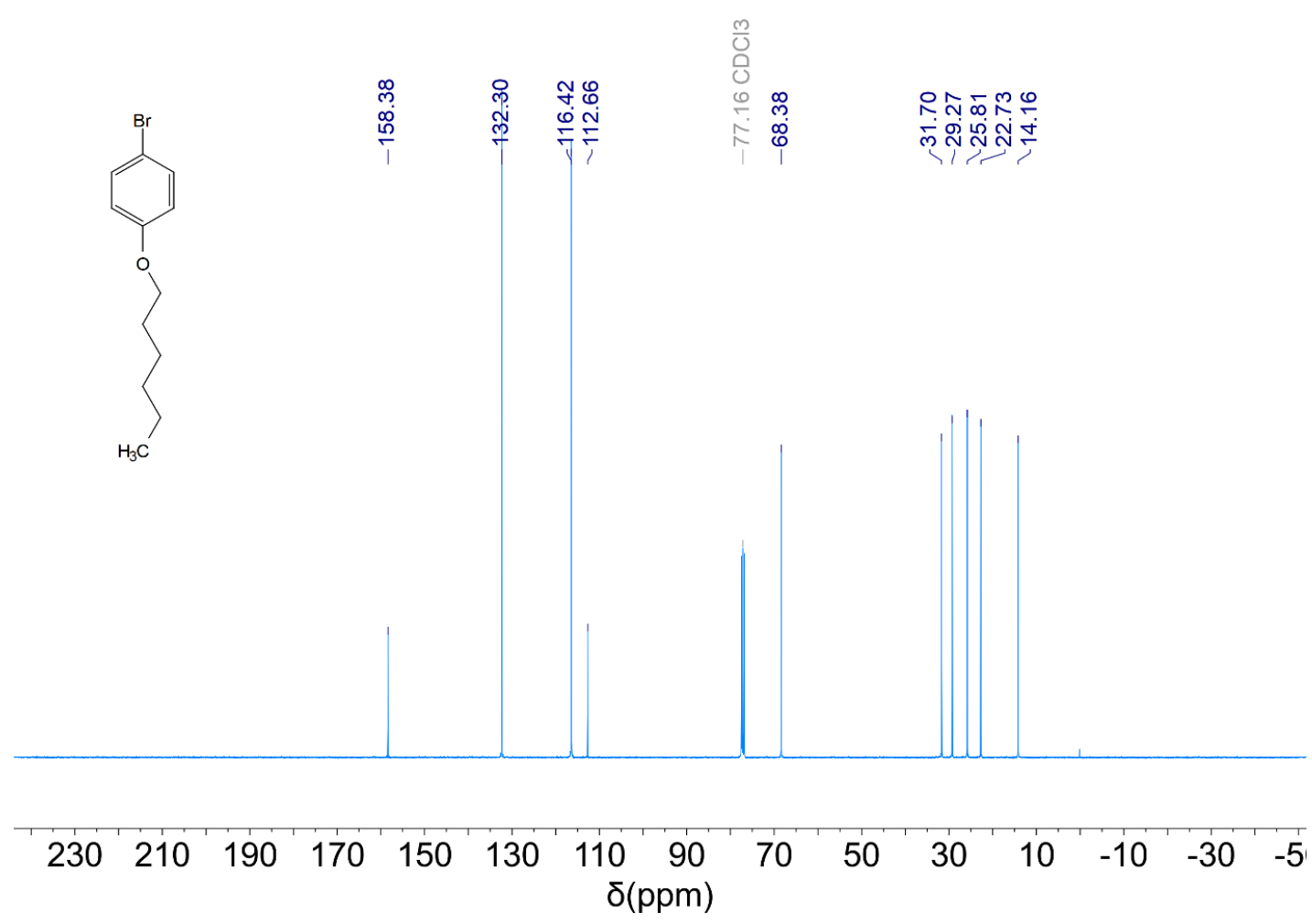

Figure S2 ${ }^{13} \mathrm{C}$-NMR spectrum of 1-bromo-4-(hexyloxy)benzene in $\mathrm{CDCl}_{3}$. 


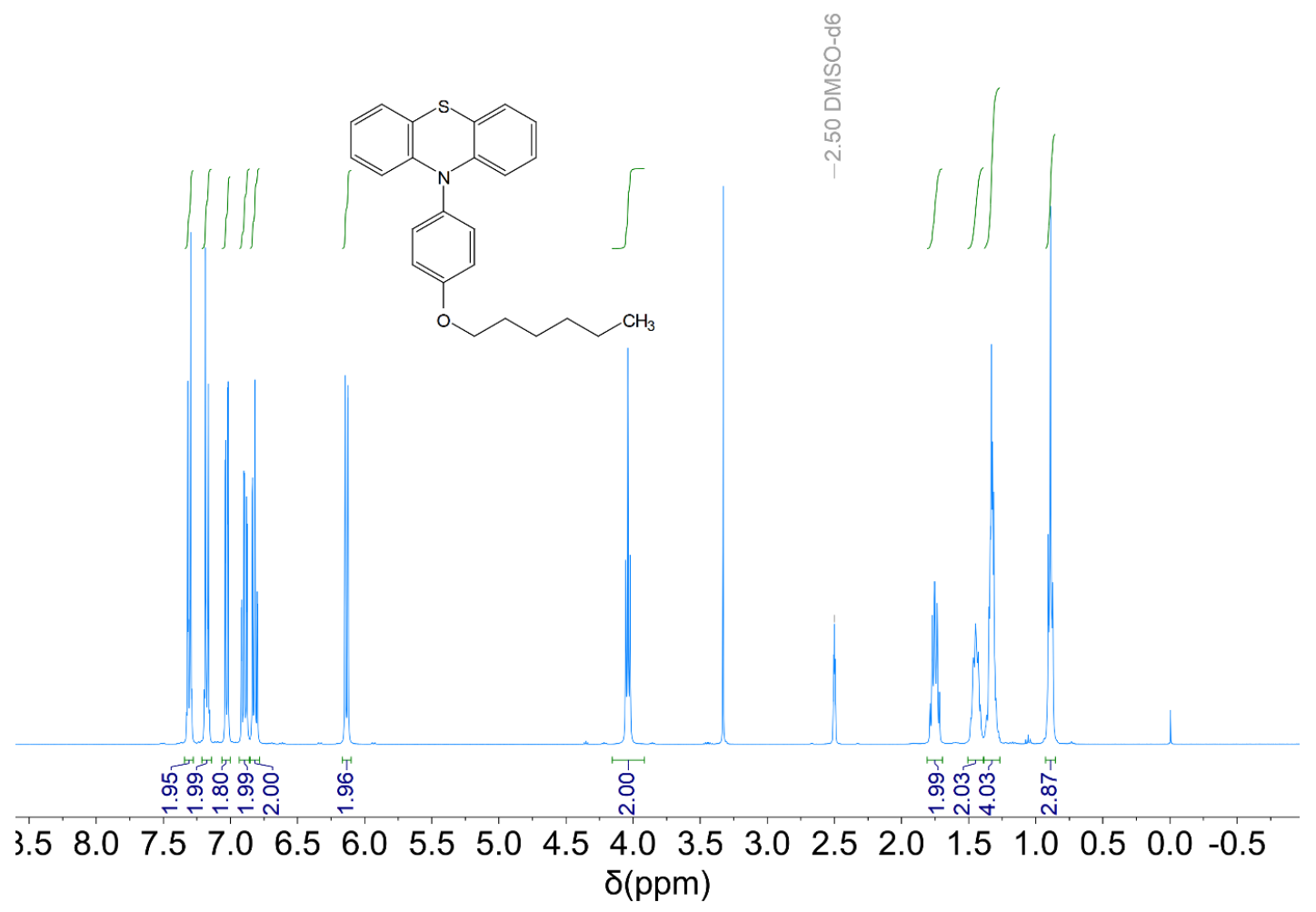

Figure S3 ${ }^{1} \mathrm{H}-\mathrm{NMR}$ spectrum of 10-(4-(hexyloxy)phenyl)-10H-phenothiazine in DMSO- $d_{6}$.
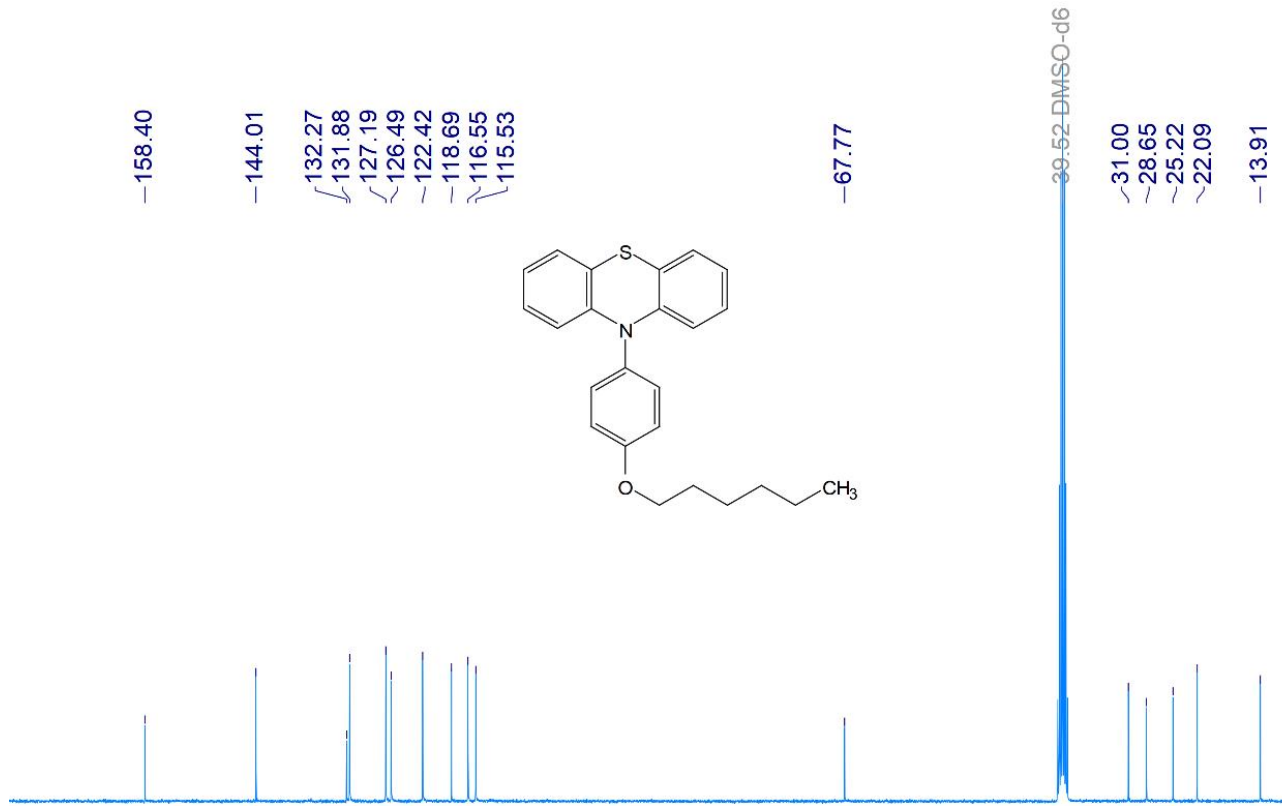

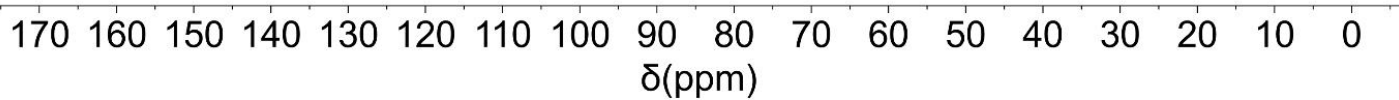

Figure S4 ${ }^{13} \mathrm{C}-\mathrm{NMR}$ spectrum of 10-(4-(hexyloxy)phenyl)-10H-phenothiazine in DMSO- $d_{6}$. 


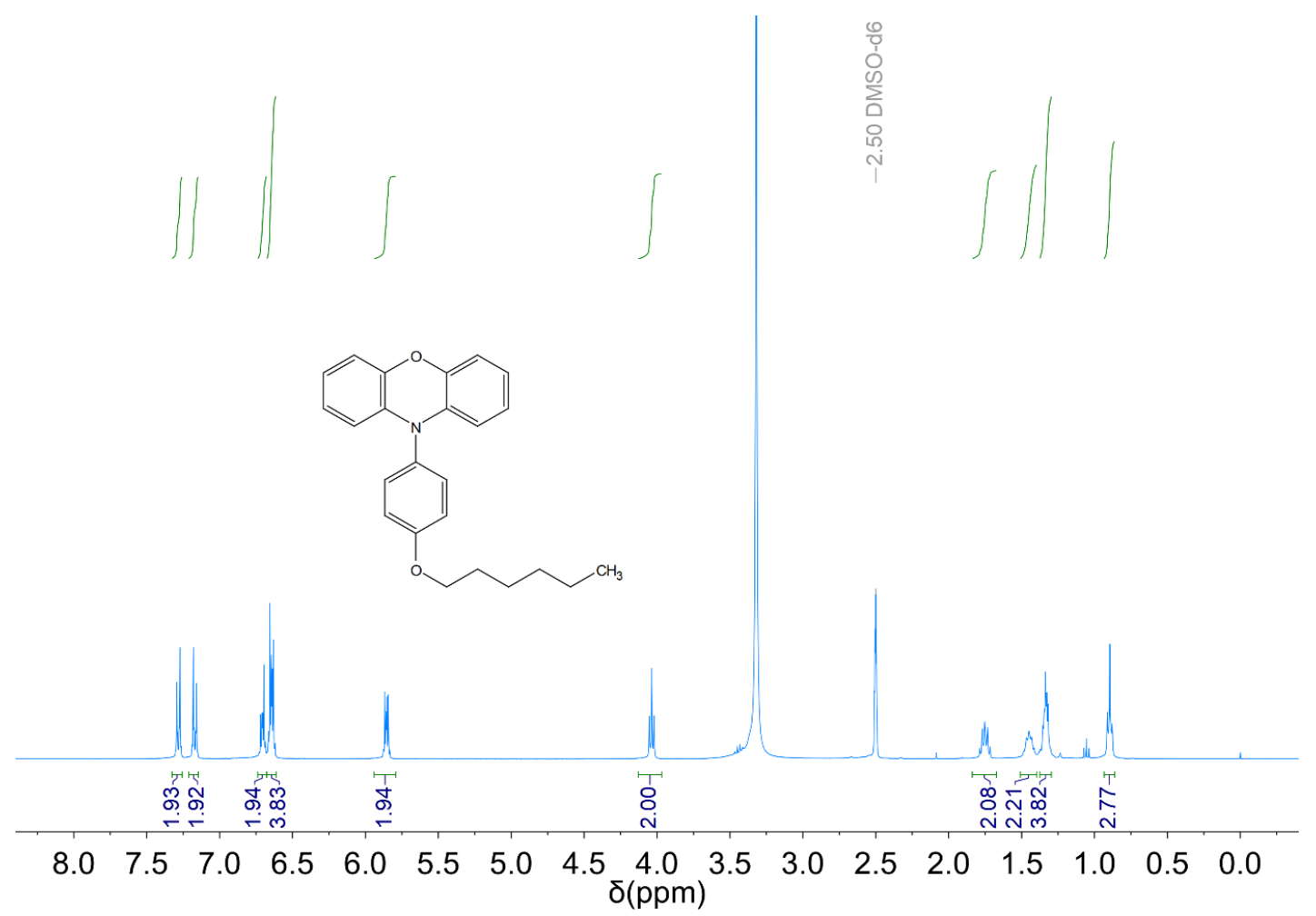

Figure S5 ${ }^{1} \mathrm{H}-\mathrm{NMR}$ spectrum of 10-(4-(hexyloxy)phenyl)-10H-phenoxazine in DMSO- $d_{6}$.
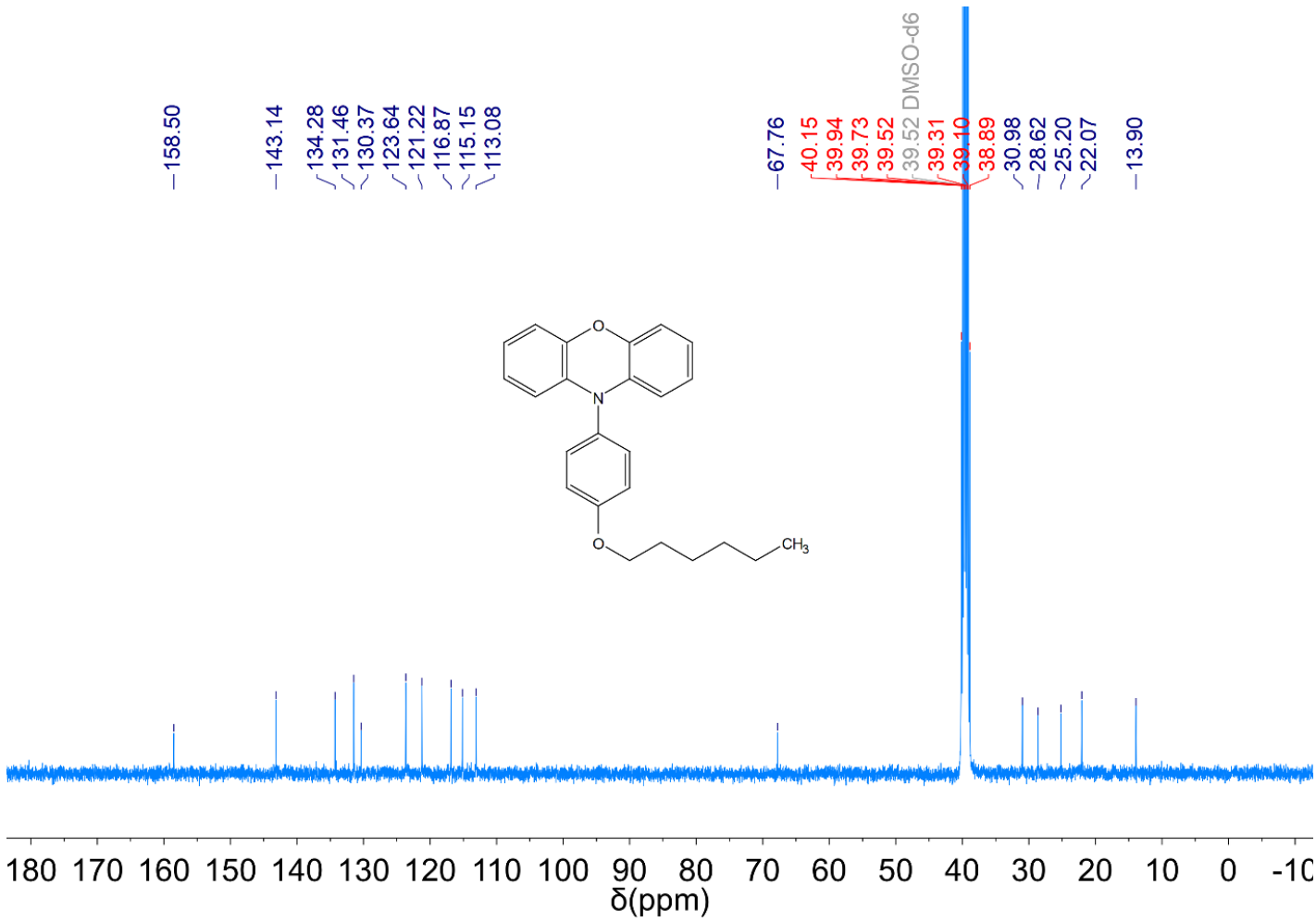

Figure S6 ${ }^{13} \mathrm{C}-\mathrm{NMR}$ spectrum of 10-(4-(hexyloxy)phenyl)-10H-phenoxazine in DMSO- $d_{6}$. 

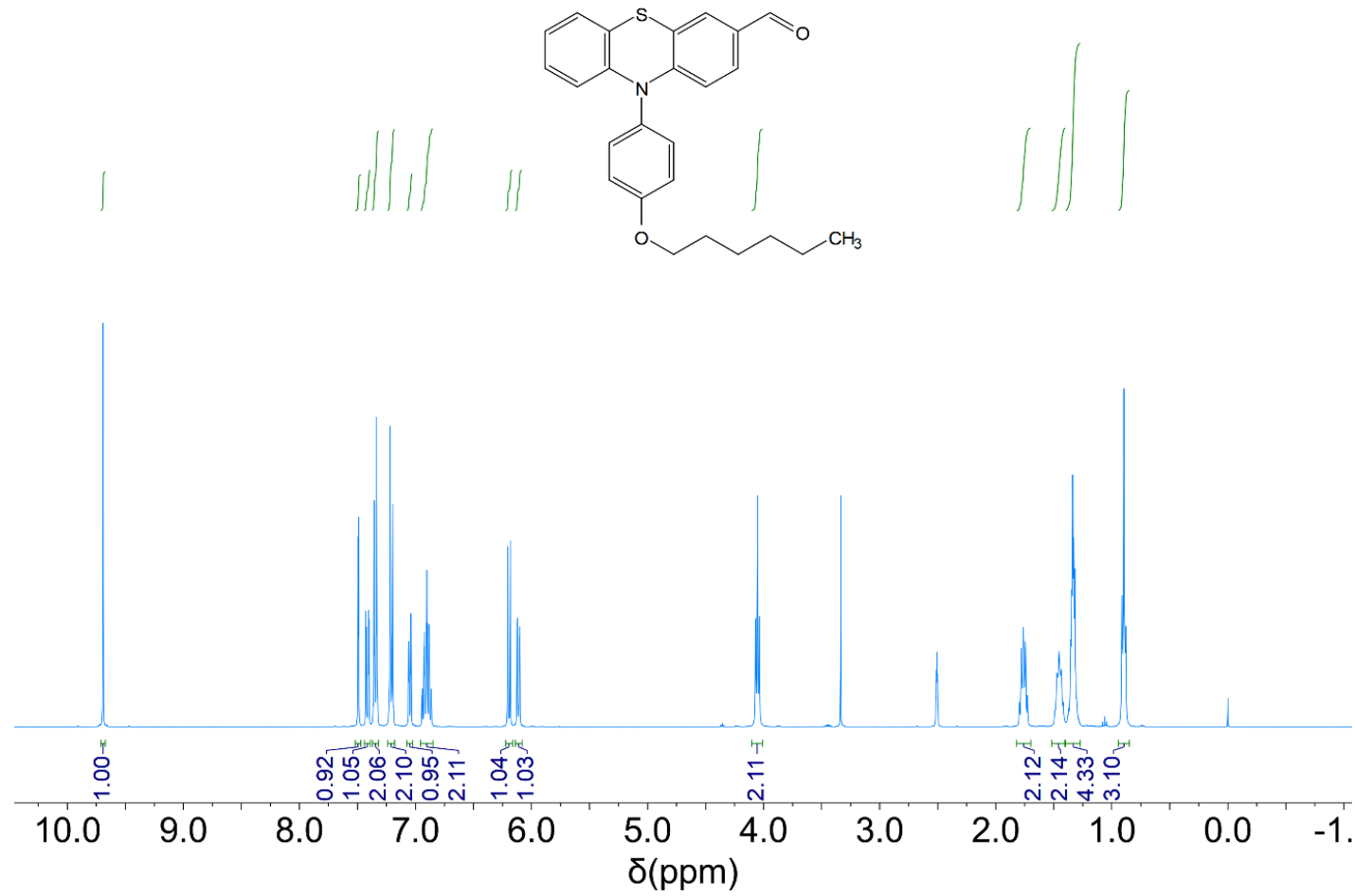

Figure S7 ${ }^{1} \mathrm{H}-\mathrm{NMR}$ spectrum of 10-(4-(hexyloxy)phenyl)-10H-phenothiazine-3-carbaldehyde in DMSO- $d_{6}$.

$\stackrel{\infty}{\circ}$

‥

立 并

ธธ์ สุดั

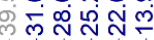
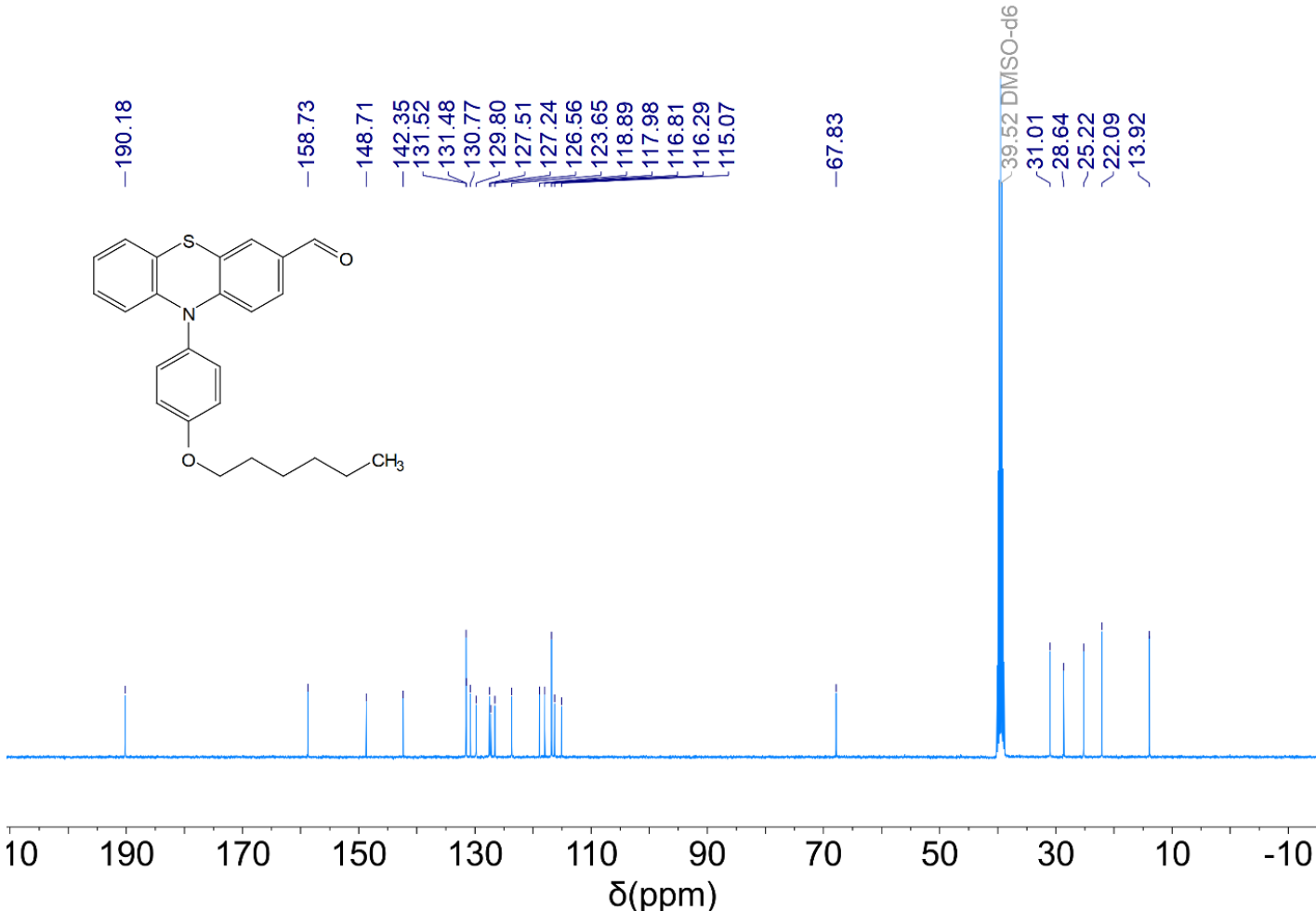

Figure S8 ${ }^{13} \mathrm{C}-\mathrm{NMR}$ spectrum of 10-(4-(hexyloxy)phenyl)-10H-phenothiazine-3-carbaldehyde in DMSO- $d_{6}$. 


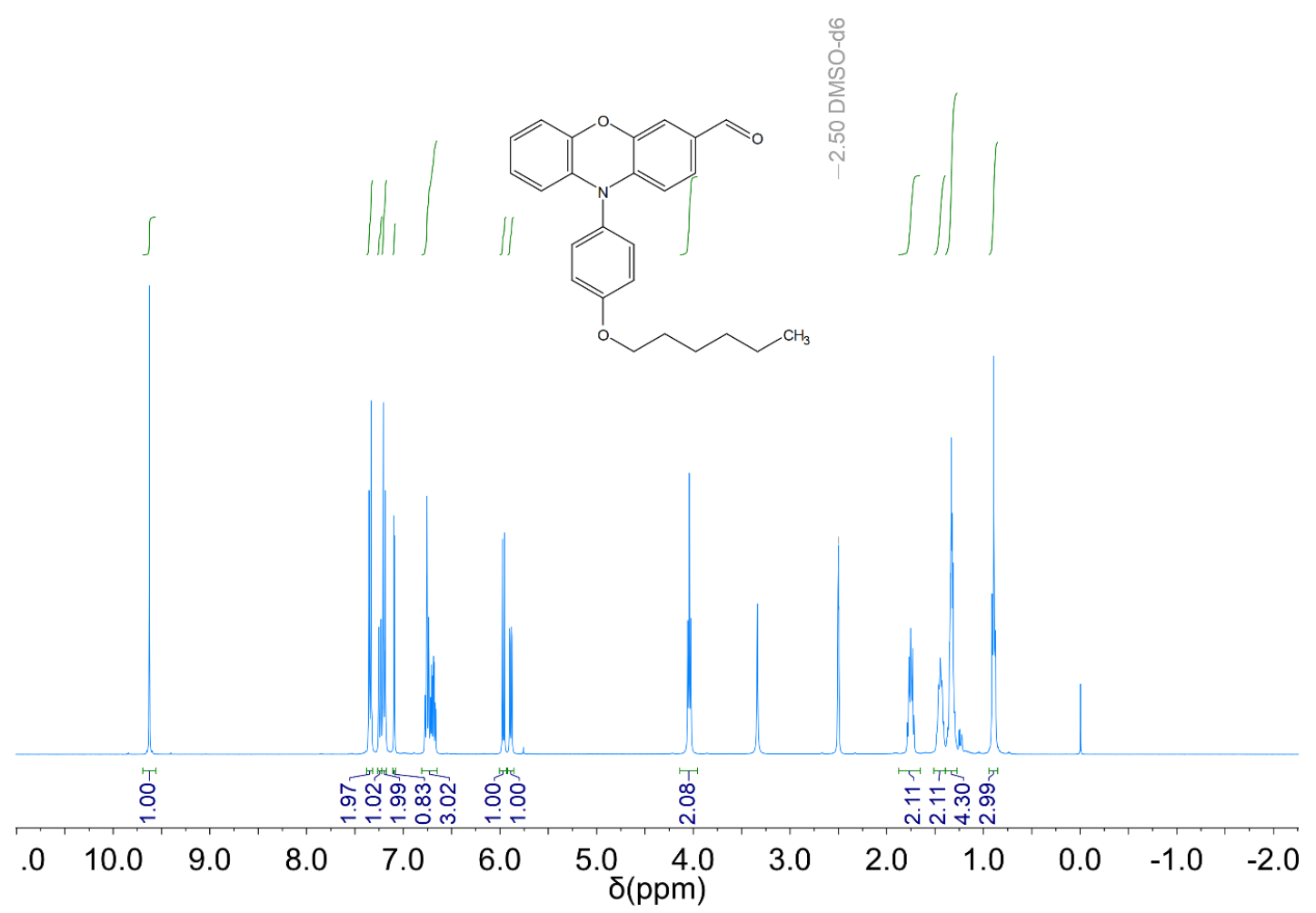

Figure S9 ${ }^{1} \mathrm{H}-\mathrm{NMR}$ spectrum of 10-(4-(hexyloxy)phenyl)-10H-phenoxazine-3-carbaldehyde in DMSO- $d_{6}$.

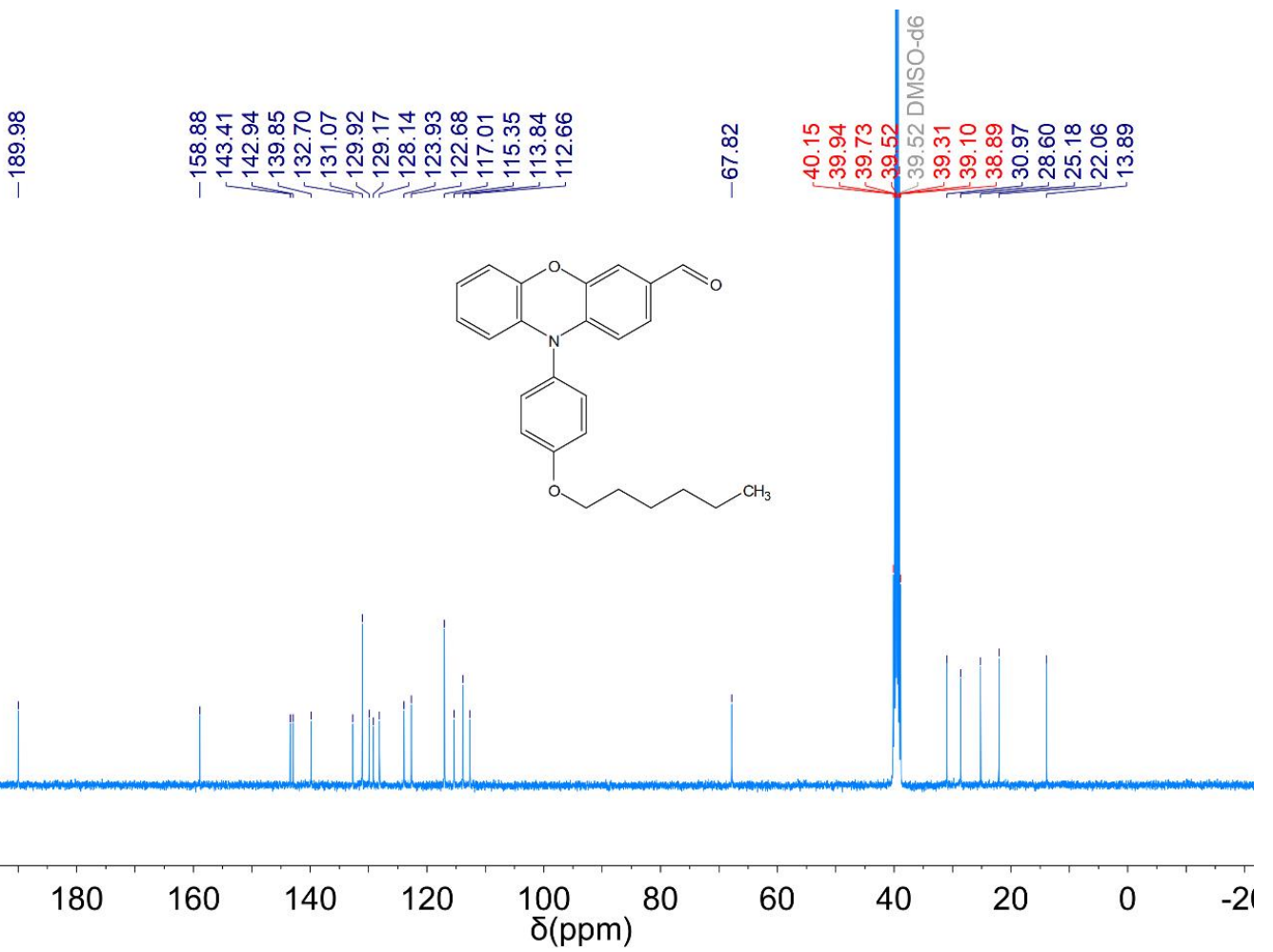

Figure S10 ${ }^{13} \mathrm{C}-\mathrm{NMR}$ spectrum of 10-(4-(hexyloxy)phenyl)-10H-phenoxazine-3-carbaldehyde in DMSO- $d_{6}$. 

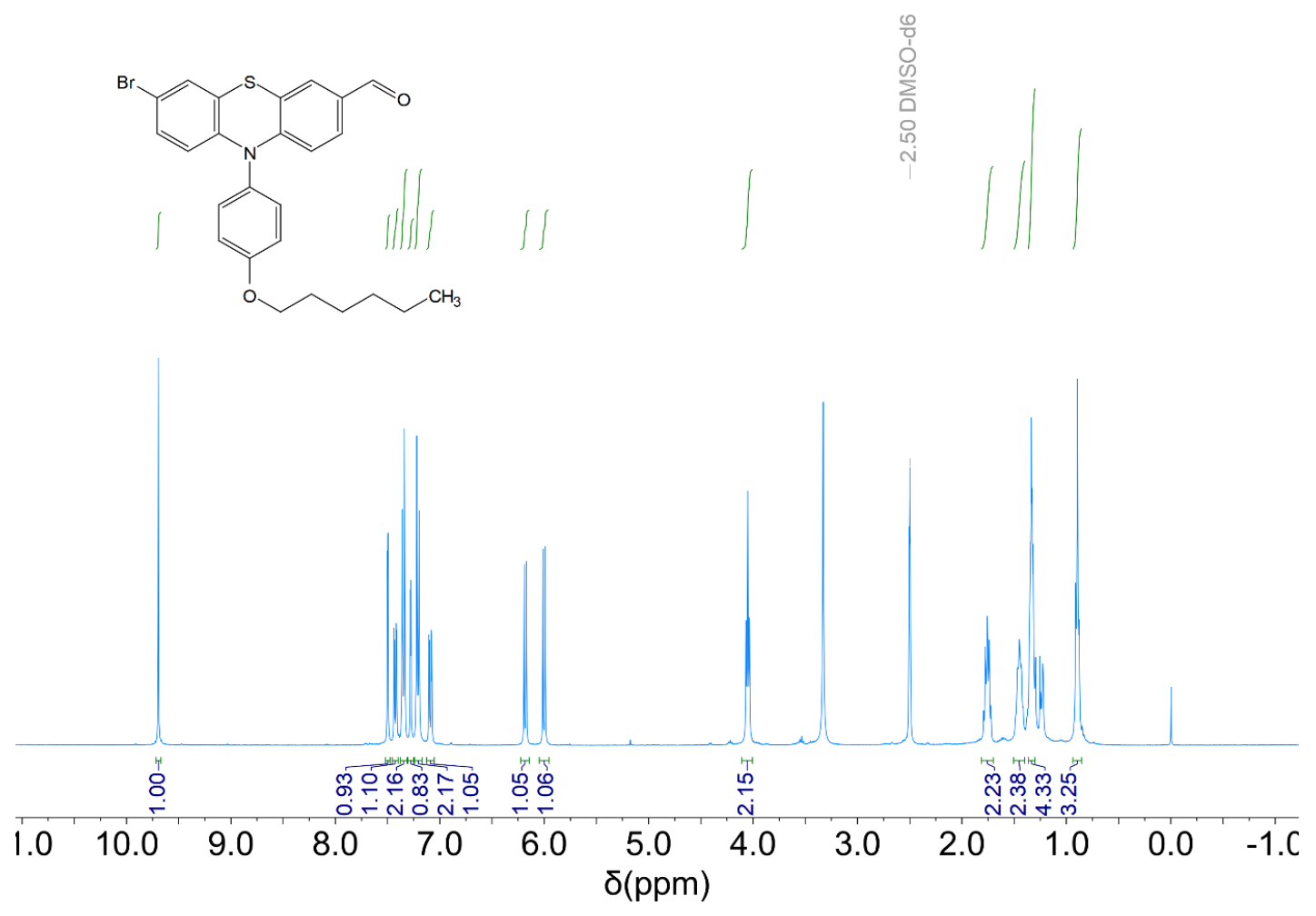

Figure S11 ${ }^{1}$ H-NMR spectrum of 7-bromo-10-(4-(hexyloxy)phenyl)-10H-phenothiazine-3carbaldehyde in DMSO- $d_{6}$.

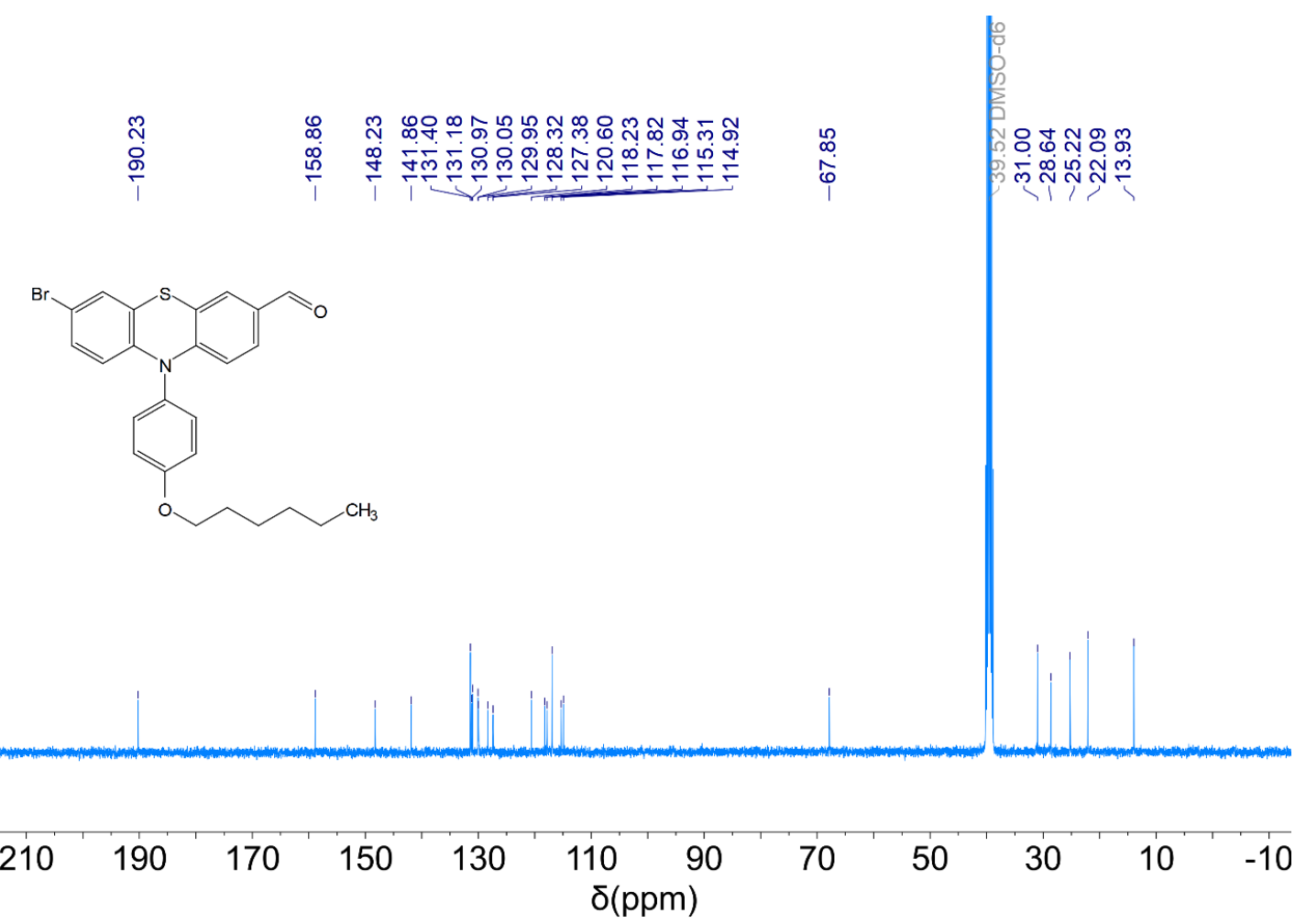

Figure S12 ${ }^{13}$ C-NMR spectrum of 7-bromo-10-(4-(hexyloxy)phenyl)-10H-phenothiazine-3carbaldehyde in DMSO- $d_{6}$. 


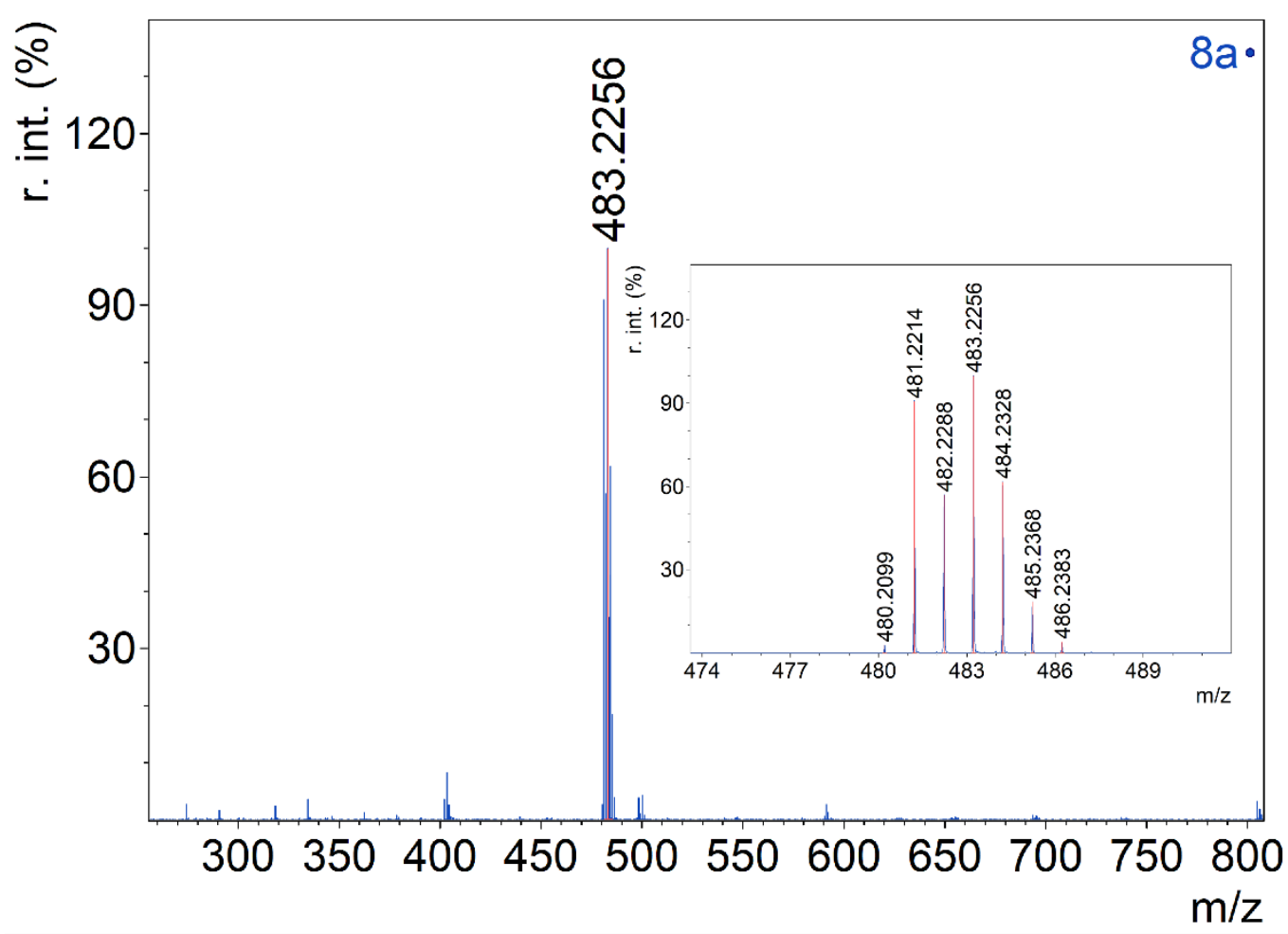

Figure S13 MALDI-TOF mass spectrum of 7-bromo-10-(4-(hexyloxy)phenyl)-10H-phenothiazine-3carbaldehyde.

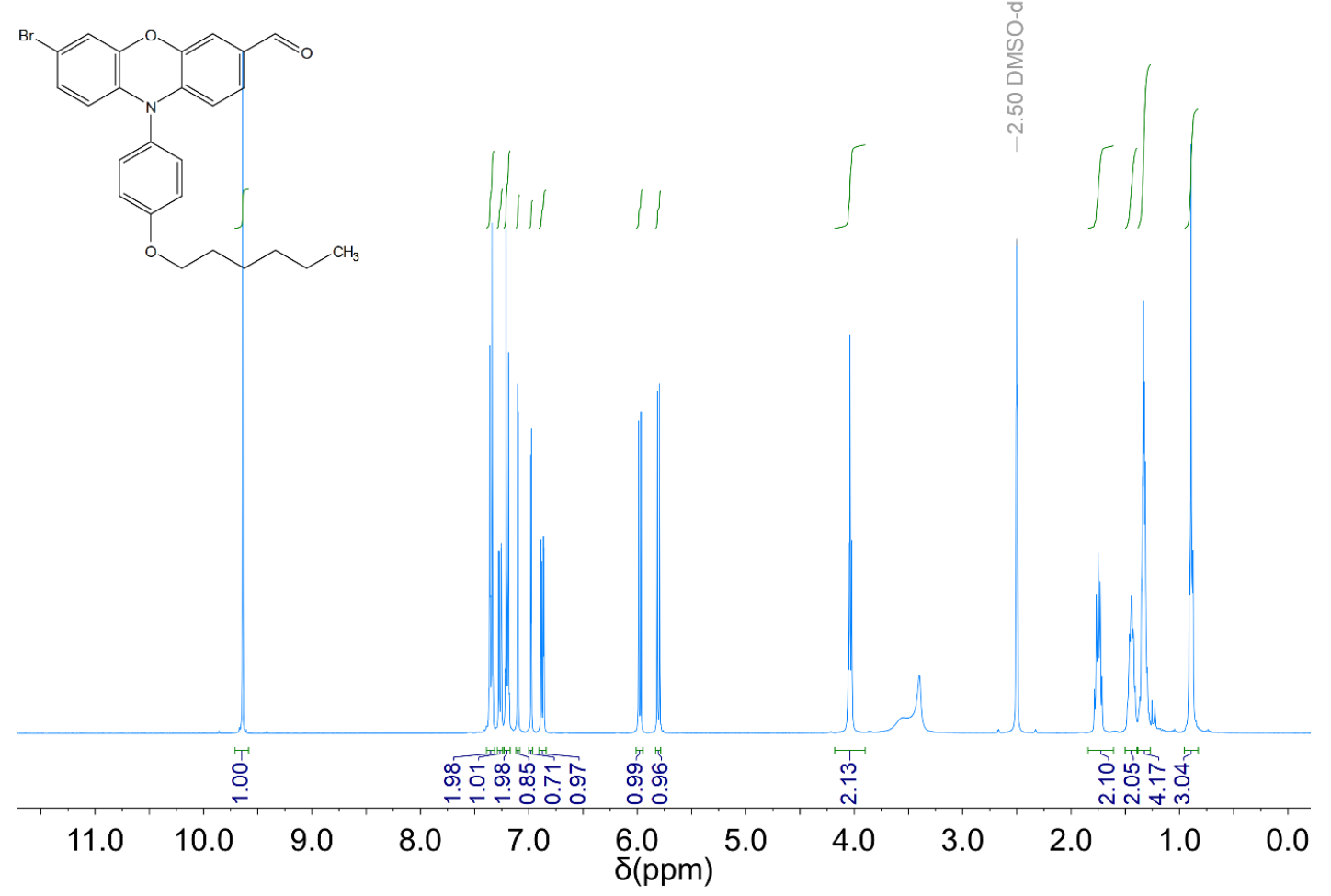

Figure S14 ${ }^{1}$ H-NMR spectrum of 7-bromo-10-(4-(hexyloxy)phenyl)-10H-phenoxazine-3carbaldehyde in DMSO- $d_{6}$. 


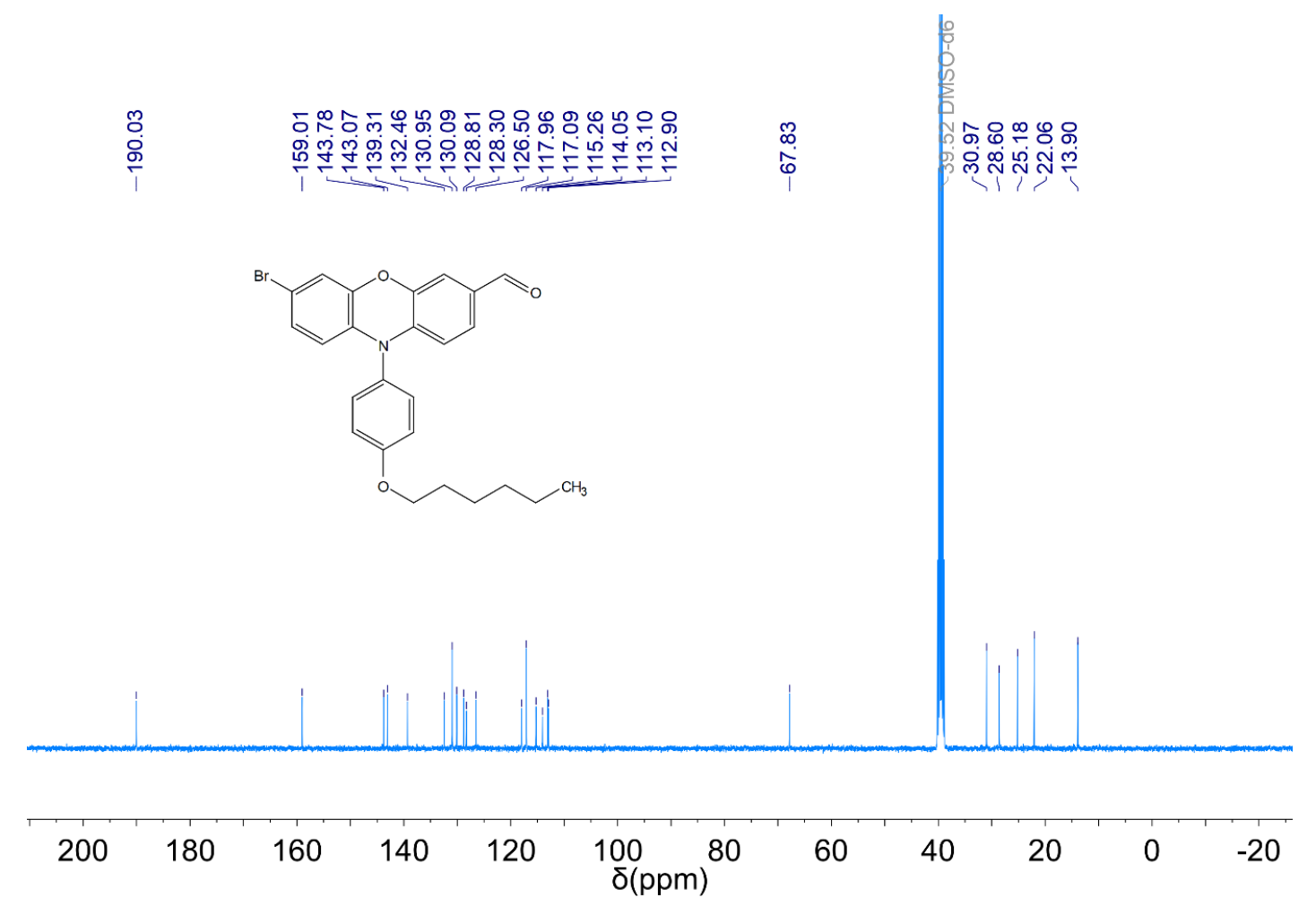

Figure S15 ${ }^{13}$ C-NMR spectrum of 7-bromo-10-(4-(hexyloxy)phenyl)-10H-phenoxazine-3carbaldehyde in DMSO- $d_{6}$.

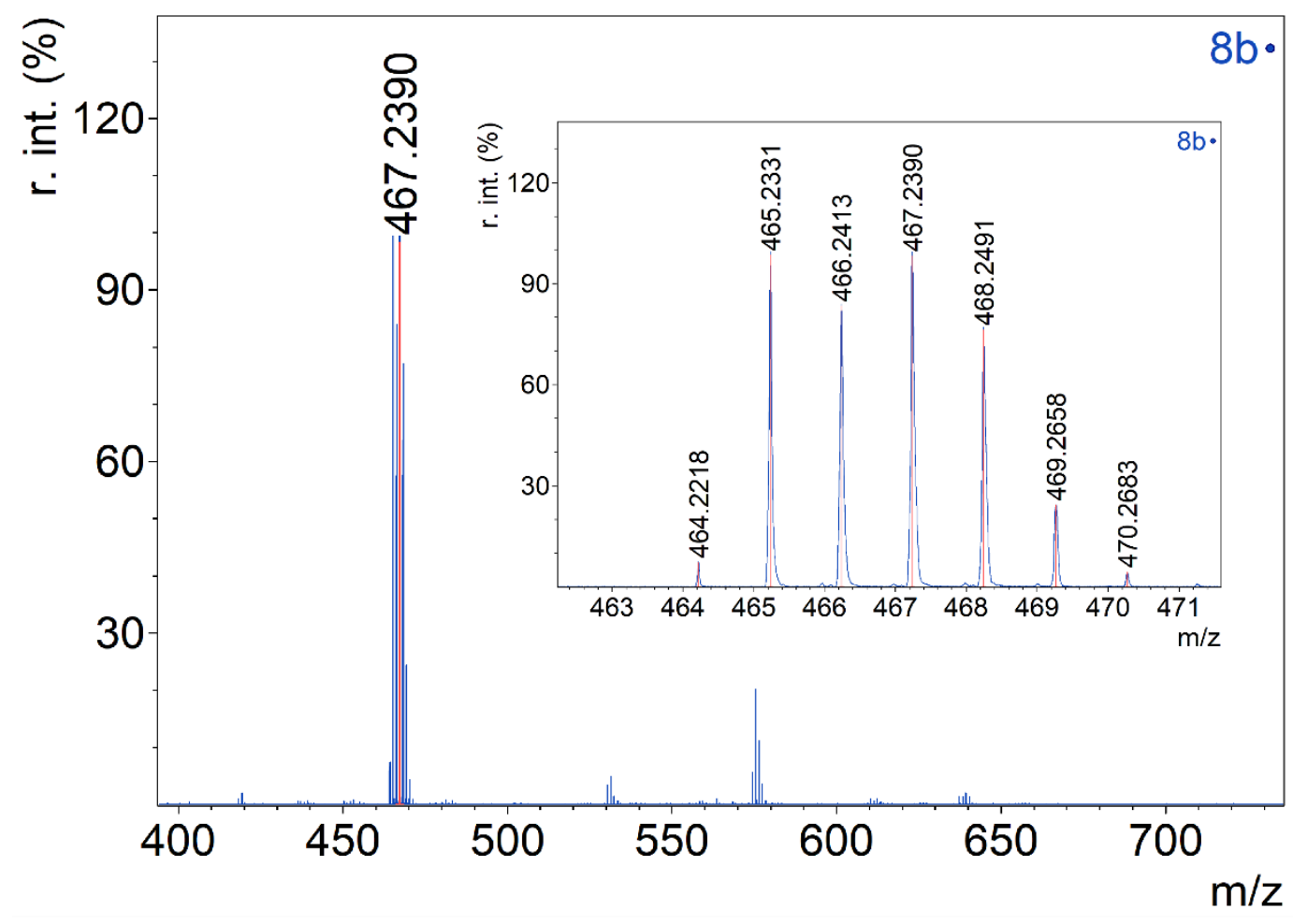

Figure S16 MALDI-TOF mass spectrum of 7-bromo-10-(4-(hexyloxy)phenyl)-10H-phenoxazine-3carbaldehyde. 

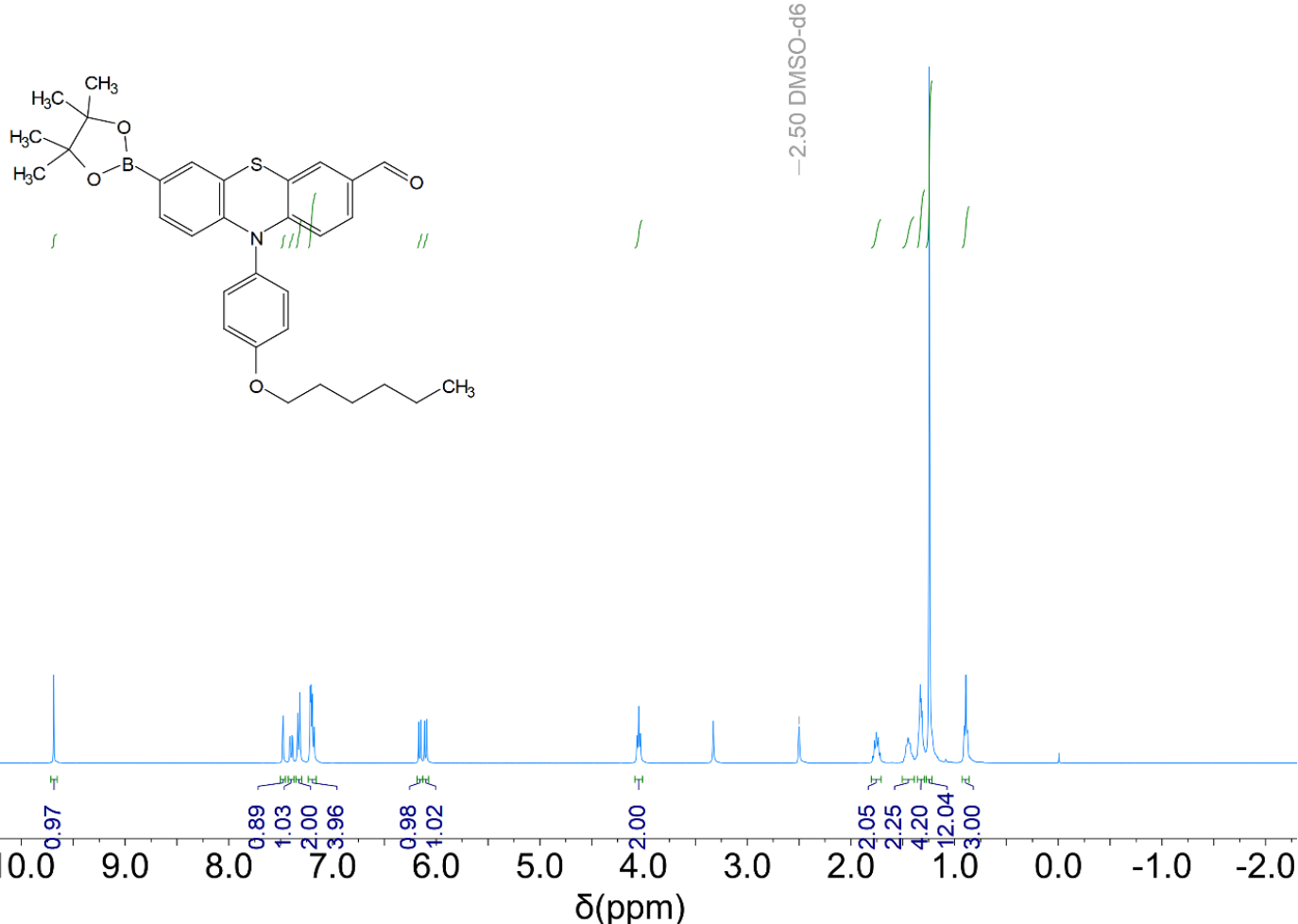

Figure S17 ${ }^{1}$ H-NMR spectrum of 10-(4-(hexyloxy)phenyl)-7-(4,4,5,5-tetramethyl-1,3,2dioxaborolan-2-yl)-10H-phenothiazine-3-carbaldehyde in DMSO- $d_{6}$.

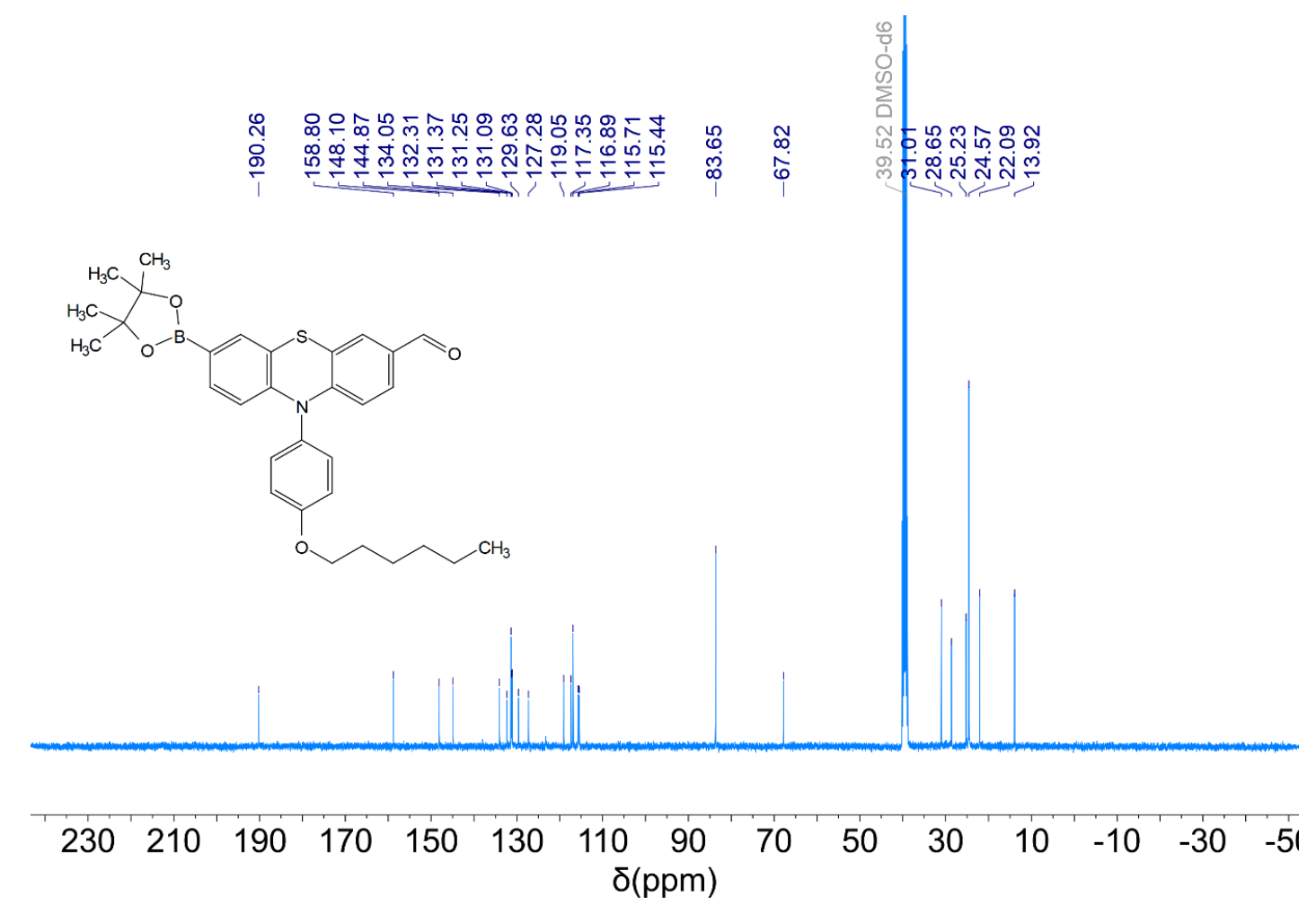

Figure S18 ${ }^{13}$ C-NMR spectrum of 10-(4-(hexyloxy)phenyl)-7-(4,4,5,5-tetramethyl-1,3,2dioxaborolan-2-yl)-10H-phenothiazine-3-carbaldehyde in DMSO- $d_{6}$. 


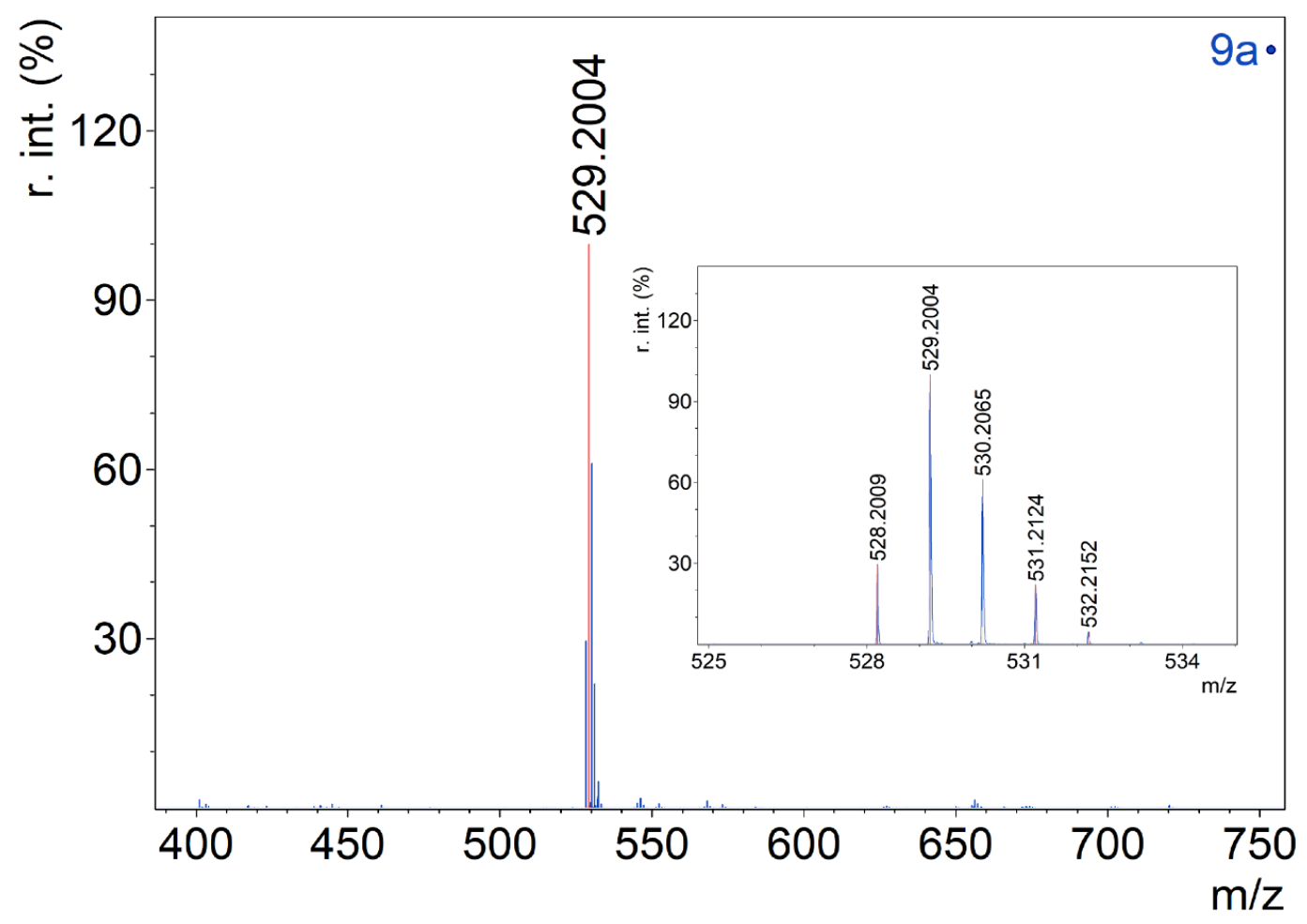

Figure S19 MALDI-TOF mass spectrum of 10-(4-(hexyloxy)phenyl)-7-(4,4,5,5-tetramethyl-1,3,2dioxaborolan-2-yl)-10H-phenothiazine-3-carbaldehyde.
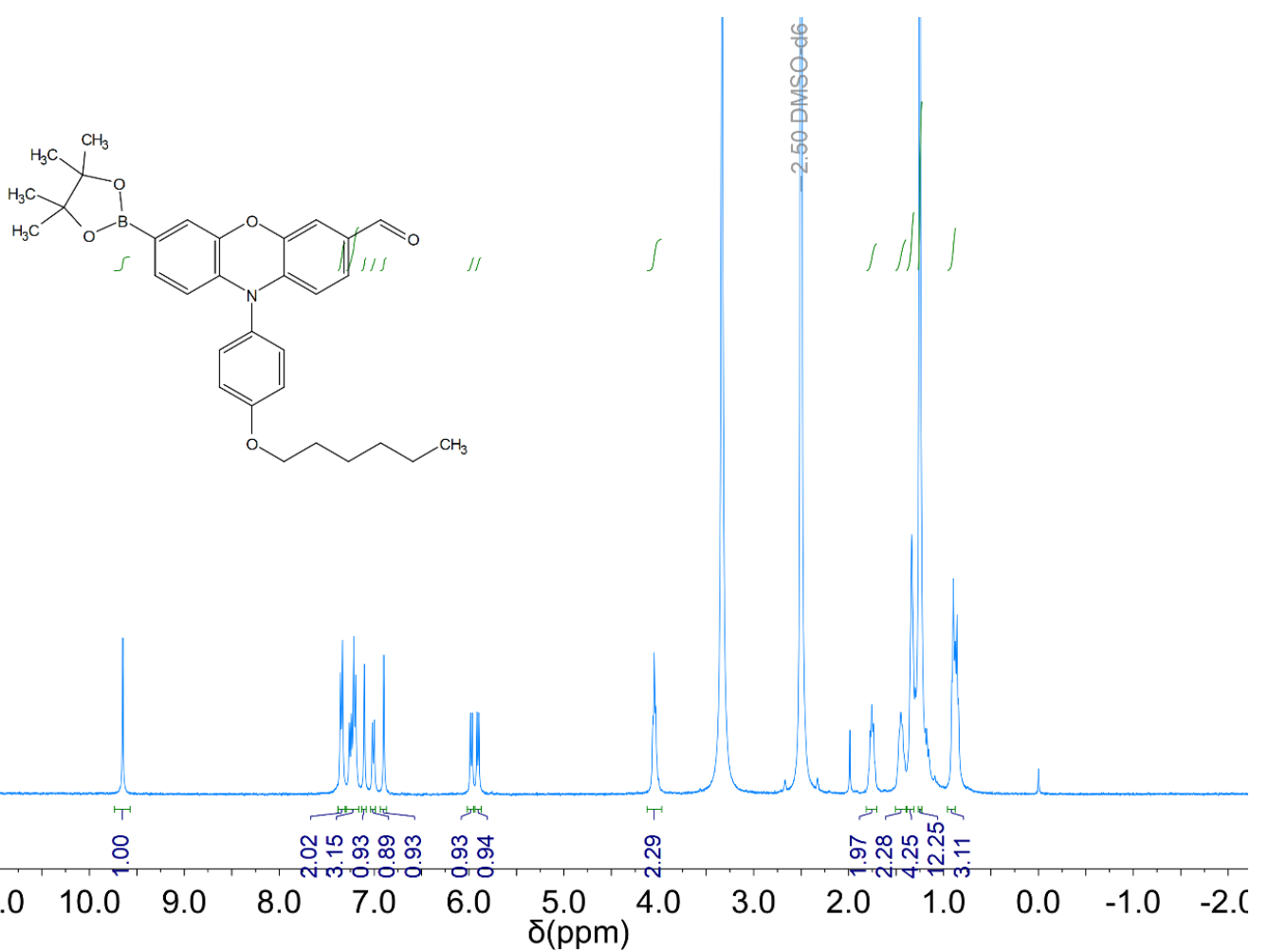

Figure S20 ${ }^{1}$ H-NMR spectrum of 10-(4-(hexyloxy)phenyl)-7-(4,4,5,5-tetramethyl-1,3,2dioxaborolan-2-yl)-10H-phenoxazine-3-carbaldehyde in DMSO- $d_{6}$. 


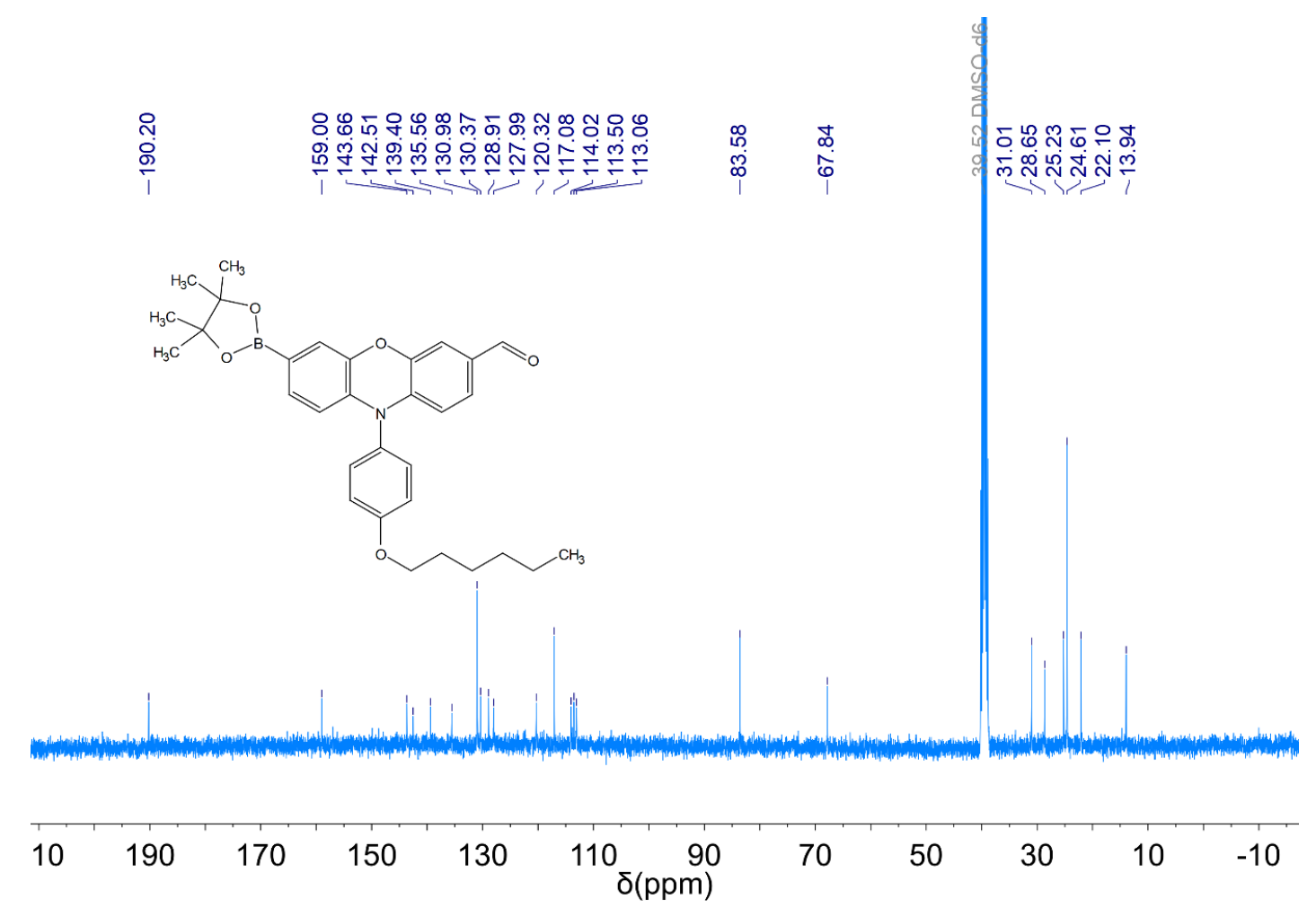

Figure S21 ${ }^{13}$ C-NMR spectrum of 10-(4-(hexyloxy)phenyl)-7-(4,4,5,5-tetramethyl-1,3,2dioxaborolan-2-yl)-10H-phenoxazine-3-carbaldehyde in DMSO- $d_{6}$.

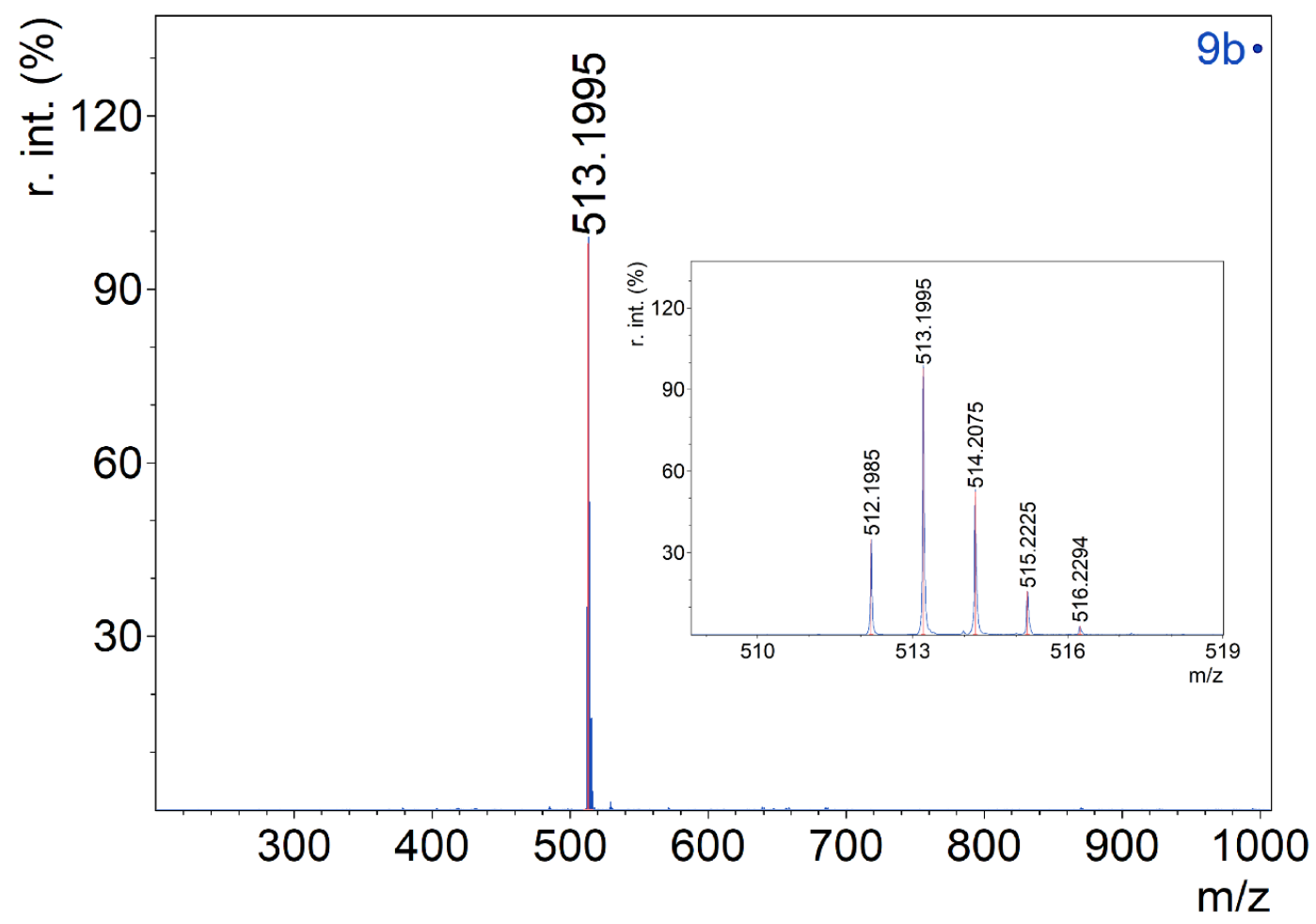

Figure S22 MALDI-TOF mass spectrum of 10-(4-(hexyloxy)phenyl)-7-(4,4,5,5-tetramethyl-1,3,2dioxaborolan-2-yl)-10H-phenoxazine-3-carbaldehyde. 


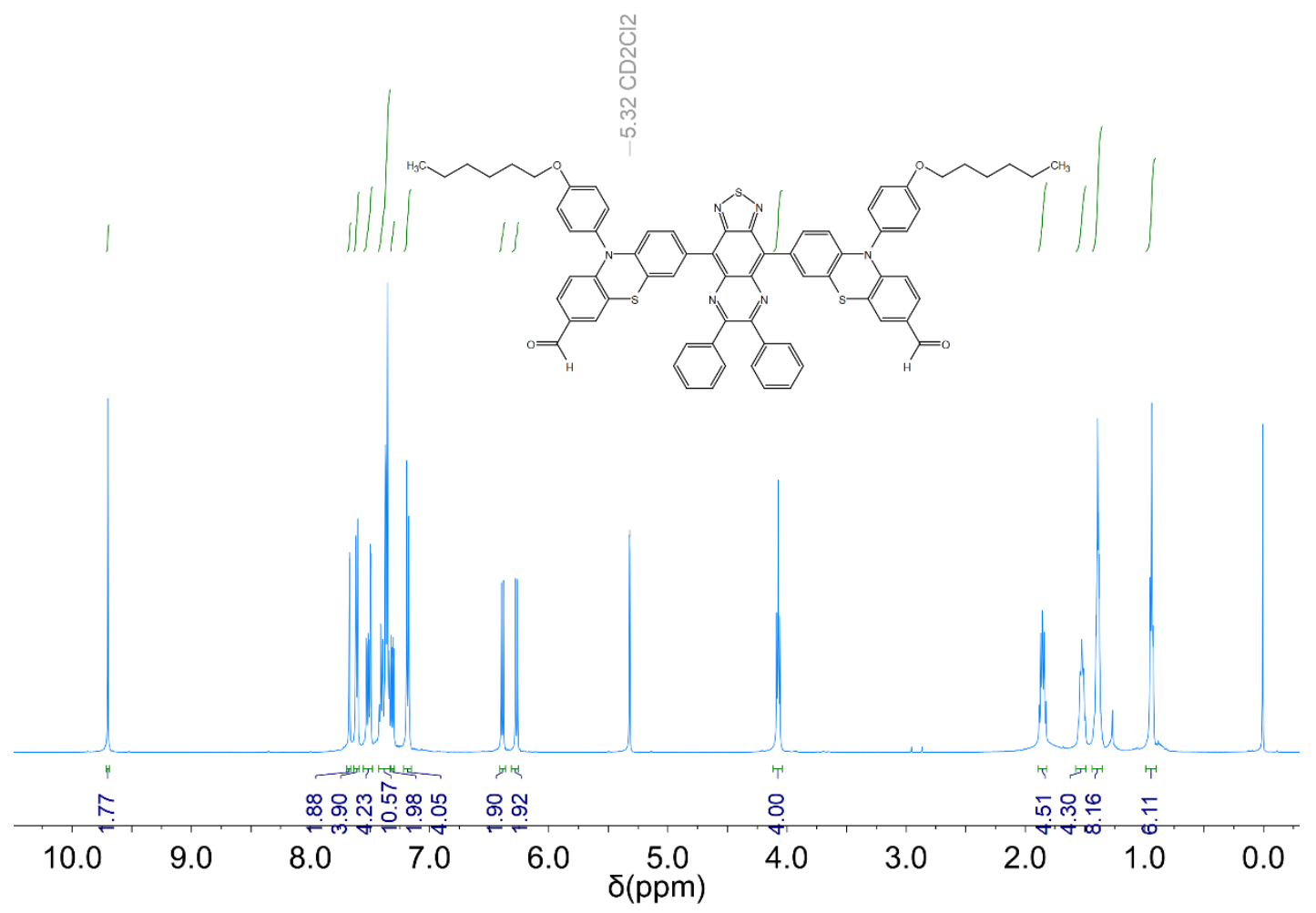

Figure S23 ${ }^{1} \mathrm{H}-\mathrm{NMR}$ spectrum of DPTQ-PhPTZ in Methylene Chloride- $d_{2}$.

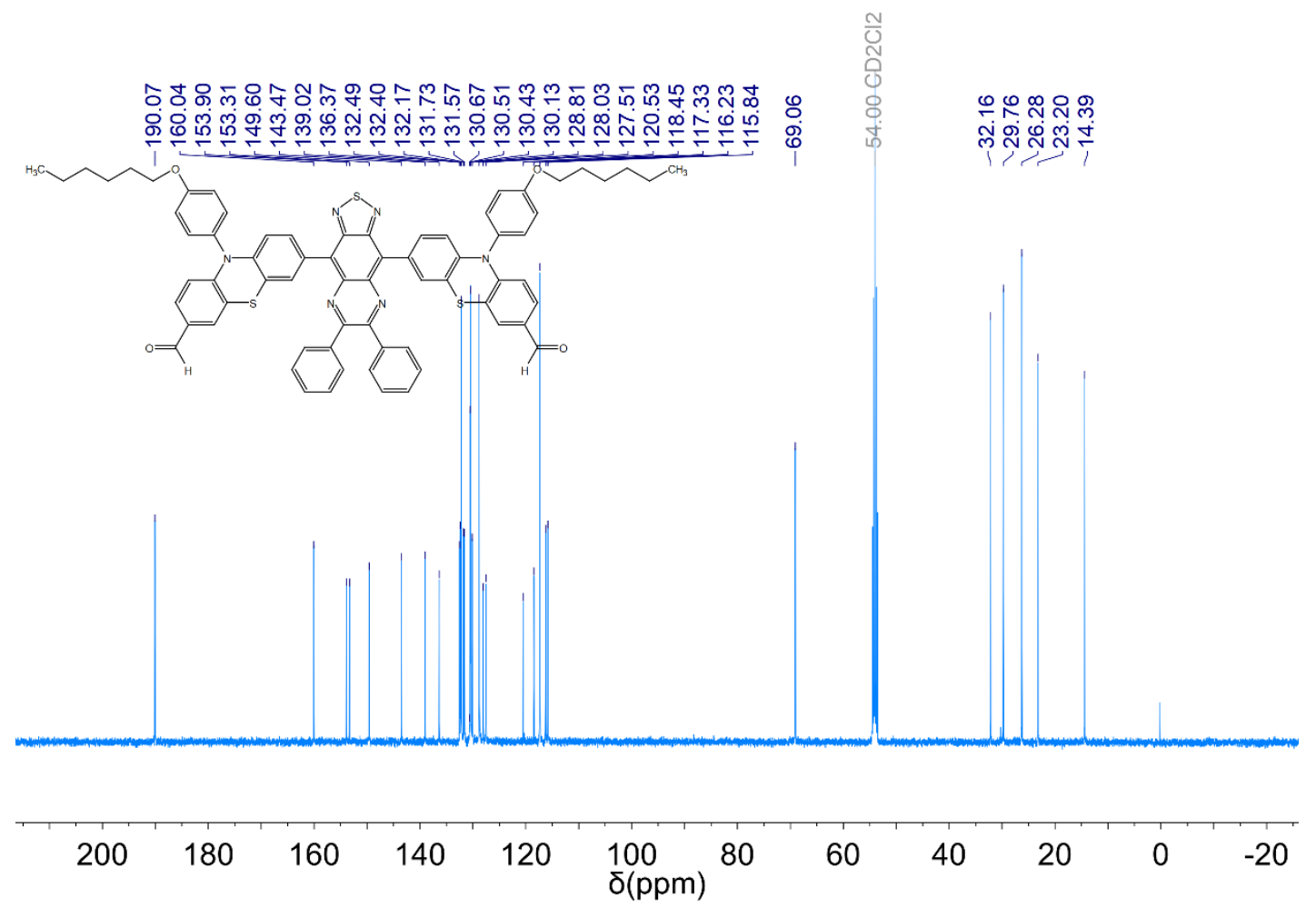

Figure S24 ${ }^{13} \mathrm{C}-\mathrm{NMR}$ spectrum of DPTQ-PhPTZ in Methylene Chloride- $d_{2}$. 


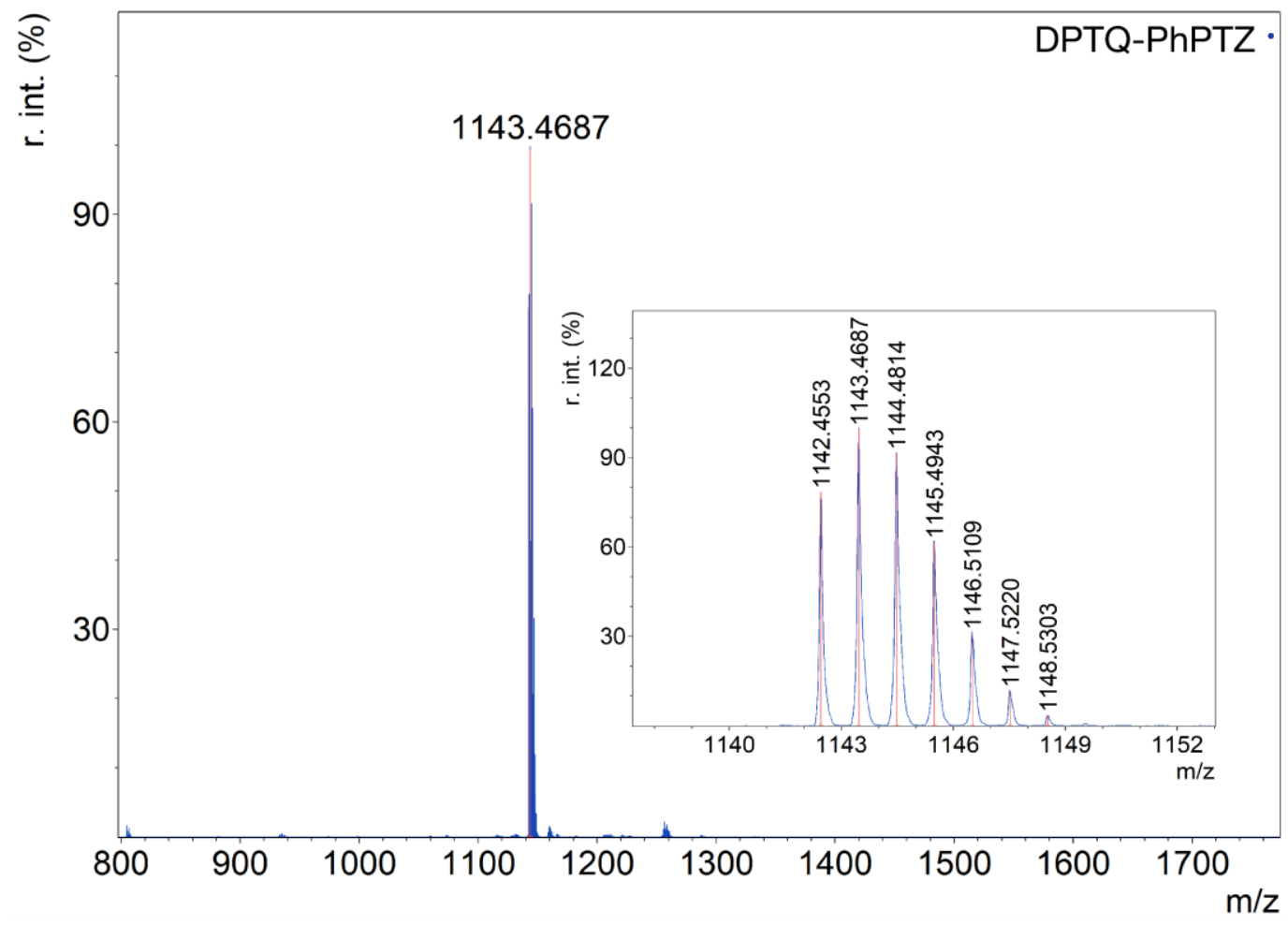

Figure S25 MALDI-TOF mass spectrum of DPTQ-PhPTZ.

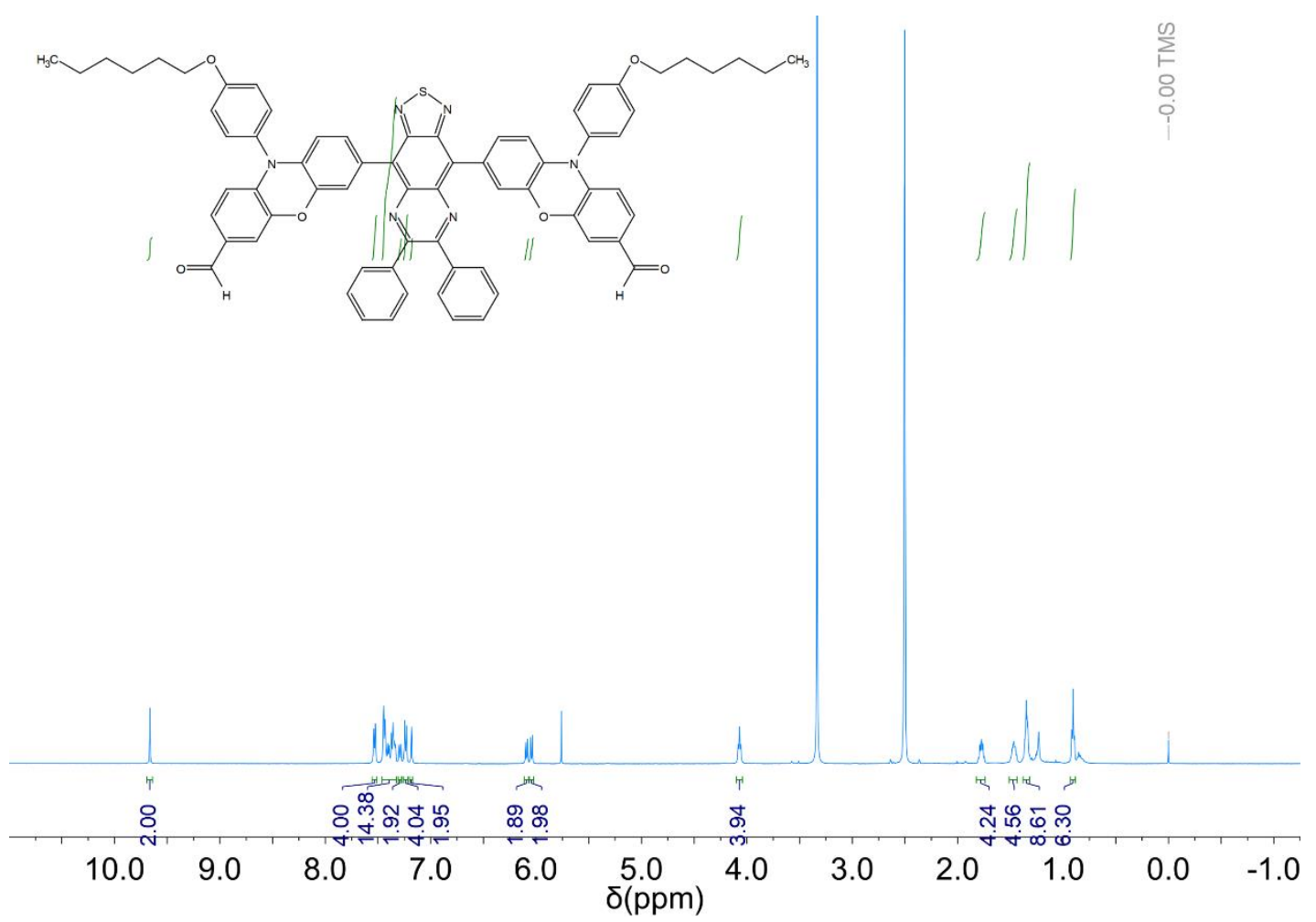

Figure S26 ${ }^{1} \mathrm{H}-\mathrm{NMR}$ spectrum of DPTQ-PhPXZ in DMSO- $d 6$. 


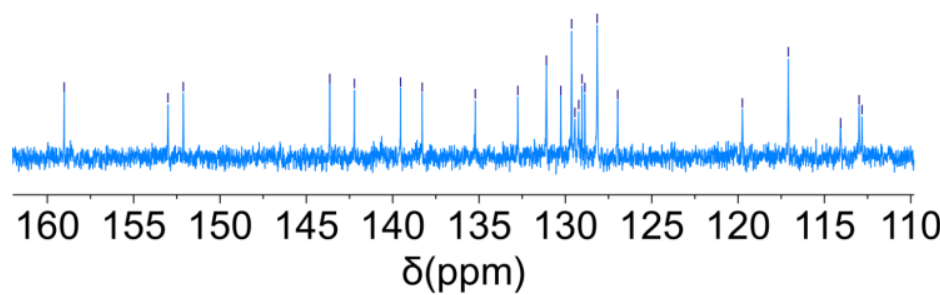

\section{?10200190180170160150140130120110100 $90 \quad 80 \quad 70 \quad 60 \quad 50 \quad 40 \quad 30 \quad 20 \quad 10$ $\delta(\mathrm{ppm})$}

Figure S27 ${ }^{13} \mathrm{C}-\mathrm{NMR}$ spectrum of DPTQ-PhPXZ in DMSO- $d_{6}$.

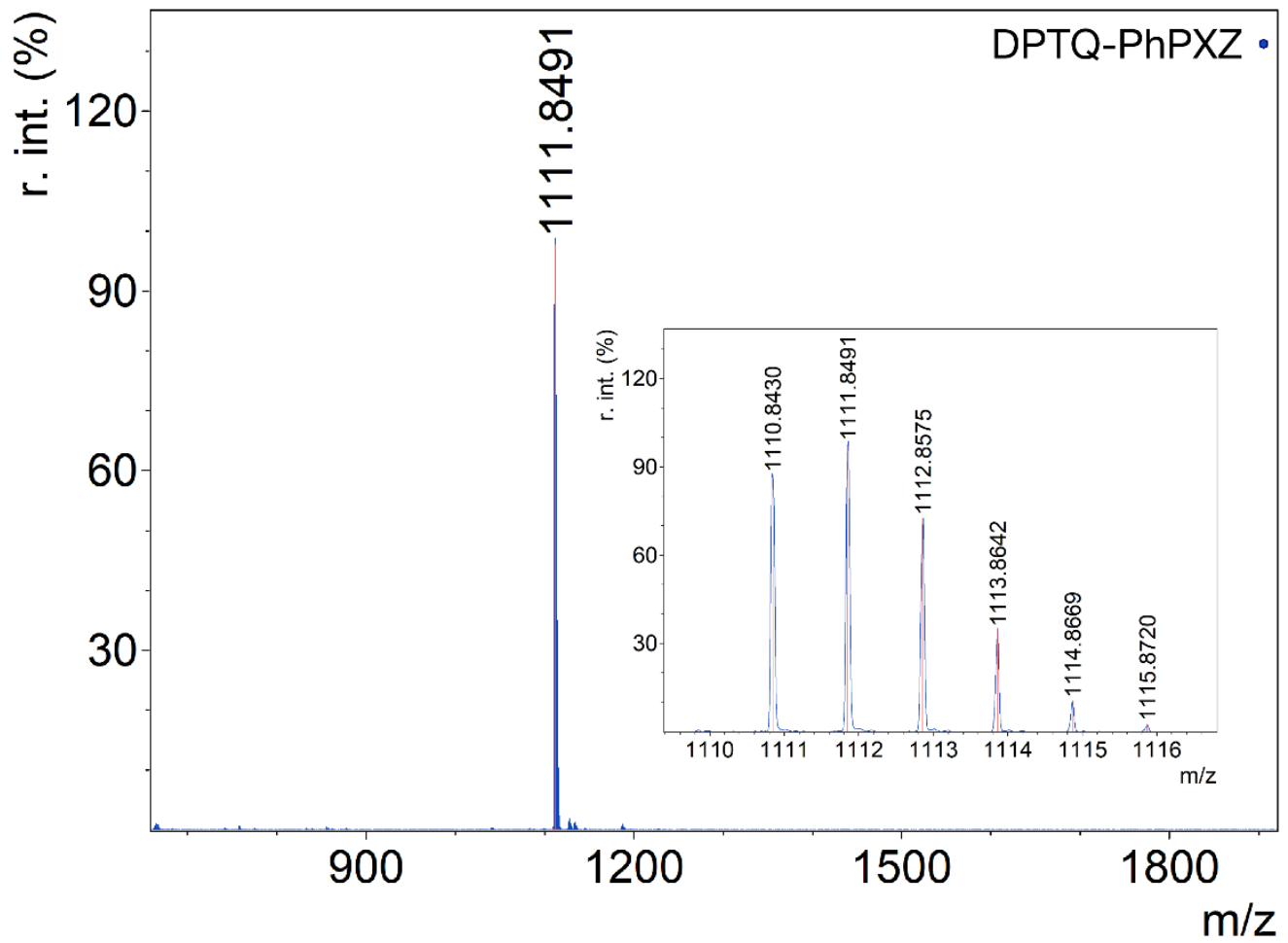

Figure S28 MALDI-TOF mass spectrum of DPTQ-PhPXZ. 


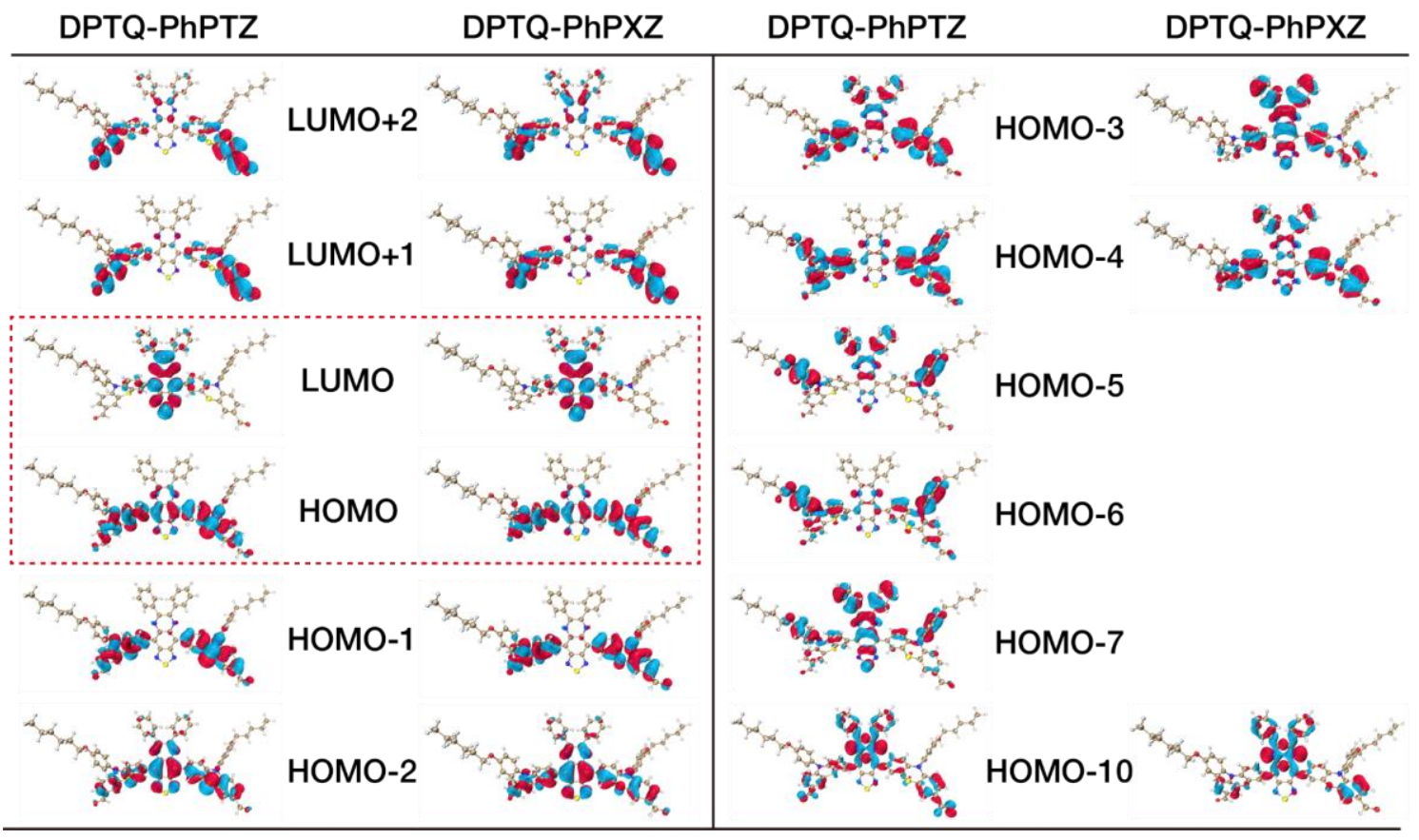

Figure S29 Calculated molecular orbitals of DPTQ-PhPTZ and DPTQ-PhPXZ at $\omega$ B97XD*/6-31G* level of theory in vacuum.
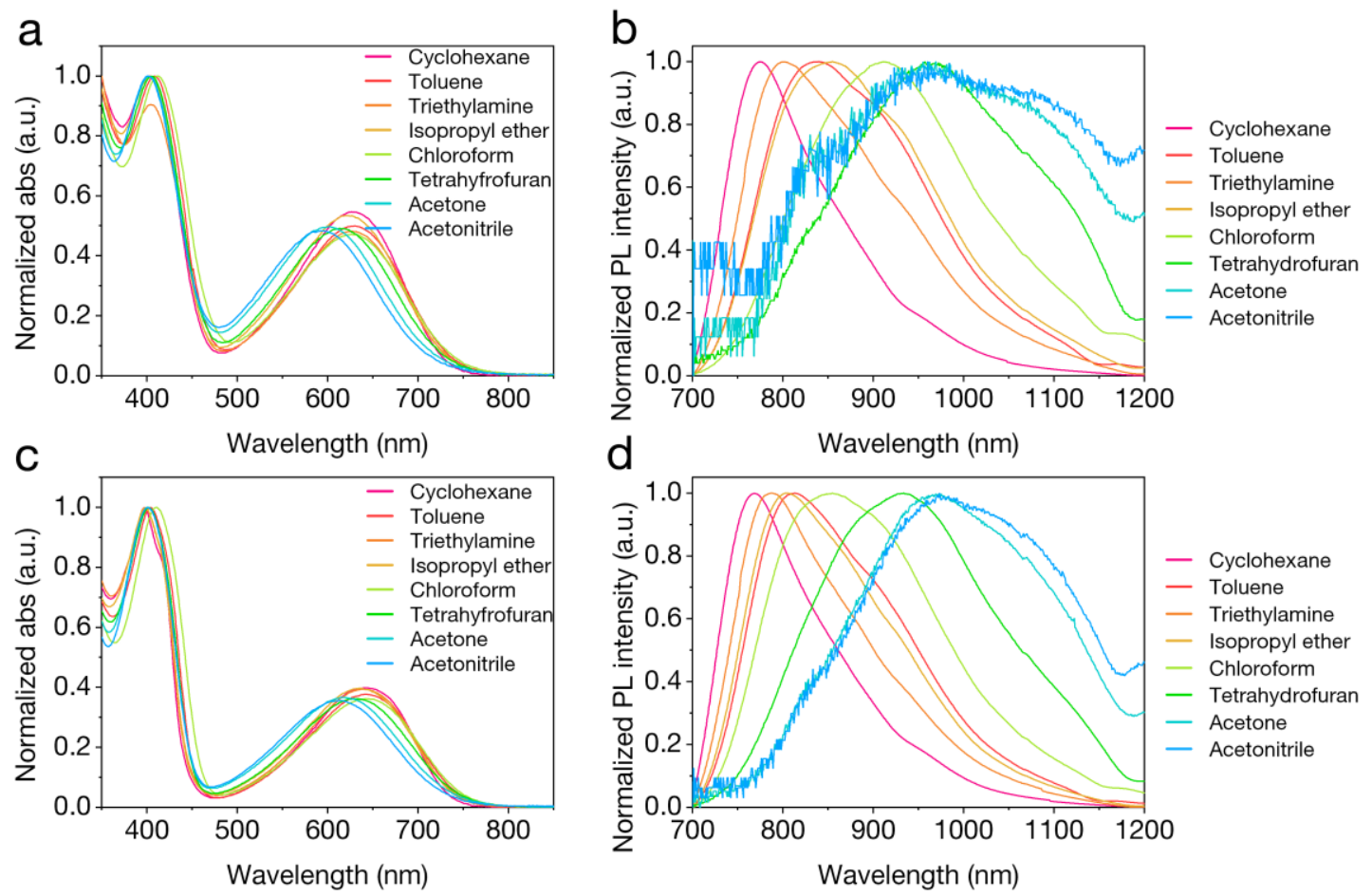

Figure S30 Absorption and PL spectra of DPTQ-PhPTZ and DPTQ-PhPXZ in different solvents. Absorption (a) and PL spectra (b) of DPTQ-PhPTZ. Absorption (c) and PL spectra (d) of DPTQPhPXZ. 


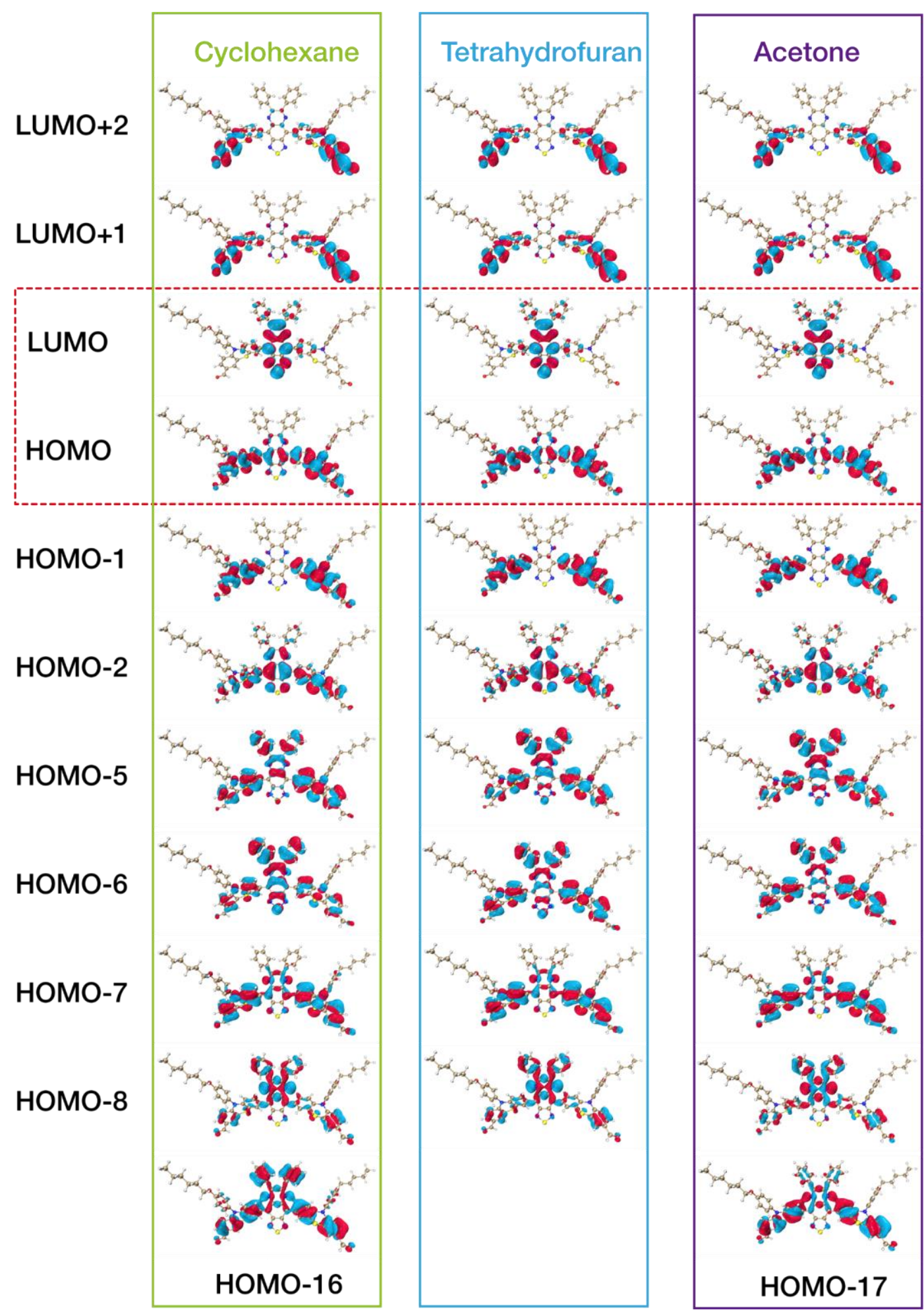

Figure S31 Calculated molecular orbitals of DPTQ-PhPTZ at $\omega$ B97XD*/6-31G* level of theory in cyclohexane, tetrahydrofuran and acetone. 


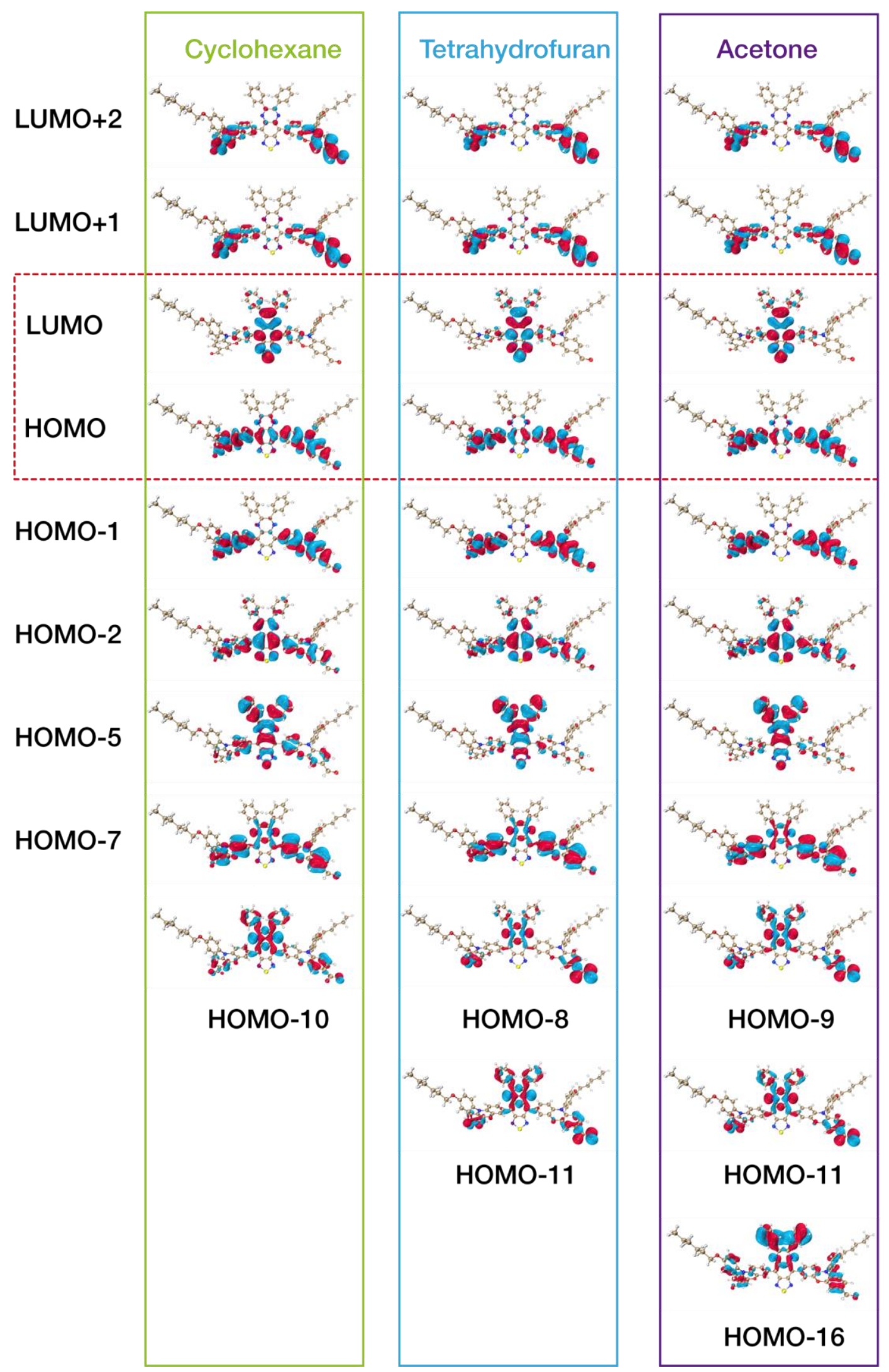

Figure S32 Calculated molecular orbitals of DPTQ-PhPXZ at $\omega$ B97XD*/6-31G* level of theory in cyclohexane, tetrahydrofuran and acetone. 


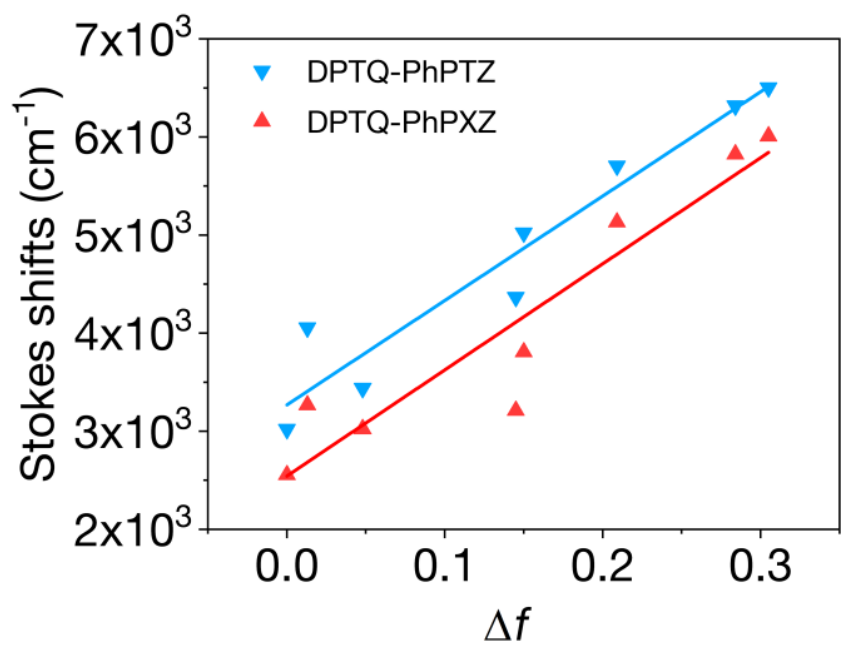

Figure S33 Linear fitting of Lippert-Mataga model for DPTQ-PhPTZ (blue line) and DPTQ-PhPXZ (red line).
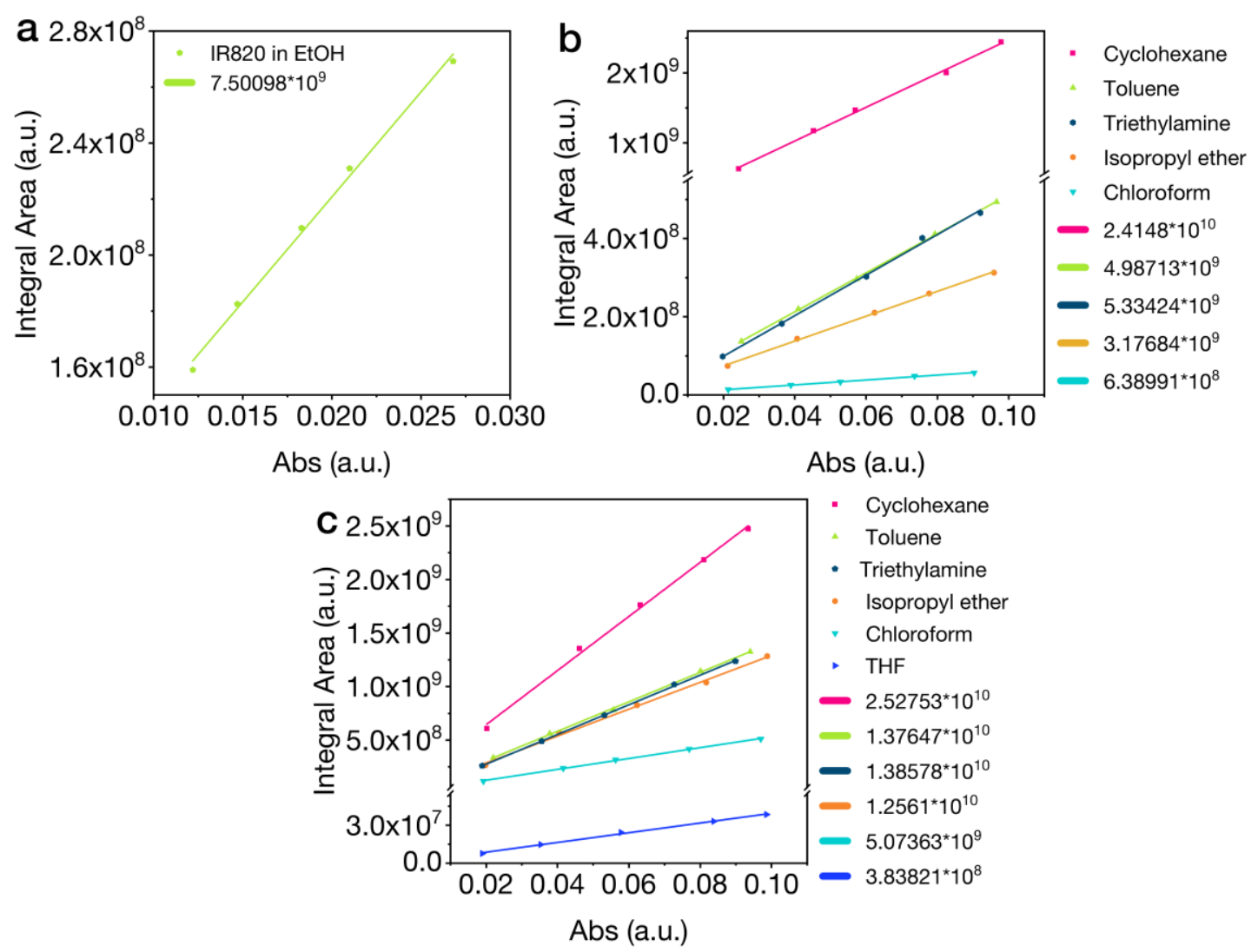

Figure S34 Determination of the QYs of DPTQ-PhPTZ and DPTQ-PhPXZ NPs in different organic solvents. (a) Plots of the fluorescence integral area of IR-820 in 750-1250 nm versus the corresponding absorption values at $655 \mathrm{~nm}$. Plots of the fluorescence integral area of DPTQ-PhPTZ (b), and DPTQPhPXZ (c) in different organic solvents in 700-1200 nm. 

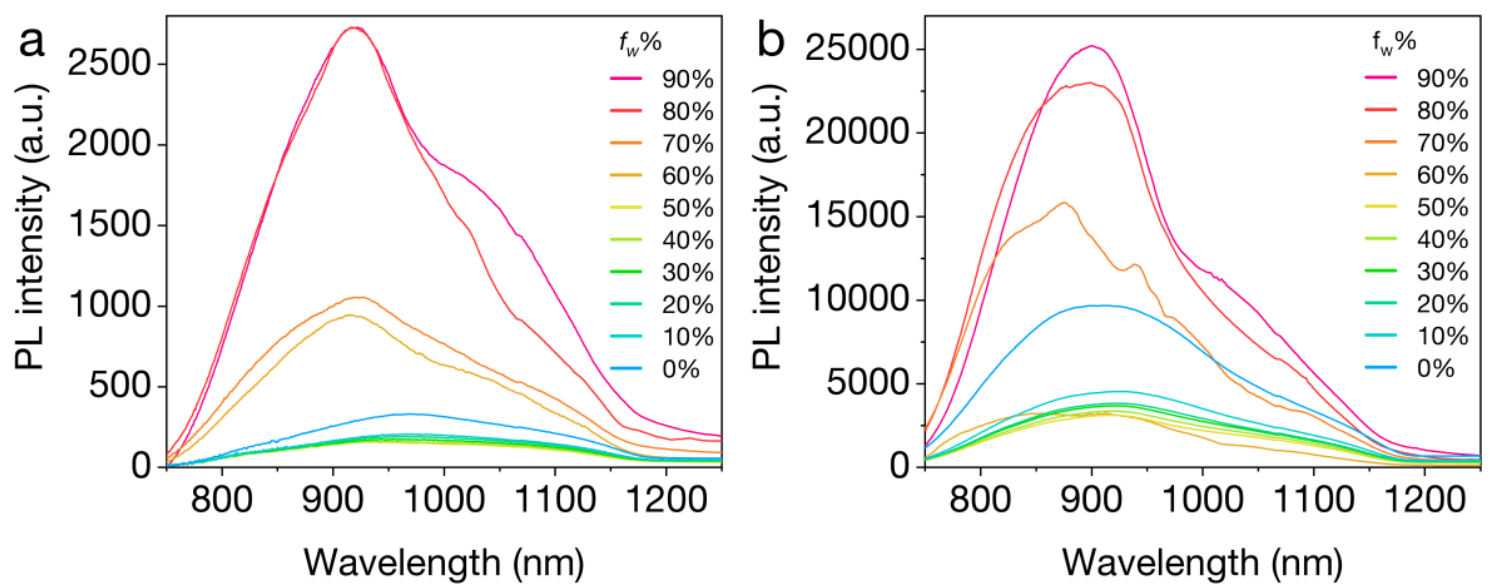

Figure S35 Evolution with water fraction $\left(f_{w}\right)$ of the PL spectra of DPTQ-PhPTZ (a) and DPTQPhPXZ (b) in THF/water mixture.

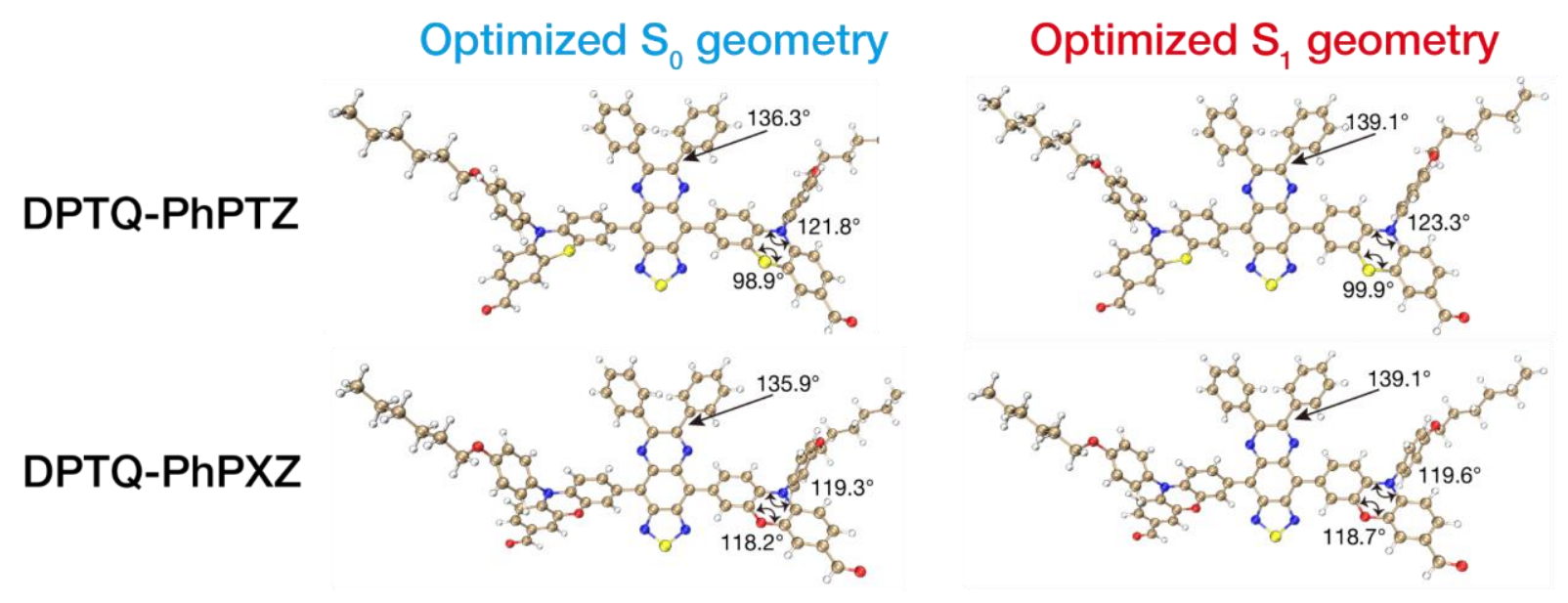

Figure S36 Front view for optimized $\mathrm{S}_{0}$ and $\mathrm{S}_{1}$ geometries of DPTQ-PhPTZ and DPTQ-PhPXZ in vacuum. 


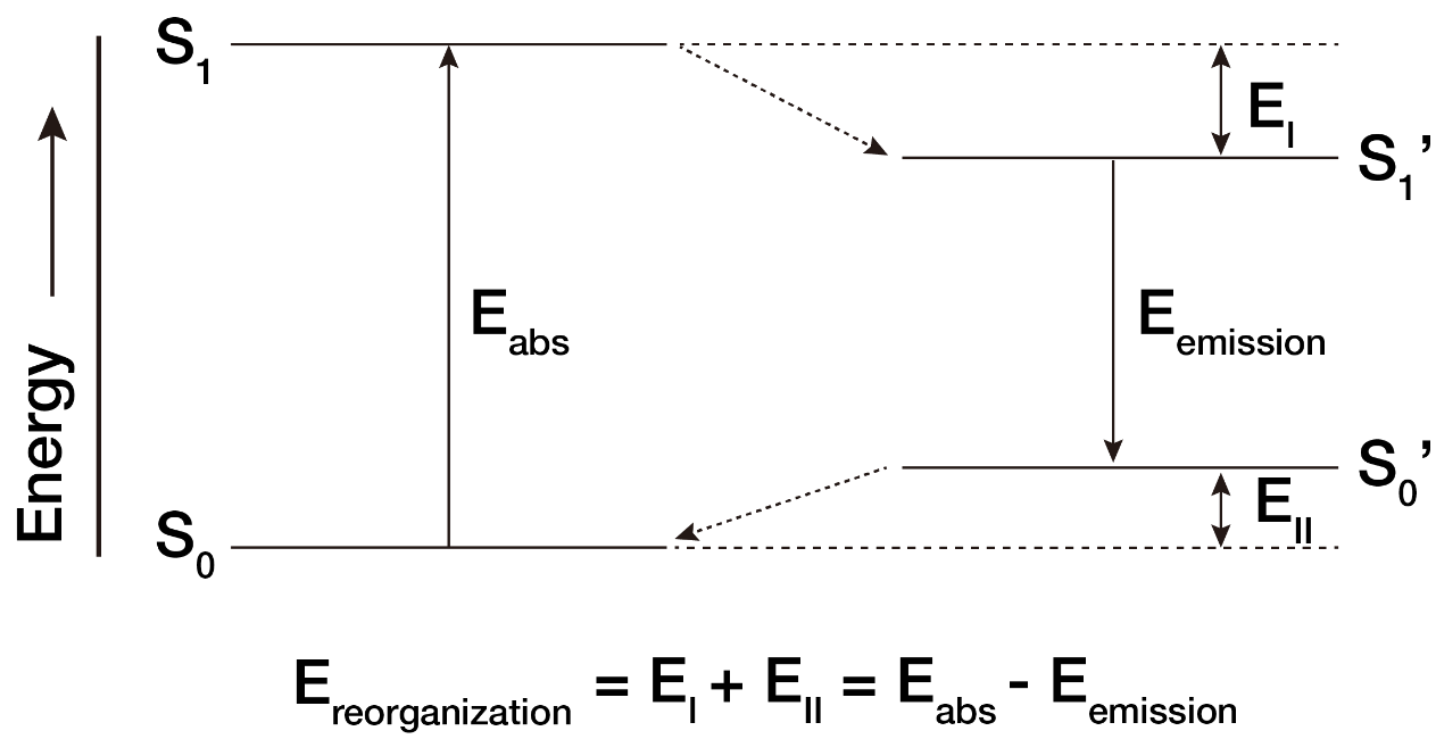

Figure S37 Schematic diagraph of geometric reorganization and the corresponding reorganization energy.
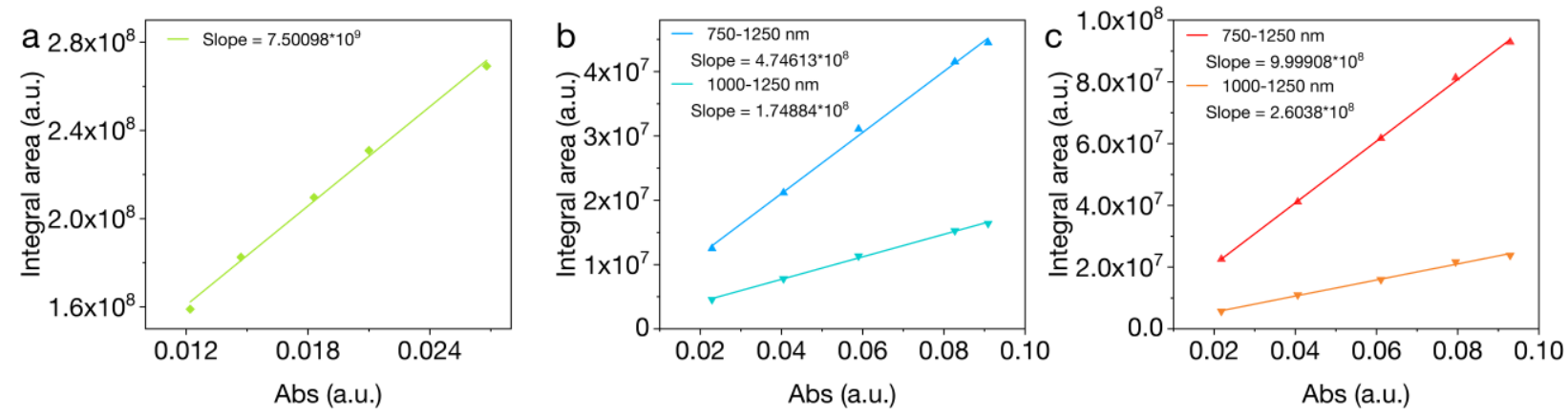

Figure S38 Determination of the QYs of DPTQ-PhPTZ and DPTQ-PhPXZ NPs in water. (a) Plots of the fluorescence integral area of IR-820 in 750-1250 nm versus the corresponding absorption values at $655 \mathrm{~nm}$. Plots of the fluorescence integral area of DPTQ-PhPTZ NPs (b), and DPTQ-PhPXZ NPs (c) in water in 750-1250 $\mathrm{nm}$ and 1000-1250 nm versus the corresponding absorption values at $655 \mathrm{~nm}$. 


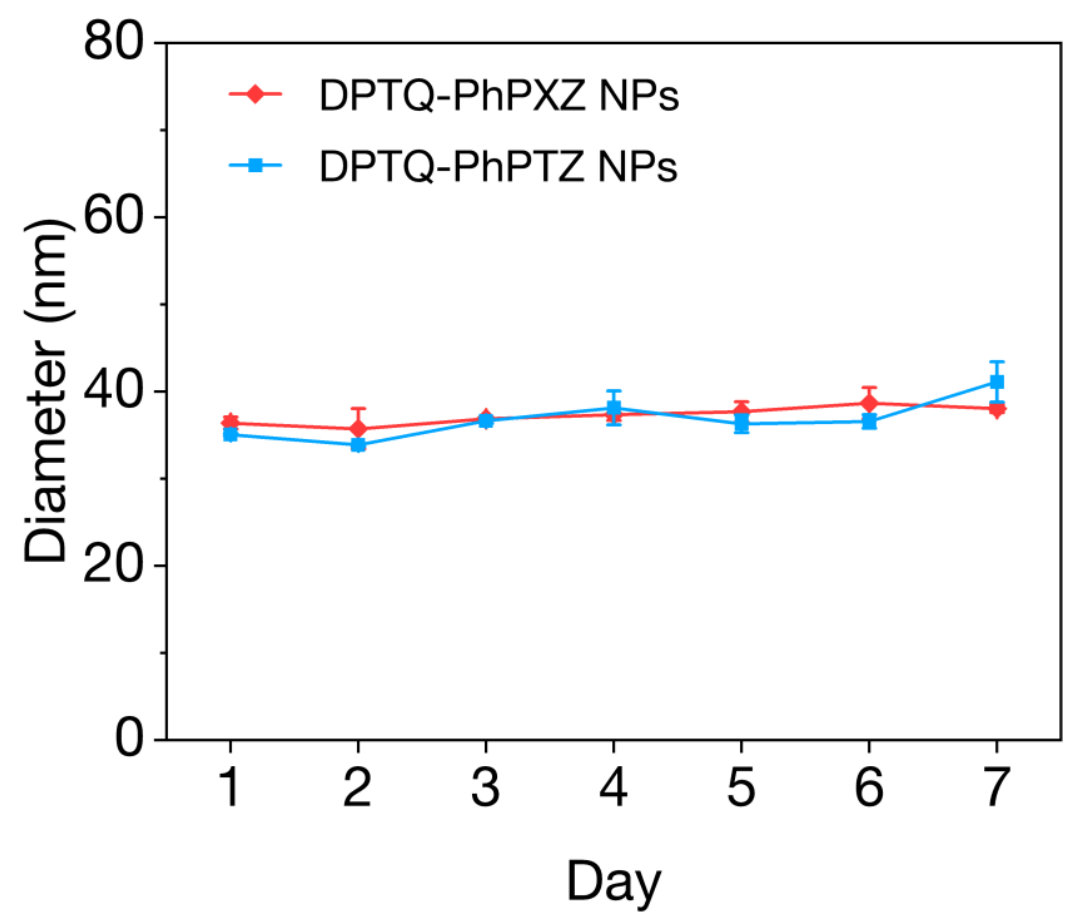

Figure S39 Hydrodynamic sizes of DPTQ-PhPTZ and DPTQ-PhPXZ NPs within one week monitored by DLS.

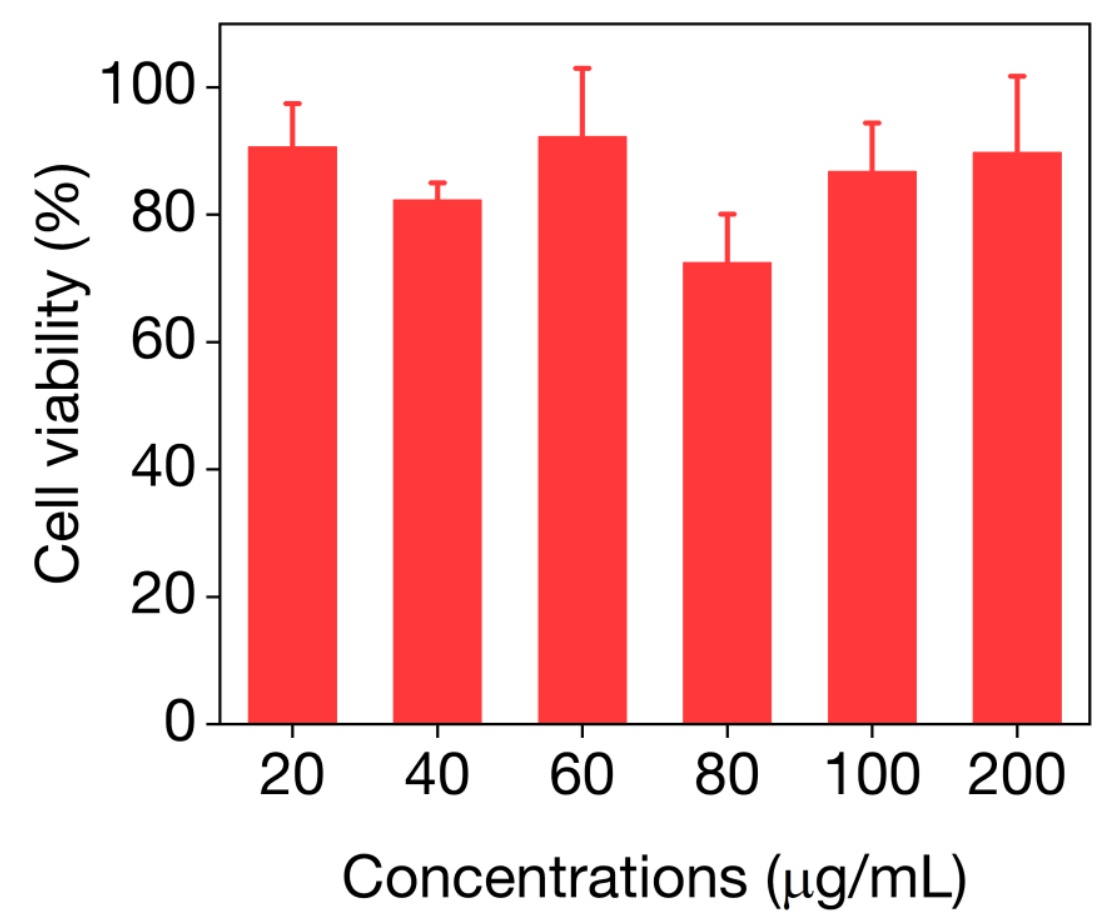

Figure S40 In vitro cytotoxicity of DPTQ-PhPXZ NPs against MCF-7 cells after $24 \mathrm{~h}$ incubation. The concentrations are expressed as the DPTQ-PhPXZ concentrations. 


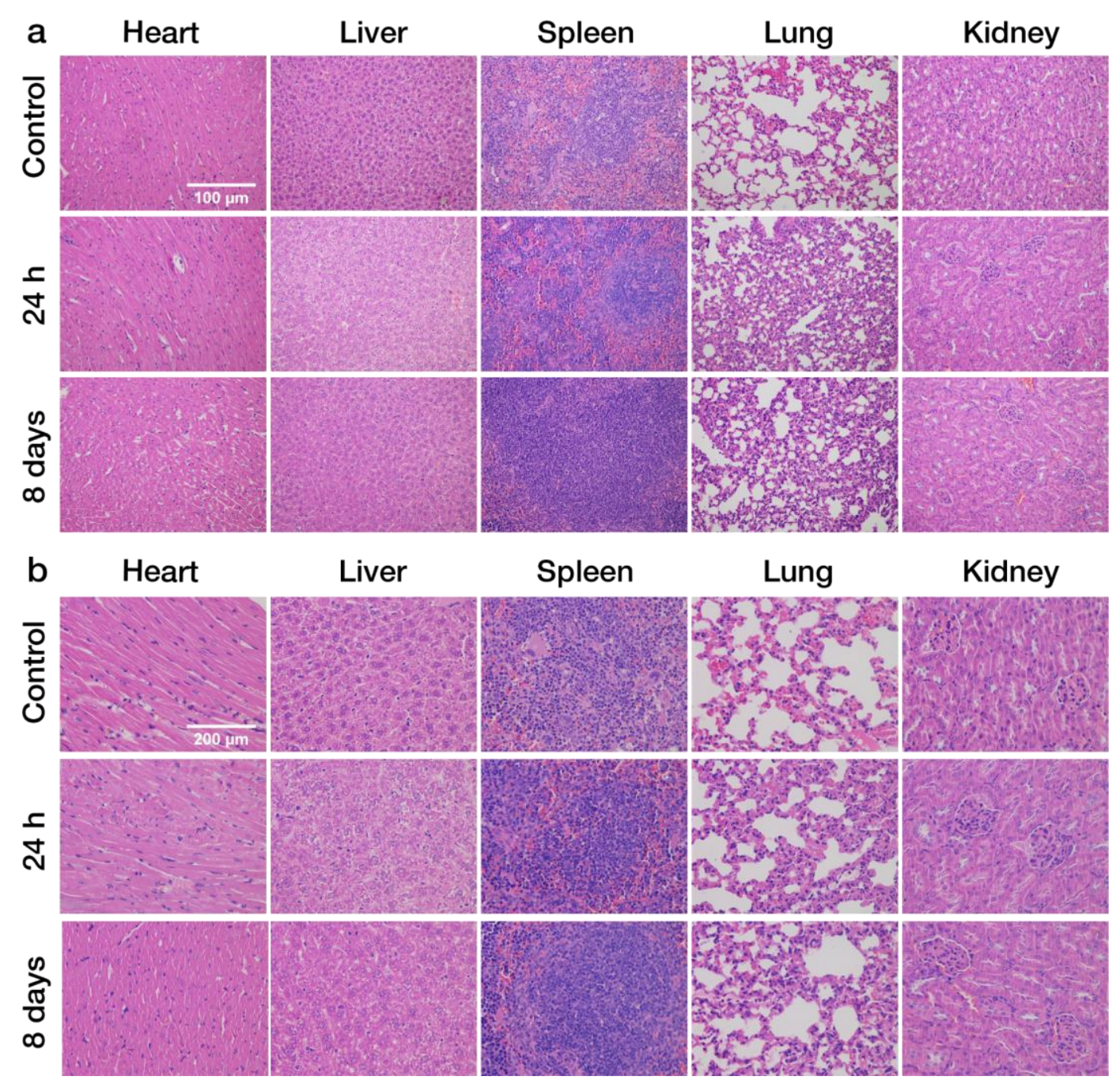

Figure S41 Representative images of the H\&E-stained organ slices for DPTQ-PhPXZ NPs. (a) Objective lens of 20X. (b) Objective lens of 40X. 
a

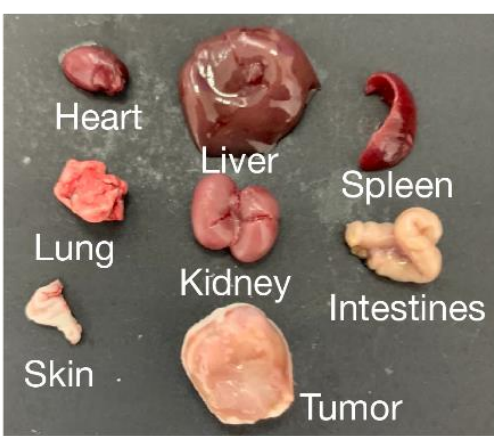

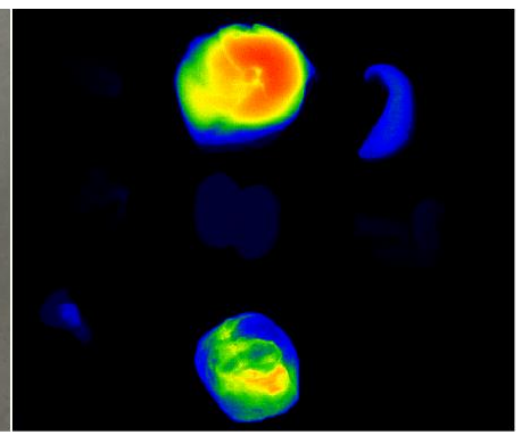
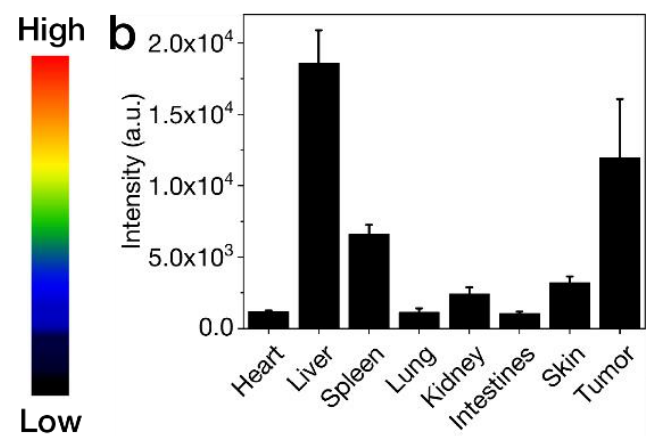

Figure S42 (a) Bright field and NIR-II Images of the main organs, tissues and tumor excised from a H22 tumor-bearing mouse sacrificed at one-week after tail-vein injection of DPTQ-PhPXZ NPs. (b) The histogram of the NIR-II signals of the organs, tissues and tumors. Data as mean values \pm S.D. $(n=3)$.

Table S1 Optimized range-separation parameters $\omega^{*}$ and calculated the first vertical excitation energies $\left(E_{01}\right)$, the first vertical emission energies $\left(E_{10}\right)$, corresponding transition oscillator strength $\left(\mathrm{f}_{01}, \mathrm{f}_{10}\right)$ and Stokes shifts at the TD- $\omega$ B97XD*/6-31G* level of theory in vacuum.

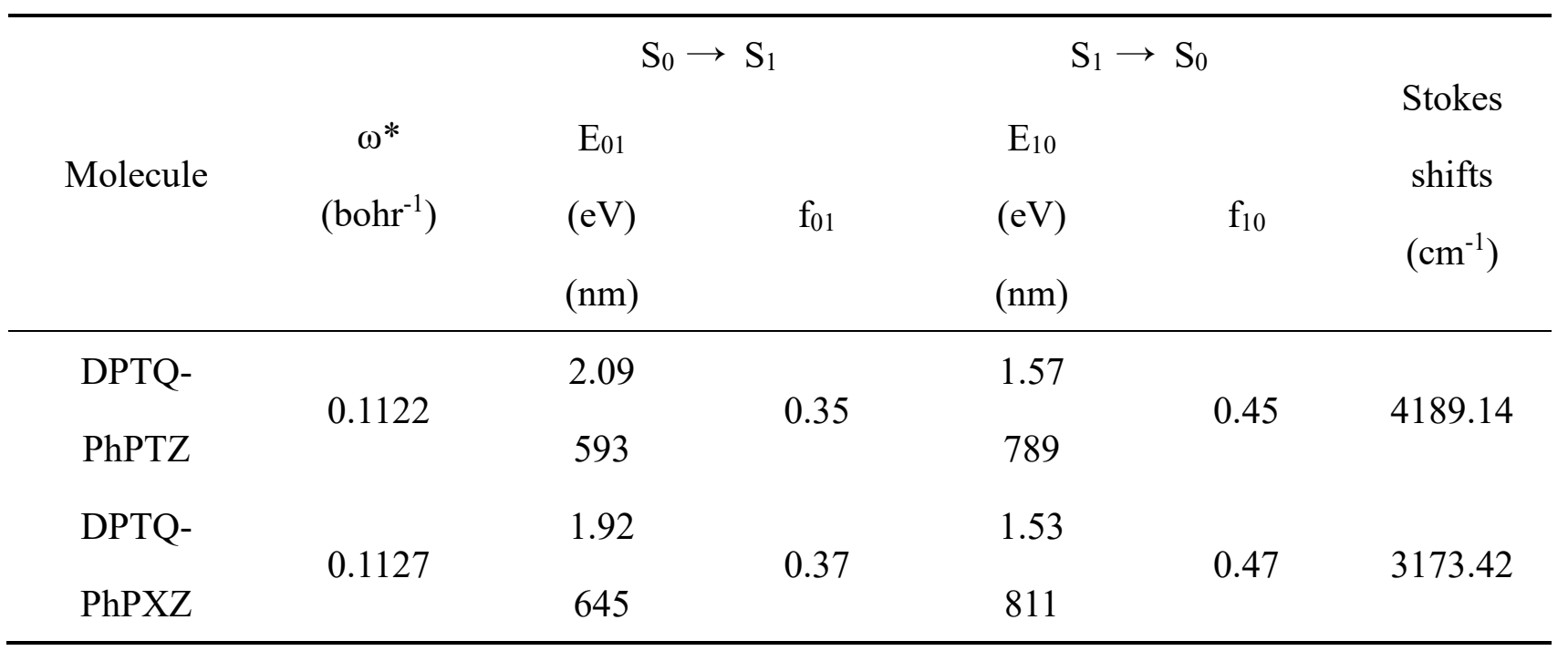


Table S2 Calculated excited state of $S_{2}$ to $S_{7}$ and corresponding natural transition orbitals analysis for DPTQ-PhPTZ in vacuum.

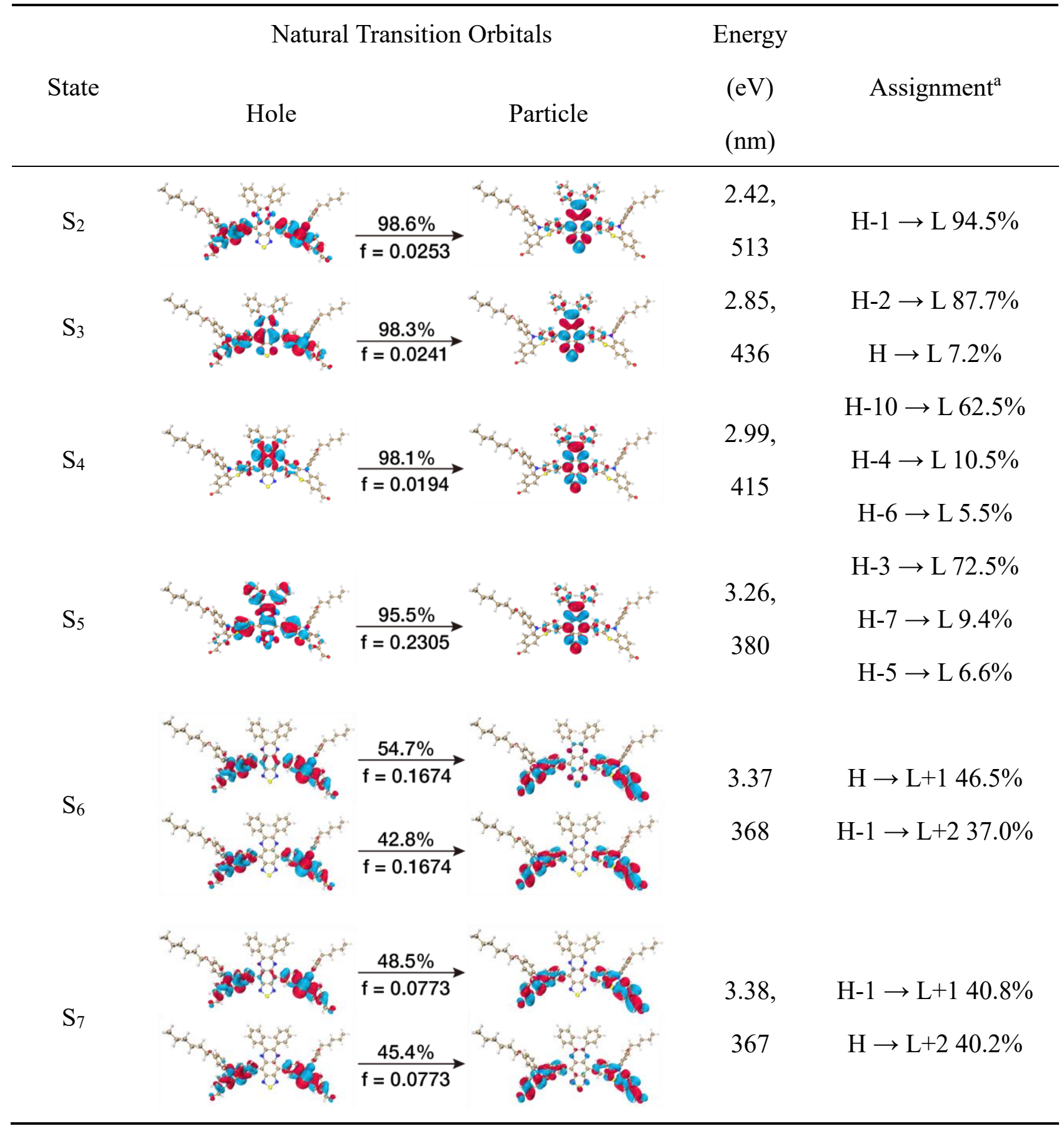

(a). H denotes HOMO, L denotes LUMO, and only MOs transitions with contributions larger than 5\% are shown. 
Table S3 Calculated excited state of $S_{2}$ to $S_{7}$ and corresponding natural transition orbitals analysis for DPTQ-PhPXZ in vacuum.

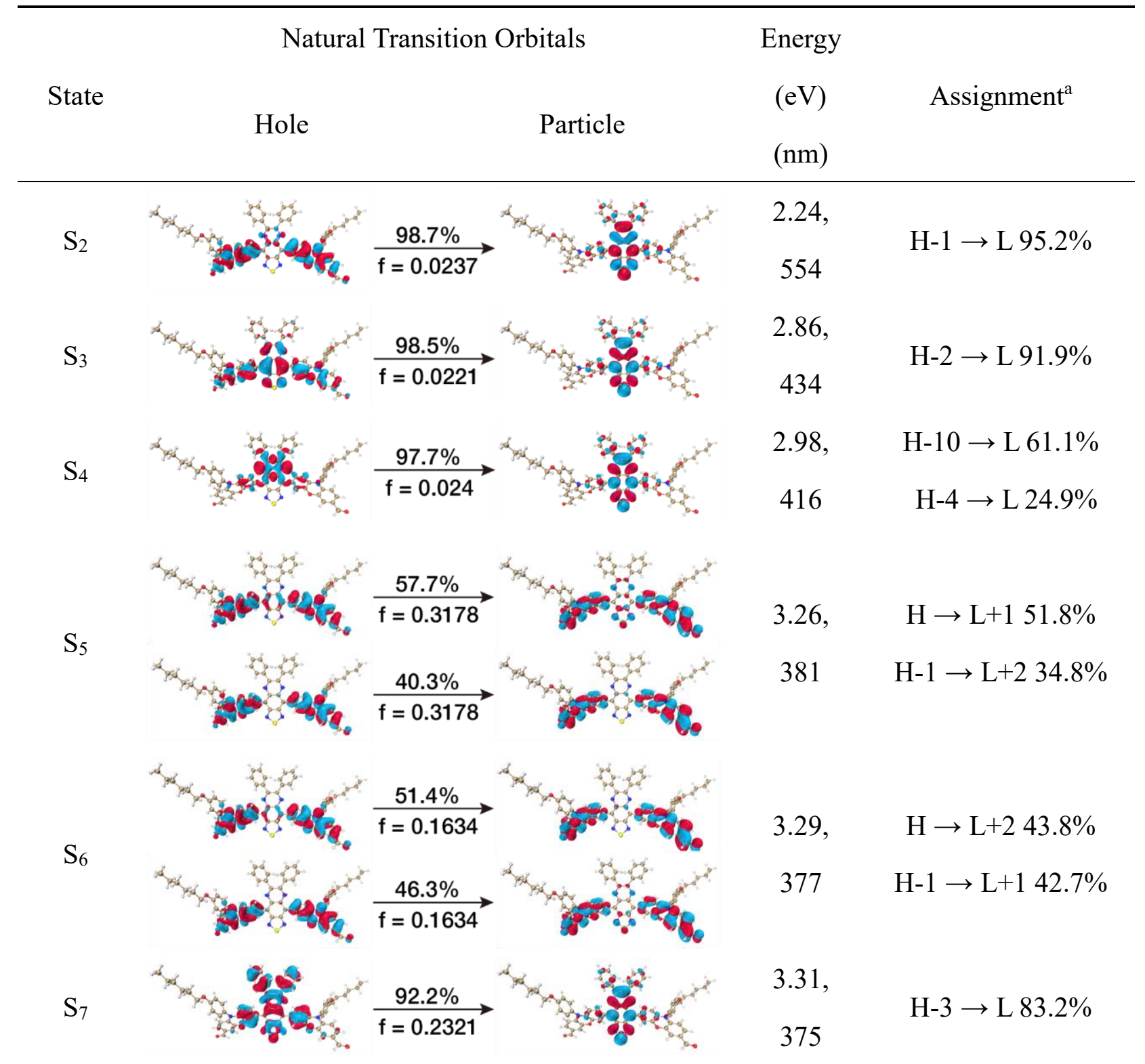

(a). H denotes HOMO, L denotes LUMO, and only MOs transitions with contributions larger than 5\% are shown. 
Table S4. Calculated excited state of $\mathrm{S}_{1}$ to $\mathrm{S}_{7}$ and corresponding natural transition orbitals analysis for DPTQ-PhPTZ in cyclohexane.

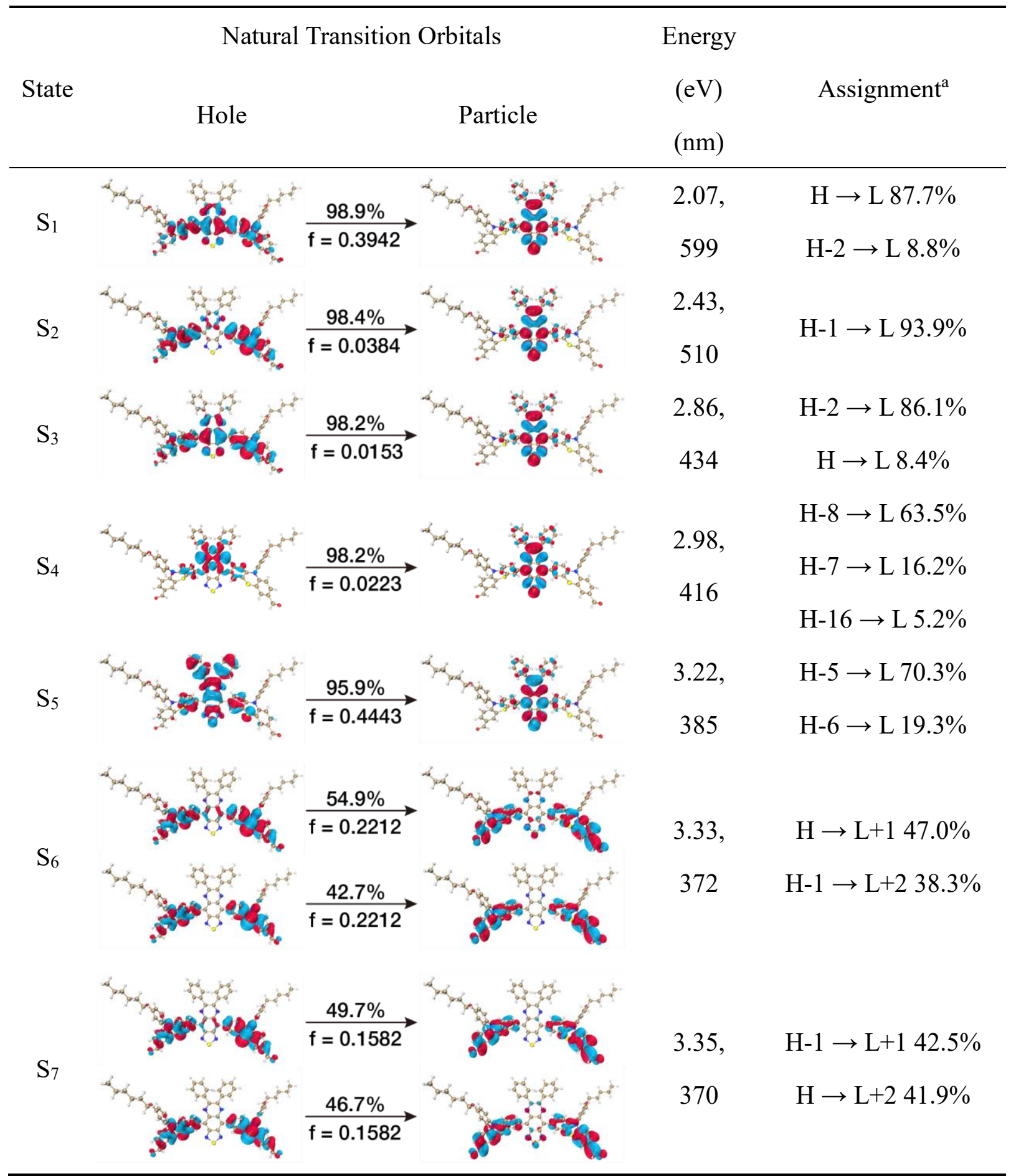

(a). H denotes HOMO, L denotes LUMO, and only MOs transitions with contributions larger than 5\% are shown. 
Table S5. Calculated excited state of $\mathrm{S}_{1}$ to $\mathrm{S}_{7}$ and corresponding natural transition orbitals analysis for DPTQ-PhPXZ in cyclohexane.

\begin{tabular}{|c|c|c|c|c|}
\hline \multirow{2}{*}{ State } & \multicolumn{2}{|c|}{ Natural Transition Orbitals } & \multirow{2}{*}{$\begin{array}{c}\text { Energy } \\
(\mathrm{eV})\end{array}$} & \multirow{2}{*}{ Assignment $^{\mathrm{a}}$} \\
\hline & Hole & Particle & & \\
\hline $\mathrm{S}_{1}$ & & & $\begin{array}{l}1.89 \\
656\end{array}$ & $\mathrm{H} \rightarrow \mathrm{L} 92.1 \%$ \\
\hline $\mathrm{S}_{2}$ & & & $\begin{array}{r}.25, \\
556\end{array}$ & $\mathrm{H}-1 \rightarrow \mathrm{L} 95.0 \%$ \\
\hline $\mathrm{S}_{3}$ & & & 2.00 & $\mathrm{H}-2 \rightarrow \mathrm{L} 91.3 \%$ \\
\hline & & & 2.97, & $\mathrm{H}-7 \rightarrow \mathrm{L} 26.0 \%$ \\
\hline & & & 3.19 & $\mathrm{H} \rightarrow \mathrm{L}+151.8 \%$ \\
\hline $\mathrm{S}_{6}$ & & & 3.21 & $\mathrm{H} \rightarrow \mathrm{L}+246.3 \%$ \\
\hline & & & 386 & $\mathrm{H}-1 \rightarrow \mathrm{L}+143.8 \%$ \\
\hline $\mathrm{S}_{7}$ & & & 3.20 & $\mathrm{H}-5 \rightarrow \mathrm{L} 87.5 \%$ \\
\hline
\end{tabular}

(a). H denotes HOMO, L denotes LUMO, and only MOs transitions with contributions larger than 5\% are shown. 
Table S6. Calculated excited state of $\mathrm{S}_{1}$ to $\mathrm{S}_{7}$ and corresponding natural transition orbitals analysis for DPTQ-PhPTZ in THF.

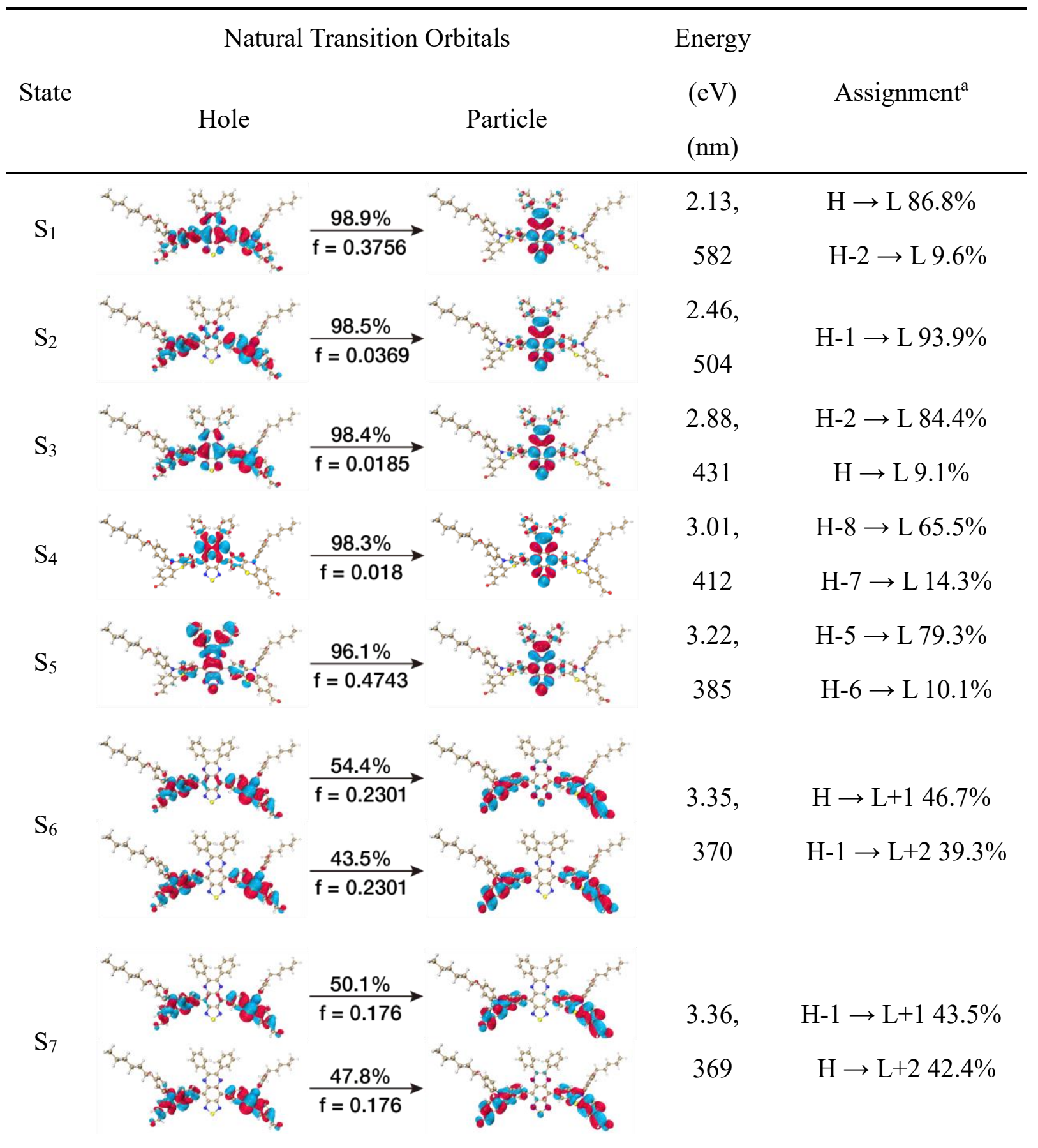

(a). H denotes HOMO, L denotes LUMO, and only MOs transitions with contributions larger than 5\% are shown. 
Table S7. Calculated excited state of $\mathrm{S}_{1}$ to $\mathrm{S}_{7}$ and corresponding natural transition orbitals analysis for DPTQ-PhPXZ in THF.

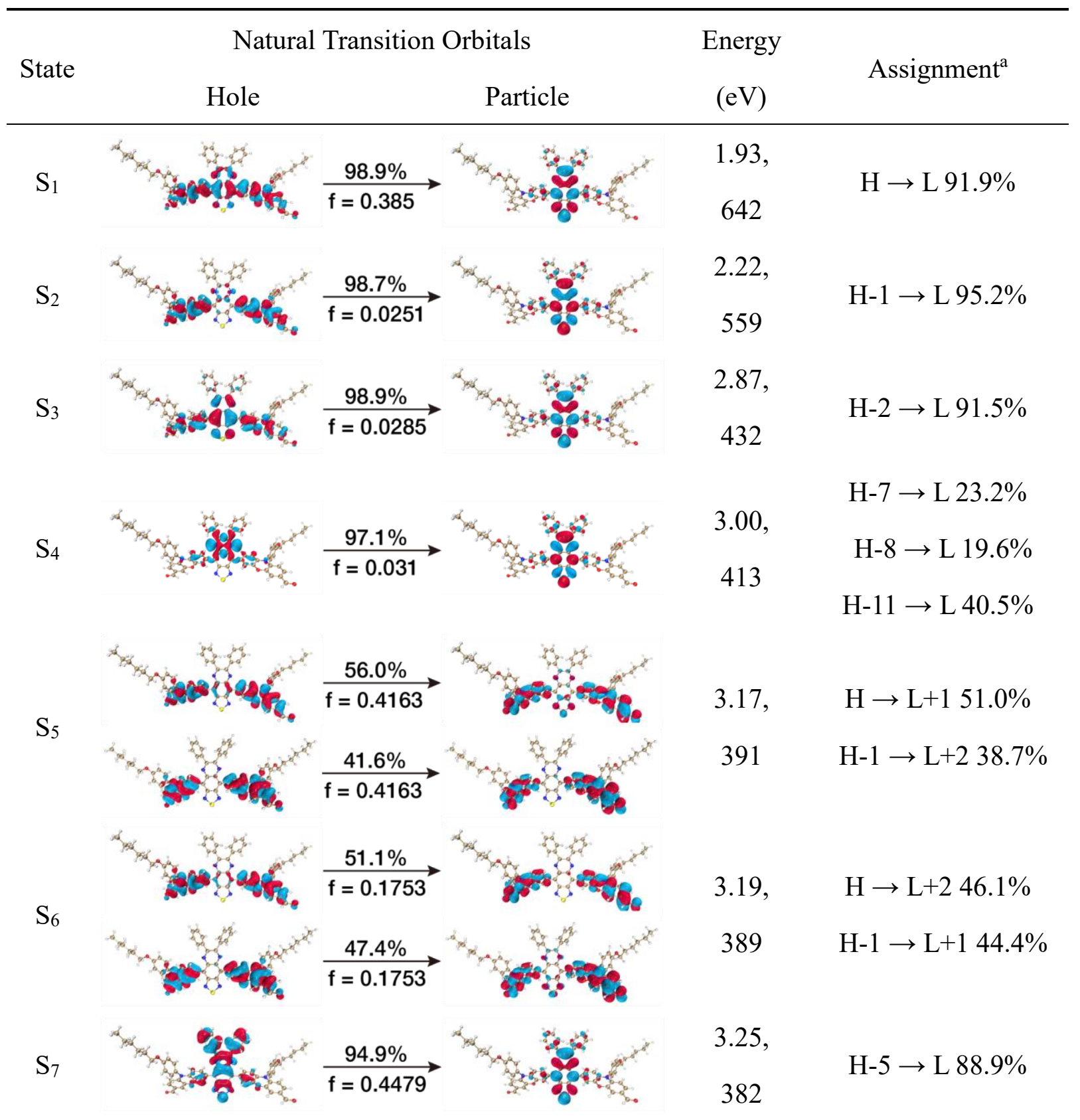

(a). H denotes HOMO, L denotes LUMO, and only MOs transitions with contributions larger than 5\% are shown. 
Table S8. Calculated excited state of $\mathrm{S}_{1}$ to $\mathrm{S}_{7}$ and corresponding natural transition orbitals analysis for DPTQ-PhPTZ in acetone.

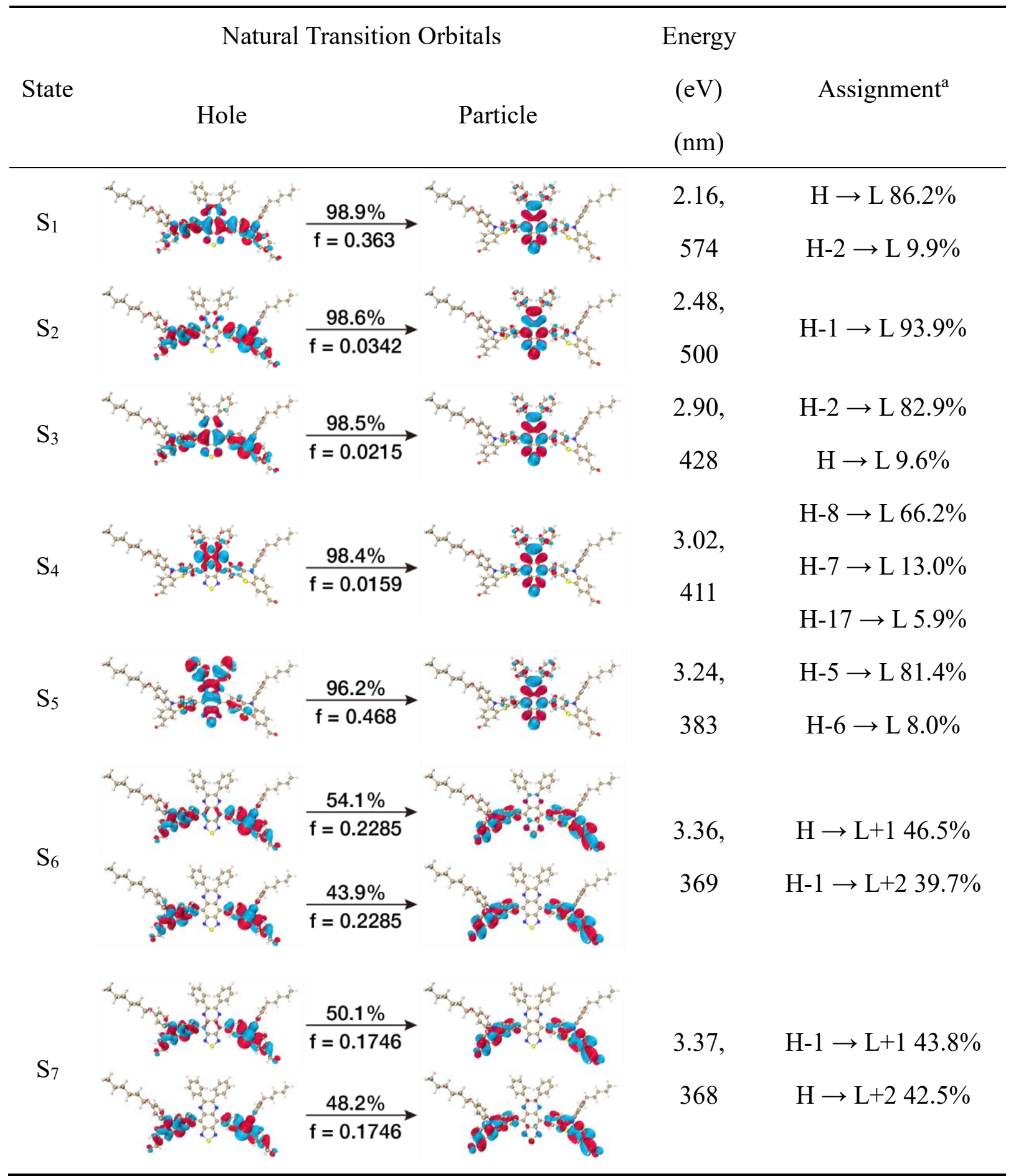

(a). H denotes HOMO, L denotes LUMO, and only MOs transitions with contributions larger than 5\% are shown. 
Table S9. Calculated excited state of $\mathrm{S}_{1}$ to $\mathrm{S}_{7}$ and corresponding natural transition orbitals analysis for DPTQ-PhPXZ in acetone.

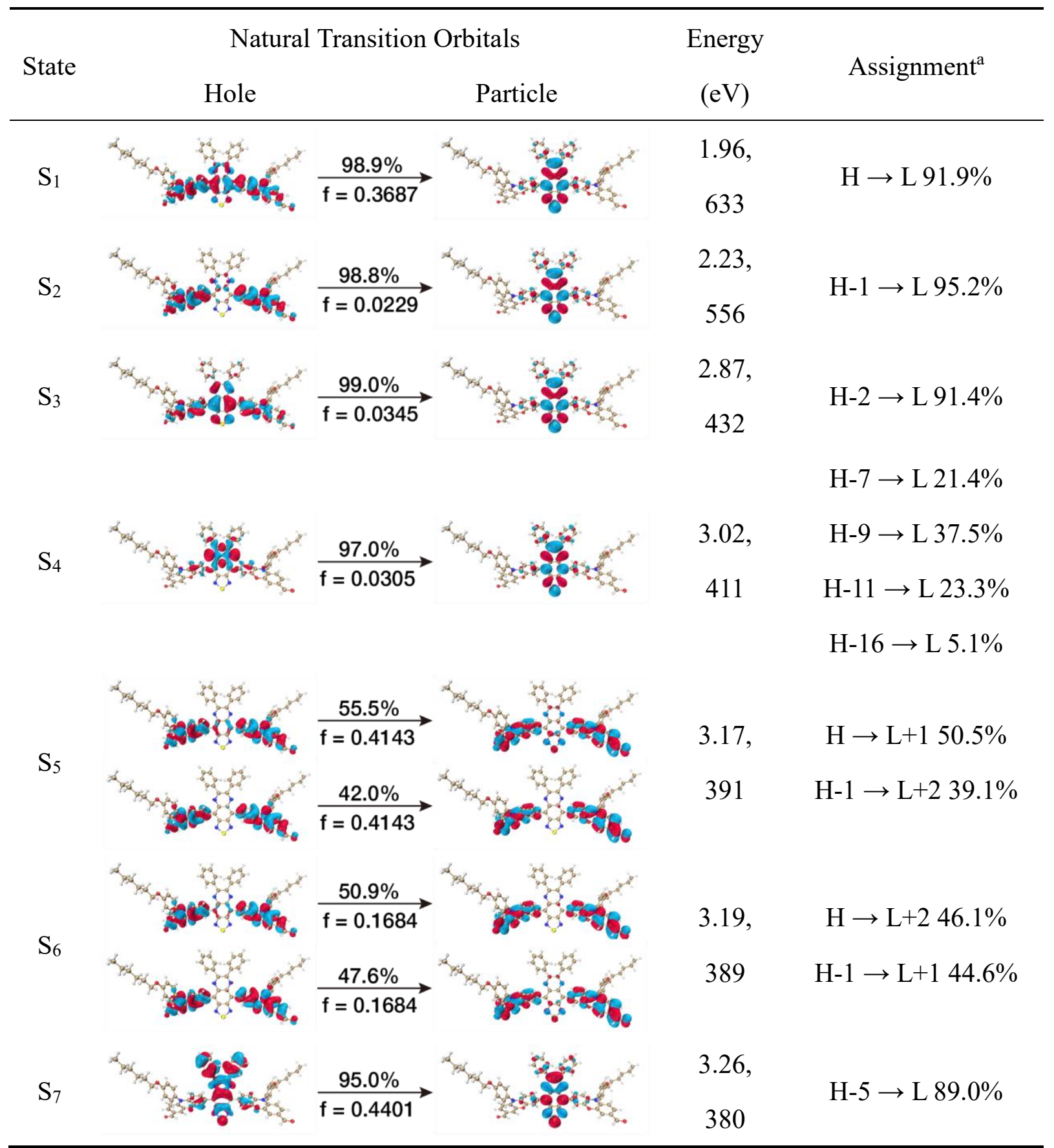

(a). H denotes HOMO, L denotes LUMO, and only MOs transitions with contributions larger than 5\% are shown. 
Table S10 Photophysical properties of DPTQ-PhPTZ in organic solvents.

\begin{tabular}{|c|c|c|c|c|c|c|}
\hline solvent & $\Delta f$ & $\begin{array}{l}\text { Abs } \\
(\mathrm{nm})\end{array}$ & $\begin{array}{c}\mathcal{E}^{\mathrm{a}} \\
\left(10^{4} \times \mathrm{L} \cdot \mathrm{M}^{-1}\right)\end{array}$ & $\begin{array}{l}\text { Emission } \\
\text { (nm) }\end{array}$ & $\begin{array}{c}\text { Stokes Shifts }{ }^{b} \\
\left(\mathrm{~cm}^{-1}\right)\end{array}$ & $\begin{array}{l}\text { Quantum } \\
\text { yield (\%) }\end{array}$ \\
\hline Cyclohexane & -0.001 & $\begin{array}{l}403 \\
624\end{array}$ & $\begin{array}{l}2.36 \\
1.30\end{array}$ & 775 & 3122.42 & 14.84 \\
\hline Toluene & 0.013 & $\begin{array}{l}409 \\
631\end{array}$ & $\begin{array}{l}2.42, \\
1.21\end{array}$ & 839 & 3928.91 & 3.37 \\
\hline Triethylamine & 0.048 & $\begin{array}{l}404 \\
628\end{array}$ & $\begin{array}{l}2.31 \\
1.24\end{array}$ & 801 & 3439.17 & 3.16 \\
\hline Isopropyl ether & 0.145 & $\begin{array}{l}403 \\
623\end{array}$ & $\begin{array}{l}2.34 \\
1.26\end{array}$ & 854 & 4341.76 & 1.80 \\
\hline Chloroform & 0.15 & $\begin{array}{l}412 \\
626\end{array}$ & $\begin{array}{l}2.50 \\
1.18\end{array}$ & 911 & 4997.49 & 0.40 \\
\hline Tetrahydrofuran & 0.209 & $\begin{array}{l}406 \\
613\end{array}$ & $\begin{array}{l}2.03 \\
1.00\end{array}$ & 957 & 5863.89 & $--^{c}$ \\
\hline Acetone & 0.284 & $\begin{array}{l}402 \\
601\end{array}$ & $\begin{array}{l}2.31 \\
1.15\end{array}$ & 969 & 6319.02 & - \\
\hline Acetonitrile & 0.305 & $\begin{array}{l}402, \\
595\end{array}$ & $\begin{array}{l}2.15 \\
1.03\end{array}$ & 960 & 6390.06 & - \\
\hline
\end{tabular}

(a) $\mathcal{E}$ is molar absorption coefficient of the absorption peak. (b) Stokes shifts equal the difference between absorption wavenumber $\left(\mathrm{cm}^{-1}\right)$ and emission wavenumber $\left(\mathrm{cm}^{-1}\right)$. (c) - denotes that the QY is too low to be measured. 
Table S11 Photophysical properties of DPTQ-PhPXZ in organic solvents.

\begin{tabular}{|c|c|c|c|c|c|c|}
\hline solvent & $\Delta f$ & $\begin{array}{l}\text { Abs } \\
(\mathrm{nm})\end{array}$ & $\begin{array}{c}\mathcal{E} \\
\left(10^{4} \times \mathrm{L} \cdot \mathrm{M}^{-1}\right)\end{array}$ & $\begin{array}{l}\text { Emission } \\
(\mathrm{nm})\end{array}$ & $\begin{array}{c}\text { Stokes Shifts } \\
\text { b } \\
\left(\mathrm{cm}^{-1}\right)\end{array}$ & $\begin{array}{l}\text { Quantum } \\
\text { yield (\%) }\end{array}$ \\
\hline Cyclohexane & -0.001 & $\begin{array}{l}397 \\
642\end{array}$ & $\begin{array}{l}3.12, \\
1.25\end{array}$ & 768 & 2555.49 & 15.54 \\
\hline Toluene & 0.013 & $\begin{array}{l}404, \\
641\end{array}$ & $\begin{array}{l}3.20 \\
1.19\end{array}$ & 814 & 3315.61 & 9.31 \\
\hline Triethylamine & 0.048 & $\begin{array}{l}398 \\
637\end{array}$ & $\begin{array}{l}3.21 \\
1.27\end{array}$ & 789 & 3024.32 & 8.21 \\
\hline Isopropyl ether & 0.145 & $\begin{array}{l}398 \\
634\end{array}$ & $\begin{array}{l}3.15 \\
1.26\end{array}$ & 804 & 3335.06 & 7.10 \\
\hline Chloroform & 0.15 & $\begin{array}{l}410 \\
642\end{array}$ & $\begin{array}{l}3.33 \\
1.20\end{array}$ & 855 & 3880.42 & 3.18 \\
\hline Tetrahydrofuran & 0.209 & $\begin{array}{l}402, \\
628\end{array}$ & $\begin{array}{l}3.16 \\
1.15\end{array}$ & 931 & 5182.43 & 0.23 \\
\hline Acetone & 0.284 & $\begin{array}{l}401 \\
617\end{array}$ & $\begin{array}{l}3.41 \\
1.25\end{array}$ & 973 & 5929.96 & $-c$ \\
\hline Acetonitrile & 0.305 & $\begin{array}{l}401 \\
613\end{array}$ & $\begin{array}{l}3.20 \\
1.15\end{array}$ & 973 & 6035.72 & - \\
\hline
\end{tabular}

(a) $\mathcal{E}$ is molar absorption coefficient of maximum absorption peak. (b) Stokes shifts equal the difference between absorption wavenumber $\left(\mathrm{cm}^{-1}\right)$ and emission wavenumber $\left(\mathrm{cm}^{-1}\right)$. (c) - denotes that QY is too low to be measured. 


\section{Reference}

1 S. Li, C. Yin, R. Wang, Q. Fan, W. Wu and X. Jiang, ACS Appl. Mater. Interfaces, 2020, 12, 20281-20286.

2 M. J. Frisch, G. W. Trucks, H. B. Schlegel, G. E. Scuseria, M. A. Robb, J. R. Cheeseman, G. Scalmani, V. Barone, G. A. Petersson, H. Nakatsuji, X. Li, M. Caricato, A. V. Marenich, J. Bloino, B. G. Janesko, R. Gomperts, B. Mennucci, H. P. Hratchian, J. V. Ortiz, A. F. Izmaylov, J. L. Sonnenberg, D. Williams-Young, F. Ding, F. Lipparini, F. Egidi, J. Goings, B. Peng, A. Petrone, T. Henderson, D. Ranasinghe, V. G. Zakrzewski, J. Gao, N. Rega, G. Zheng, W. Liang, M. Hada, M. Ehara, K. Toyota, R. Fukuda, J. Hasegawa, M. Ishida, T. Nakajima, Y. Honda, O. Kitao, H. Nakai, T. Vreven, K. Throssell, J. A. Montgomery Jr., J. E. Peralta, F. Ogliaro, M. J. Bearpark, J. J. Heyd, E. N. Brothers, K. N. Kudin, V. N. Staroverov, T. A. Keith, R. Kobayashi, J. Normand, K. Raghavachari, A. P. Rendell, J. C. Burant, S. S. Iyengar, J. Tomasi, M. Cossi, J. M. Millam, M. Klene, C. Adamo, R. Cammi, J. W. Ochterski, R. L. Martin, K. Morokuma, O. Farkas, J. B. Foresman and D. J. Fox, Gaussian 16 Revision A.03, 2016.

3 Tian Lu, optDFTw program v1.0, webpage:http://sobereva.com/346.

4 W. Humphrey, A. Dalke and K. Schulten, J. Mol. Graph., 1996, 14, 33-38. 